THREE ESSAYS ON IMMIGRANT NONPROFIT ORGANIZATIONS AND IMMIGRANT USE OF SOCIAL SERVICES

A Dissertation
presented to
the Faculty of the Graduate School
at the University of Missouri - Columbia
In Partial Fulfillment
Of the Requirements for the Degree
Doctor of Philosophy
Br. Colleen Heflin, Dissertation Supervisor
JULY 2017
KATE C. OLSON


(C) Copyright by Kate C. Olson 2017

All Rights Reserved 
The undersigned, appointed by the dean of the Graduate School, have examined the dissertation entitled

\section{THREE ESSAYS ON IMMIGRANT NONPROFIT ORGANIZATIONS AND IMMIGRANT USE OF SOCIAL SERVICES}

presented by Kate C. Olson, a candidate for the degree of Doctor of Philosophy in Public Affairs, and hereby certify that, in their opinion, it is worthy of acceptance.

Professor Colleen Heflin

Professor Claire Altman

Professor Matt Foulkes

Professor Peter Mueser 


\section{DEDICATION}

To my parents - mom and dad, thank you for supporting me, whichever path I take.

To my partner, Terrance La-Shon, who didn't know what he was getting into with a doctoral student fiancé: Thank you for joining me on this path; I love you. And to our son, Treston, who has tested my concentration numerous times, but is also our sun. To my grandparents who paved the way to get to where I am now, especially to the three grandparents I lost over the course of my studies — grandma Ruth, grandpa John, and grandma Olson. 


\section{ACKNOWLEDGEMENTS}

Many people supported me to get to where I am now. First and foremost, I want to thank my adviser, Dr. Colleen Heflin. Since my first semester of the doctoral program, Dr. Heflin supported me to learn and succeed. When Treston was born, Dr. Heflin offered understanding that my focus was off, but also told me when I needed to get it together.

In addition to Dr. Heflin, I want to extend thanks to my committee members, Drs. Claire Altman, Matt Foulkes, and Peter Mueser. These committee members stepped in and assisted my scholarship, encouraged and challenged me. I am grateful for their time and commitment to my success.

Next, I would like to thank Erwin de Leon. Dr. de Leon offered me use of his immigrant nonprofit database in exchange for some cleaning and coding of the database. We also spoke every few months at the beginning of my dissertation process and he was always cheerful and, despite the difficulties, encouraged me to work on immigrant nonprofit research. I thank him for his support.

I would like to thank the professors of the Truman School of Public Affairs. They have aided and challenged my understanding of our field of study and my growth as a person and scholar. Especially, I would like to thank Dr. Michael Diamond who challenged how I thought about social science during our Logics of Inquiry course. I would like to thank Drs. Tom Johnson, William Meyers, and Judy Stallmann for their guidance and support of international thinking and programs. I would also like to thank Dean Bart Wechsler for his strong student support.

My professors and mentors from my master's program were also vital in my success in this doctoral program, Drs. Avra Johnson, Jeff Bumgarner, Michael Fagin, and 
Fred Slocum. I would particularly like to thank Dr. Avra for her support, friendship, and most important, her honesty.

Thank you to my colleagues who came before me, specifically, Drs. Matty Figueroa-Armijos, Elijah Agyapong, and Grichawat Lowatcharin. Thank you to my cohort, colleagues, friends, and mentors, Darima Butitova, Jacob Cronin, Isaac Edwards, Jinhyong Kim, Fridah Mubichi, Ashley Price, Sarah Parsons, and Lindsey Saunders. Thank you to all of my colleagues in the Truman School PhD program, everyone who has been part of the program has enhanced my understanding of our field as well as the world. Although I wasn't in the office very often, I would like to thank my officemate, Christal Hamilton. She always has a smile on her face, a positive approach to things, and was a great person to be around when I was feeling frustrated with my progress.

Thank you to everyone who has been a part of this process, whether big or small. It has been a difficult journey, but because of you I was able to make it to the finish line. 


\section{TABLE OF CONTENTS}

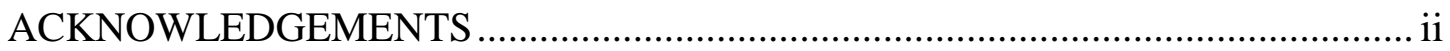

LIST OF ILLUSTRATIONS ................................................................... viii

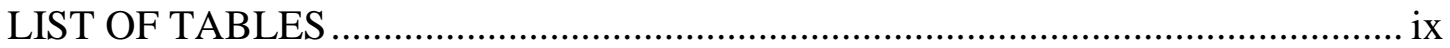

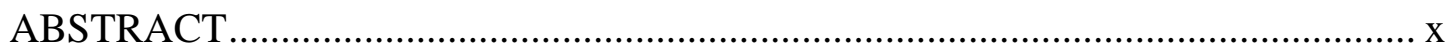

Chapter

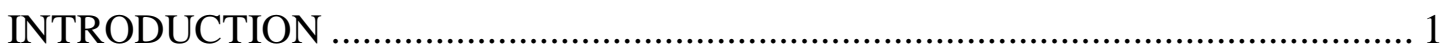

References

1. NONPROFIT STRATEGIES TO CONNECT IMMIGRANTS TO FEDERAL FOOD ASSISTANCE: A CASE STUDY OF FOOD BANK SNAP

OUTREACH................................................................................ 9

Introduction

SNAP Background

Data and Method

Results

1. Overcoming language barriers

2. Providing convenient and "safe" service delivery

3. Clarifying misinformation about SNAP participation

4. Enhancing computer literacy and access

Discussion

References

2. IMMIGRANT NONPROFIT ORGANIZATIONS IN NEW AND ESTABLISHED IMMIGRANT DESTINATION COUNTIES.

Introduction

New and Established Immigrant Destinations 
Immigrant Nonrpofit Organizations

Determinants of Nonprofit Sector Growth

Community Need

Community Resources

Community Structure

Data, Measures, and Methods

Data

Immigrant Analysis Database

Measures

Community need

Community resources

Community structure

Method

Results

(1) Where are immigrant nonprofit organizations located?

(2) How do community need, community resources, and community structure differ in counties with and without an immigrant nonprofit and in new and established immigrant destination counties?

Community need

Community resources

Community structure

(3) Using probit regression, what county characteristics predict the likelihood of an immigrant nonprofit organization in a county?

Community need 
Community resources

Community structure

Discussion

Conclusion

References

Appendix A

Appendix B

3. A METROPOLITAN AREA'S RACIAL AND ETHNIC DISTRIBUTION AND IMMIGRANT NONPROFIT ORGANIZATIONS .......................... 94

Introduction

Literature Review

Diverse Metropolitan Areas

Segregated Metropolitan Areas

Hypotheses

Data, Measures, and Methods

Data

Measures

Method

Findings

Descriptive Results

Regression Results

Sensitivity analysis

Discussion

References 
Appendix A

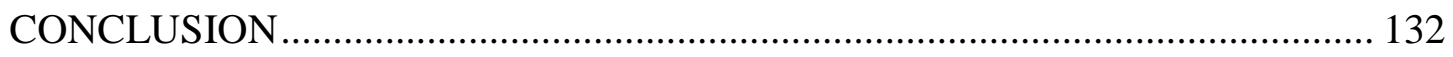

\section{References}

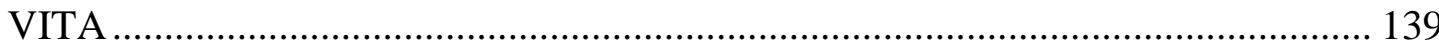




\section{LIST OF ILLUSTRATIONS}

Figure

Page

Chapter 2

1: Immigrant Destination Types: New, Established, and Non-Destination Counties. 54

2: Number of Immigrant Nonprofit Organizations by County

A 1: National Taxonomy of Exempt Entities Codes for Immigrant Nonprofit Organizations in the immigrant Analysis Database $(\mathrm{N}=5,286)$ 86

A 2: Regions of Origins Served by Immigrant Nonprofit Organizations in the Immigrant Analysis Database $(\mathrm{N}=5,286)$ 86

A 3: Percent of Immigrant Nonprofit Organizations and Percent of Foreign-Born Population by Destination Type................................................................... 87

A 4: Percent of Immigrant Nonprofit Organizations and Percent of Foreign-Born Population by Region

Chapter 3

1: Overview of Hypotheses Support....... 


\section{LIST OF TABLES}

Table

Page

Chapter 2

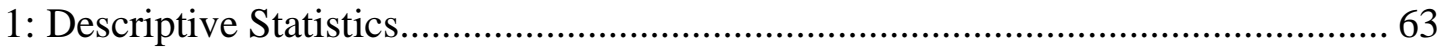

2: Probability of an Immigrant Nonprofit Organization in County .......................... 67

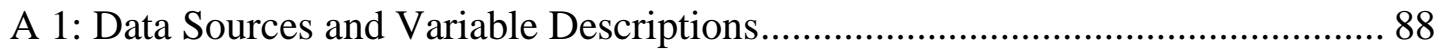

\section{Chapter 3}

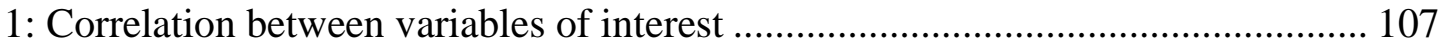

2: Descriptive Statistics, N=333 Metropolitan Areas .......................................... 110

3: Number of immigrant nonprofit organizations per 1,000 foreign-born residents 113

A 2: Top 10 metropolitan areas with highest Diversity or Segregation scores ....... 131 


\title{
THREE ESSAYS ON IMMIGRANT NONPROFIT ORGANIZATIONS AND IMMIGRANT USE OF SOCIAL SERVICES
}

Kate C. Olson

\author{
Dr. Colleen Heflin, Dissertation Supervisor
}

\begin{abstract}
Immigrant populations are moving to new destinations across the country and no longer settling predominantly in established immigrant destinations, causing stress on local governments. Local governments increasingly rely on nonprofit organizations to provide services to immigrant and refugee populations. To contribute to research in this area, this dissertation examines ways nonprofit organizations work with immigrant populations. In Chapter 1, I use qualitative interview data to examine how food bank staff connect immigrant groups to public services. In Chapters 2 and 3, I focus on immigrant nonprofit organizations. I use census and immigrant nonprofit data and regression analysis to examine where immigrant nonprofits may be located. Findings from this dissertation highlight the importance of the local context when initiating strategies to engage with immigrant populations and when examining factors associated with the presence of an immigrant nonprofit.
\end{abstract}




\section{INTRODUCTION}

Demographics are changing in the United States. Higher fertility rates among minority women and immigration to the United States contribute to population growth among minorities, both U.S. and foreign-born. Immigrants tend to be poorer than nativeborn residents (Raphael \& Smolensky 2009) and eligible immigrant populations utilize public benefit programs such as food stamps at lower rates than eligible citizen populations (Fix, Capps, \& Kaushal 2009; Fortuny \& Chaudry 2011; Leftin 2010; Skinner 2012). Traditionally, nonprofit organizations have filled the gaps in local service provision adapting to the population's shifting needs. Additionally, local governments increasingly depend on nonprofits to provide services to immigrant and refugee populations (Joassart-Marcelli 2013; Salamon 2012; Tseng 2006).

The three chapters of this dissertation examine different ways nonprofit organizations work with immigrant populations. The first chapter focuses on outreach to immigrant populations by food bank employees. The second and third chapter focus specifically on immigrant nonprofit organizations. Chapter 2 analyzes community need, resources and structure and how these may be associated with the presence of an immigrant nonprofit in counties across the United States. Chapter 3 examines how the distribution of racial and ethnic groups may be associated with the quantity of immigrant nonprofit organizations in metropolitan areas.

Immigrant nonprofit organizations are similar to general nonprofits, offering human, social, and cultural service provision (Boris \& Steuerle 2006; Salamon 2012); but they do so with cultural-specific perspectives, language capacity, and a focus on immigrant concerns (Gleeson \& Bloemraad 2013; Joassart-Marcelli 2013; Hung \& Ong 
2012). In recent years, scholarly interest in immigrant nonprofit organizations has increased (i.e. Cordero-Guzmán 2005; de Graauw, Gleeson, \& Bloemraad 2013; Gleeson \& Bloemraad 2013; Hung 2007; Hung \& Ong 2012; Zhou \& Lee 2013); however, the lack of a cohesive and widespread definition of an immigrant organization limits the understanding of "who these groups are, what kinds of programs and services they provide, where they are located, who they serve, and what kinds of resources they have" (Cordero-Guzmán 2005, p. 891).

General nonprofit organizations have traditionally filled gaps in local service provision and adapted to the needs of their target populations. Recently, social services have been shifting to more modernized service delivery approaches, creating barriers to participation for some groups. Chapter 1 describes how staff from one type of nonprofit organization connects immigrant groups to public services. Specifically, in Chapter 1, Dr. Colleen Heflin and I analyzed the actions of food bank staff conducting Supplemental Nutrition Assistance Program (SNAP) outreach to immigrant populations. The research questions addressed in Chapter 1 focus on outreach workers' perceptions of their work with immigrant populations: 1) What barriers do food bank employees believe are preventing eligible immigrants from accessing federal food assistance? And 2) What actions do food bank employees take to connect qualified immigrant populations to federal food assistance? Drawing on qualitative data from 48 key informants in nine sites across the United States, we discovered a range of strategies that food bank SNAP outreach workers use to reach eligible immigrants. Our findings indicate that food bank employees bridge gaps in language ability, offer assistance in a convenient and safe environment, have knowledge of multiple policies, offer clear information to clients, and 
mitigate computer difficulties. The interviews from our study make clear that nonprofit organizations offer a different environment for public benefit application than what may be possible from government agencies.

As seen in Chapter 1, nonprofit organizations play an important role working with immigrant populations. Especially in new immigrant destinations, nonprofit organizations, and immigrant nonprofits in particular, may assist strained local government officials with their constituent foreign-born populations. In Chapter 2, I examine community need, community resources, and community structure to understand the determinants of where immigrant nonprofit organizations are located. Specifically, I analyze county-level data from a national database of immigrant nonprofit organizations and the American Community Survey (ACS) focusing on three research questions: (1) Where are immigrant nonprofit organizations located in the United States? (2) How do community need (i.e. poverty), community resources (i.e. charitable giving), and community structure (i.e. education, employment structure) differ in counties with and without an immigrant nonprofit and in new and established immigrant destination counties? And (3) What county characteristics predict the likelihood that an immigrant nonprofit organization is present in a county? Findings in Chapter 2 suggest that immigrant nonprofit organizations are located in counties with a large population and in established immigrant destinations.

In addition to new and established immigrant destination counties, a community's racial or ethnic composition can take many forms and influences the presence of one type of resource, nonprofit organizations. In Chapter 3, I analyze different racial and ethnic distribution patterns and the presence of immigrant nonprofit organizations. Utilizing two 
different racial and ethnic composition measures, the Entropy Index and the Dissimilarity Index, I examine the implications of diversity and segregation on the number of immigrant nonprofit organizations per 1,000 foreign-born residents. I employ multiple regression to answer the question: How does a metropolitan area's racial and ethnic distribution (i.e. diversity or segregation) influence the number of immigrant nonprofit organizations? Findings from Chapter 3 suggest that diverse metropolitan areas and areas with segregated Hispanic populations have fewer immigrant nonprofit organizations per 1,000 foreign-born residents.

Immigration, immigrant integration, and nonprofit organizations working with immigrant populations have been a long-time interest for me. My general interest in immigration stems from my mother's interest in genealogy. From a young age, my mother spoke about our ancestors, how they migrated to the United States, and how my grandparents' parents spoke Swedish so the kids (my grandparents) would not know what they were saying. My interest in nonprofit organizations working with immigrant groups comes from my personal experience as a Belgian immigrant. In 2003, I migrated to Belgium on a cohabitation visa. Shortly thereafter, a new integration policy was introduced. The policy required new Belgian immigrants to participate in a "Social Integration Orientation Course" organized by nonprofit organizations. This course offered newcomers information on how to navigate Belgian healthcare; social culture and norms; history; employment; social services; and other such things, including an introductory language course. This social orientation course was useful to me and taught me a lot about my new country. 
In 2009, however, I returned to the United States - to Minnesota — and my interest in immigration peaked. People saw me as an immigrant (I spoke with an accent), they spoke louder and slower to be sure I understood. I realized that the United States did not offer such a social orientation course and I became very active with nonprofit organizations offering prejudice reduction workshops and community forums to connect long-time residents and newcomers. I also learned about the challenges and benefits of trying to become an official 501(c)3 immigrant nonprofit organization.

Fast-forward a few years into my doctoral program. During an Association for Public Policy Analysis and Management (APPAM) conference, I attended sessions discussing immigrant integration. I talked with someone from the Urban Institute after her presentation and she told me about her colleague's database of immigrant nonprofit organizations. Once I narrowed my dissertation topic, I reached out to these people from the Urban Institute and received encouragement for my dissertation topic and Erwin de Leon (no longer with the Urban Institute) offered me use of his immigrant nonprofit database in exchange for data cleaning. This was an exciting opportunity for me to use a previously unpublished national database of immigrant nonprofit organizations to understand more about the location and types of immigrant nonprofits.

Using this national database of immigrant nonprofit organizations is a valuable contribution from this research. Examining immigrant nonprofit organizations nationally allows some generalizability about factors associated with the presence of an immigrant nonprofit. Much of the previous work on immigrant nonprofit organizations has been local or regionally based, with a few studies at the metropolitan level. In addition, a common thread tying these chapters together is the importance of the local context. The 
local context matters when initiating strategies to engage with immigrant populations and local context matters when examining factors associated with the presence of an immigrant nonprofit (i.e. new or established destination, and the racial and ethnic distribution). 


\section{References}

Boris, E.T. \& Steuerle, C.E. (Eds.) 2006. Nonprofits and Government: Collaboration and Conflict. Washington DC: Urban Institute Press.

Cordero-Guzmán, H. R. 2005. Community-based organisations and migration in New York City. Journal of Ethnic and Migration Studies, 31, 889-909.

de Graauw, E.; Gleeson, S.; \& Bloemraad, I. 2013. Funding Immigrant Organizations: Suburban Free Riding and Local Civic Presence. American Journal of Sociology, 119(1), 75-130.

Fix, M.; Capps, R.; \& Kaushal, N. 2009. Immigrants and Welfare: Overview. In M. Fix (ed) Immigrants and Welfare, The Impact of Welfare Reform on America's Newcomers, New York, Russell Sage Foundation.

Fortuny, K. \& Chaudry, A. 2011. A Comprehensive Review of Immigrant Access to Health and Human Services. Washington, DC, The Urban Institute.

Gleeson, S. \& Bloemraad, I. 2013. Assessing the Scope of Immigrant Organizations: Official undercounts and actual underrepresentation. Nonprofit and Voluntary Sector Quarterly, 42(2), 346-370.

Hung, C. R. 2007. Immigrant Nonprofit Organizations in U.S. Metropolitan Areas. Nonprofit \& Voluntary Sector Quarterly, 36(4), 707-729. doi:10.177/0899764006298962.

Hung, C.R. \& Ong, P. 2012. Sustainability of Asian-American Nonprofit Organizations in the U.S. Metropolitan Areas. Nonprofit and Voluntary Sector Quarterly, 41(6), $1136-1152$.

Joassart-Marcelli, P. 2013. Ethnic Concentration and Nonprofit Organizations: The 
Political and Urban Geography of Immigrant Services in Boston, Massachusetts. International Migration Review, 47(3):730-772 DOI: 10.1111/imre.12041.

Leftin, J. 2010. Trends in Supplemental Nutrition Assistance Program Participation Rates: 2001 to 2008. Washington, DC, Mathematica Policy Research.

Raphael, S. \& Smolensky, E. 2009. Immigration and Poverty in the United States. In Cancian, M. \& Danziger, S. (Eds.) Changing Poverty, Changing Policies. New York: Russell Sage Foundation.

Salamon, L. M. (ed). 2012. The State of Nonprofit America. Washington DC: Brookings Institution.

Skinner, C. 2012. State Immigration Legislation and SNAP Take-Up Among Immigrant Families with Children. Journal of Economic Issues, 46(3), 661-681.

Tseng, W. 2006. Government Dependence of Chinese and Vietnamese Community Organizations and Fiscal Politics of Immigrant Services. Journal of Health and Social Policy, 20(4), 51-74.

Zhou, M.; \& Lee, R. 2013. Transnationalism and Community Building: Chinese Immigrant Organizations in the United States. The ANNALS of the American Academy of Political and Social Science, 647,(1), 22-49. 


\title{
CHAPTER 1:
}

\section{NONPROFIT STRATEGIES TO CONNECT IMMIGRANTS TO FEDERAL \\ FOOD ASSISTANCE: A CASE STUDY OF FOOD BANK SNAP OUTREACH}

\author{
Kate C. Olson \& Colleen M. Heflin
}

\section{Introduction}

Traditionally, nonprofit organizations have filled the gaps in local service provision adapting to the shifting needs of their target population. Recently, as efficiency and cost saving have become the main concerns behind social service delivery, government benefit application systems have shifted to on-line applications, call-centers, and a less individualized approach (Leftin 2010; Rowe et al. 2010). While modernized delivery systems may increase staff efficiency, they are often less accessible to populations with computer literacy difficulties, those who lack English language proficiency, or those who fear contact with the government. To address these concerns, locally based nonprofit organizations may utilize their neutral position to bridge vulnerable populations and government services.

Prior research indicates that one vulnerable population, eligible immigrants ${ }^{1}$, utilize food stamp benefits at lower rates than eligible citizen populations (Fix, Capps, \& Kaushal 2009; Fortuny \& Chaudry 2011; Leftin 2010; Skinner 2012). Modernized application systems may exacerbate immigrants' distinct challenges accessing benefits (Heflin, London \& Mueser 2013). Obstacles preventing eligible immigrants from participating in federal food assistance could lead to long-term health consequences to U.S. born children of immigrants. American born children of immigrants are a rapidly

\footnotetext{
${ }^{1}$ Immigrants and foreign-born residents are used interchangeably referring to individuals who may be naturalized citizens, lawful permanent residents, refugees, or undocumented migrants
} 
growing population (Passel \& Cohn 2009) and a group that has historically experienced high levels of food insecurity (Van Hook \& Stamper Balistreri 2006). This case study documents strategies used by nonprofit employees to connect eligible immigrants to federal food assistance.

Specifically, this case study details the actions of food bank employees conducting food stamp (Supplemental Nutrition Assistance Program, SNAP) outreach to immigrant populations. In this paper, we address two questions in our analysis of 48 interviews with food bank employees: 1) What barriers do food bank employees believe are preventing eligible immigrants from accessing federal food assistance? And 2) What actions do food bank employees take to connect qualified immigrant populations to federal food assistance?

The food bank employees highlighted in this study are nonprofit employees working with a federal food assistance program in a neutral location (the food bank is a nonprofit organization as opposed to a government office). The research questions addressed in this paper focus on outreach workers' perceptions of their work with immigrant populations. This paper adds to the existing literature on nonprofit service delivery and government partnerships (i.e. Allard \& Small 2013; Salamon 1995; Young 2000) by looking specifically at one type of service delivery. This case study is unique highlighting results from interviews with outreach workers as opposed to the clients: we document the strategies nonprofit food bank employees use to address perceived barriers immigrants face to accessing a key public service. This paper also contributes to existing research on immigrant use of social services and the difficulties immigrants have accessing these services (Broder 2007; Derose, Escarce \& Luri 2007; Earner 2007; 
Fortuny \& Chaudry 2011; FRAC 2008; Gorman et al. 2013; Perreira et al. 2012; Skinner 2012; Tumlin \& Zimmerman 2003; Van Hook \& Stamper Balistreri 2006). The interviews from our study make clear that nonprofit organizations offer a different environment for public benefit application than what may be possible from government agencies.

To begin, we provide background information on SNAP eligibility, participation rates, and local service provision. Next, we describe the qualitative methods we used for data collection and our analytic method. In the results section, we present key findings that emerged from our analysis. Our findings indicate that SNAP food bank outreach workers bridge gaps in language ability, give assistance in a convenient and safe environment, have knowledge of multiple policies, offer clear information to clients, and mitigate computer literacy problems. In the conclusion, we discuss the implications of these findings for local government officials and social service providers.

\section{SNAP Background}

The Supplemental Nutrition Assistance Program (SNAP) is one of the country's largest public assistance programs. SNAP is a means-tested federal program that provides households with benefits through an electronic debit card that can be used for food purchases. To be eligible, a household must either have a gross income less than 130 percent of the U.S. poverty level (approximately $\$ 2,500$ per month for a family of four) or be categorically eligible through participation in other programs such as Temporary Assistance for Needy Families (TANF) or Supplemental Security Income (SSI). Although details of eligibility and program administration differ across states, the program's basic structure and payment amounts are set federally and benefits are reduced 
by $\$ 0.30$ for each dollar of net income. For example, as of October 2016, a family of four with no income is eligible for a monthly SNAP benefit payment of \$649 (USDA 2016).

In August 2016, the most recent data available, 43.6 million individuals participated in SNAP across the country (USDA 2016). Current participation is below the historic high of 47.8 million individuals in December 2012; but recent participation numbers are much higher than the pre-recession monthly participation of 21 million in 2003 (USDA 2016). The growth in SNAP caseloads triggered by the Great Recession has received much media and political attention. The growth reflects both the expanded population eligible for benefits due to local employment conditions and changes in formal eligibility rules. Owing to both factors, during the Great Recession there was a nearly 20-percentage point increase in the participation rate among the population eligible for benefits (Ganong \& Liebman 2013). Increasing the SNAP participation rates of eligible populations not only offers low-income people the ability to purchase healthy food, it also offers an economic benefit to communities. Communities benefit from SNAP use because it is estimated that every five dollars of SNAP benefits spent in the community generates $\$ 9.20$ of economic activity (USDA 2014).

Although SNAP participation is at record high levels, obstacles to utilizing SNAP benefits remain. Some barriers exist for both citizens and non-citizens alike, including stigma, misinformation, beliefs about ineligibility, the costs of participation (i.e., transportation, time, phone, and cost of stamps), as well as long applications, and limited locations to submit applications or complete the eligibility interview (Allard \& Roth 2010; Castner \& Rosso 2000; Daponte, Sanders \& Taylor 1999; Dion \& Pavetti 2000; FRAC 2008; Moffitt 1983). Non-citizens face additional obstacles to accessing SNAP 
benefits. While the 1996 welfare reform greatly limited immigrant access to SNAP, the 2002 Farm Bill largely reinstated their eligibility (USDA 2007). Currently, qualified immigrants are eligible for SNAP benefits if they have been legally present in the United States for at least five years; some groups such as refugees, however, are immediately eligible (USDA 2011, 2012). In addition to policy restrictions, eligible immigrants often do not access benefits because they are confused about their eligibility; fear immigration enforcement or how receiving benefits may impact their current or future immigration status; have difficulty obtaining a driver's license and difficulty traveling to application sites; or speak limited English and lack the bicultural or bilingual services they need to apply (Fix \& Passel 2002; Fix, Capps, \& Kaushal 2009; Fortuny \& Chaudry 2011; FRAC 2008, 2011; Gorman et al. 2013; Skinner 2012; Zimmerman \& Tumlin 1999).

A major strategy to increase SNAP participation among all types of applicants has been to offer federal funds for partnerships between SNAP agencies and local organizations to implement state SNAP outreach plans. State outreach plans allowed community organizations, such as food banks, to engage in SNAP education and outreach activities, such as application assistance, to increase benefit uptake. The U.S. Department of Agriculture (USDA) partially funds state outreach plans by reimbursing states up to 50 percent of their administrative expenses (USDA 2014). In addition to USDA funding, SNAP outreach funding comes from an organization's internal funds, state or county outreach plans and/or corporate and foundation grants. The nine food banks in this study participated in their state's SNAP outreach plan and received up to 50 percent reimbursement from the USDA. Only three food banks in this study, however, used internal funds to cover SNAP outreach programming (Feeding America 2014). 
Feeding America has also been active in increasing the number of SNAP agency partnerships with local food banks to increase SNAP outreach (USDA 2014). Between 2009 and 2013, the Feeding America network experienced an almost 100 percent increase in the number of member food banks that offered SNAP outreach and application assistance (Alford, Heflin \& Waxman 2014). The impact of this outreach on SNAP caseloads is difficult to determine, but certainly not negligible. ${ }^{2}$

Given the additional constraints eligible non-citizens face to accessing SNAP and the expanding size of this subgroup, it is valuable to study the possible approaches that nonprofit organizations, such as food banks, can use to increase SNAP participation. In what follows, we present strategies used by one type of nonprofit organization to help immigrant populations overcome barriers to participation and gain access to SNAP benefits. This study is unique in its focus on food bank employees conducting outreach for a government nutrition assistance program instead of the more traditional public management focus on street-level bureaucrats. Food bank employees are a neutral third party, have no authority in eligibility determination, yet their relationship with the government is not always clear. ${ }^{3}$ The role of food bank employees, however, is critical for increasing access for certain population groups to formal government social services. As such, this study focuses on how food banks engaged in front line policy implementation to eligible immigrant populations, a group often constructed in a negative

\footnotetext{
${ }^{2}$ Seven of the nine food banks in our study conducted outreach to an average of 20,000 people per food bank. On average, nearly 6,000 individuals per food bank went through the pre-screening process and about 1,500 applied for SNAP benefits using food bank staff assistance (Feeding America 2014).

${ }^{3}$ The relationship dynamics between the government agency that administers SNAP (U.S. Department of Agriculture) and the food banks implementing SNAP outreach is of interest. In this study, however, we only interviewed food bank employees and are therefore unable to examine this relationship.
} 
manner or as undeserving of public benefits (Fix \& Passel 2002; Magaña \& Short 2002;

Parsons Dick 2011; Schneider \& Ingram 1993).

\section{Data and Method}

During the summer of 2013, we completed 48 interviews across six states

(Arizona, California, New York, Ohio, Texas, and Wisconsin) with staff from nine food banks. We conducted interviews by telephone (42) and in-person (6) ${ }^{4}$. The food banks and interviewees included in this study were convenience samples and chosen as part of a larger study directed by Feeding America ${ }^{5}$. The interviewees were purposefully selected based on their connection to their foodbank's SNAP outreach program and included employees at varying levels in the food bank. Interviewees included chief executive or operations officers (4); SNAP outreach program directors (13); employees affiliated with SNAP advocacy and education (5); and SNAP outreach staff (26).

Interviews followed a semi-structured guide with open-ended questions. Interviews differed slightly depending on the interviewee's position within the food bank; for example, SNAP outreach workers received slightly different questions than a food bank chief executive officer. In all cases, however, the focus was the interviewee's main functions regarding SNAP outreach. Questions were designed to document the food bank's SNAP program history and detail how SNAP program operations worked on the ground. Respondents were asked to describe perceived barriers to SNAP participation specific vulnerable populations (i.e. elderly, people with disabilities, veterans, immigrants, rural populations, and the working poor) in the community faced and how

\footnotetext{
${ }^{4}$ During one site visit, six face-to-face interviews were conducted. In addition, we observed the geographic location of the food bank and the physical design of the SNAP outreach area.

${ }^{5}$ For a comprehensive overview of the economic, political and administrative context for each state and site in our study, please refer to Alford, Heflin and Waxman (2014) and Feeding America (2014).
} 
they designed SNAP outreach activities to reach these groups. Immigrants were one of the specific populations discussed in every interview.

The purpose of the interviews was to understand the outreach provided by food bank employees. In general, we know that food bank employees facilitate the SNAP application process by offering information and application assistance to potential SNAP clients. Outreach programs are designed for workers to assist applicants with any difficulties they encounter in the application. The SNAP applications themselves are either submitted online, by mail, or dropped off at a particular SNAP application site. After this initial submission, SNAP outreach workers no longer have follow-up information for their clients, unless the client provided that information. At some locations, in addition to application assistance, the food bank offered applicants a space and a phone for their SNAP phone interview.

Our interviews lasted, on average, about forty-five minutes and ranged from 30 75 minutes. All interviews were conducted in English, recorded, and transcribed. The verbatim interview transcripts comprise the data for the results section. To code and analyze the data, we followed a process that is consistent with the standard in the field (Creswell 2013; Patton 2002). We started with the preliminary topic areas that arose from our initial conceptualization of the interview guide and during interviews. We then coded the interview transcripts for words and ideas related to immigrants and immigration (i.e. non-citizen; Latinos; English; Spanish; Chinese; language; culture; cultural differences; et cetera). Next, we coded the data into themes found within the sections on immigrants and immigration (i.e. language barriers; mixed status and legal implications; accessibility of service and barriers; stigma). Transcripts were coded individually by members of the 
research team and then triangulated for validity of the data. Finally, we used manual content analysis to examine the data and we reviewed our findings. In the results section below, we present our findings categorized into four main themes that came from the transcript analysis. Generally, we find SNAP outreach workers had the most contact with immigrant populations and their perceptions are prominent within our results. Our findings make clear that the sites studied engaged in a wide range of outreach activities. Our analysis works across this range of activities to summarize existing gaps in formal services for immigrant populations and specify how one type of nonprofit organization (i.e. food banks) worked to fill that gap. As we discuss in the conclusion, these results provide insight into strategies other nonprofit organizations can take to increase access to social services beyond SNAP.

\section{Results}

Based on our analysis, we present our findings organized into the four main strategies food bank employees used to increase access to SNAP participation: 1) overcoming language barriers; 2) providing convenient and "safe" service delivery; 3) clarifying misinformation about SNAP participation; and 4) enhancing computer literacy and access. Essentially, these strategies are organized by the barrier they are designed to address. We use our interview data to document each barrier, then present information on the variety of strategies that food bank employees reported using to link clients to services. Presenting our findings in this way allows us to answer our two research questions: 1) What barriers do food bank employees believe are preventing eligible immigrants from accessing federal food assistance? 2) What actions do food bank employees take to connect qualified immigrant populations to federal food assistance? 


\section{Overcoming language barriers}

Language is one aspect of the changing demography in the United States that can create barriers to social services. There are currently more than 381 different languages spoken in homes across the country and 20 percent of Americans speak a language other than English at home (Ryan 2013). After English, Spanish is the second most frequently spoken language in the United States followed by Chinese, with 37.6 and 2.8 million speakers respectively (Gonzalez-Barrera \& Lopez 2013; Ryan 2013). The USDA encourages local SNAP offices to be sensitive to language needs by trying to accommodate clients with language barriers and to conduct outreach in languages other than English (USDA 2014).

It is, perhaps, no surprise that SNAP outreach workers identified language as the first barrier to SNAP participation for immigrant clients. All outreach staff interviewed recognized the benefit of bi-lingual, English-Spanish speaking employees, as well as printing outreach and application materials in both English and Spanish or other dominant languages in their service area. Many food banks had a call-center hotline or customer support center option for employees to access multiple languages when necessary. Additionally, websites from all six states had SNAP benefit information available in both English and Spanish, including a basic description of SNAP benefits and a link to start the application process.

Locations in our study varied greatly in how they responded to language needs. Responses ranged from having Spanish speakers among the staff (eight sites), requiring Spanish language for new hires (four sites), offering free language classes to staff members (one site), to trying to identify volunteers in the community or caseworkers with 
the needed language skills (eight sites). Other, less preferred methods included using computer translation services or call-in language lines. An outreach worker from New York specifically noticed the changing demographic in his community. He explained how it influenced his way of working and thinking about hiring:

We as an organization have really needed to adapt to [the increase of Spanish speakers in the community]. So basically when we hire at this point in time, if there's gonna be interaction with clients, the Spanish is necessary.

Offering free language classes to employees was only discussed by one employee from Ohio. She thought that the department offering a Spanish language course was a great way to adapt to the changing clientele:

We have so many people here who took that [Spanish language] class so I think we kind of hit that head on several years ago.

However, without ongoing language use and instruction, it may be debatable how effective it is to offer a one-time training. If the instruction is ongoing, this may be a relevant manner to address language barriers in an area, especially in areas with only one dominant foreign language. While most locations mentioned that staff members spoke multiple languages, a SNAP coordinator in Wisconsin preferred a candidate who possessed the necessary skill over requiring a candidate who spoke a second language (Spanish). The SNAP project coordinator's rationale was that:

Ideally we would have more Spanish speakers but then you get into the cost benefit and I'm not going to sacrifice and hire somebody that's bilingual just because they speak Spanish.... ideally that is what I want, that is fantastic, but if I 
can find somebody that just has the skills and they're going to be able to serve more people but not speak Spanish then that's what I've got to go for.

The SNAP project coordinator went on to explain that previously she had job applicants that could speak Spanish but they were not qualified for the job. She did not want to make that kind of sacrifice again. She also explained that the number of Spanish speakers in the food bank's service area was not very large. Perhaps she would make a different decision if this food bank experienced an influx of Spanish speaking clients in their service area, as the outreach worker in New York experienced.

Two food banks identified the largest language group in their service area (after English) and focused resources on that specific language, instead of trying to reach all language groups. For example, a food stamp advocacy coordinator in California noted that:

Right now our biggest challenge is our lack of Spanish speaking professional staff....The majority [of our clients] would be...50 percent Spanish speaking and the rest, well probably 48 percent is gonna be English and the other would be a variety of Cantonese, Chinese and Russian and Farsi.

This outreach worker reasoned that focusing on the largest language group, Spanish, would be more efficient than trying to focus on all language minorities within her food bank service area. Another site in California noticed that they were underserving the Chinese population in their service area. This prompted the SNAP programming supervisor, in addition to other media campaigns, to appear on a local Chinese language talk show. On that program, the supervisor discussed various aspects of SNAP for a population that may not otherwise be familiar with the program. Several (seven) sites, 
however, noted the difficulty they are having communicating with minority languages in their area, especially languages spoken by refugees in the community.

The need to provide information about social services, including SNAP, in many languages besides English is a growing issue in America. Given the high SNAP caseloads during and after the Great Recession and the changing patterns of immigrant settlement, there is an immediate and pressing need for delivery of SNAP application assistance in non-English languages that has been filled, in part, by nonprofit organizations. Our analysis indicates that strategies and the languages served varied greatly by location, however, all sites indicated that non-English service delivery was a growing concern for their organization. This finding highlights the important role that language supports are likely to play in other social service areas in the coming years.

\section{Providing convenient and "safe" service delivery}

In the nine locations we studied, submitting a SNAP application usually required interacting with the county or state SNAP eligibility workers at least once either face-toface or by telephone. During standard business hours, wait times for either service were reported to be substantial. In addition, in at least one location, finger printing was still required. According to our interviewees, these aspects of the application process are barriers because immigrants often feared contacting government employees directly and had difficulty arranging transportation around work and family obligations.

SNAP outreach workers at food banks made the SNAP application process more accessible by allowing the initial submission of the application and accompanying documentation to occur off-site from official government offices and to make that submission possible during evenings and weekends. The specific ways outreach workers 
made this happen varied across the locations we studied. Some SNAP outreach workers reported conducting outreach activities in local libraries (one site), while others drove several hours to conduct outreach in rural communities (three sites), and still others worked with community organizations targeting immigrant groups (six sites), such as free clinics, food pantries, local immigrant and farm worker nonprofit organizations, and the Mexican Consulate.

In addition to creating more convenient entry into the SNAP application system, the manner in which outreach workers provided services was also identified as important. SNAP outreach workers in seven locations reported consciously trying to create a neutral, safe, and respectful space. For example, in cases where families lived in mixed-status situations ${ }^{6}$, immigration status was only discussed in relation to those family members covered directly by SNAP benefits and the rules were clearly and respectfully explained. Offering outreach at a non-governmental neutral space, such as food distribution points, helps those who qualify for benefits but also fear government contact. Mixed-family clientele came up often in interviews with staff in Arizona. The staff made it clear that they were not judging their clients and that:

[We are] incredibly upfront at the beginning that this is a safe space for all people and...our objective is to tell you about these programs...not to ask them any personal information or anything else.

Community partnerships helped some food banks gain access to hard-to-reach populations, such as seasonal agricultural workers. In one location in California, the agricultural firm placed a flyer from the food bank with SNAP eligibility and application

\footnotetext{
${ }^{6}$ A mixed-status household has one or more members with U.S. citizenship and one or more members who are undocumented.
} 
information in the last paycheck of the season and the outreach workers were invited to participate in the employee fairs held at the farm. Three other sites discussed collaborations with migrant worker organizations to get into contact with migrant workers and increase the visibility and accessibility of SNAP services. Working with farms employing large numbers of seasonal workers, migrant worker organizations as well as working with foreign embassies or consulates were cited as effective strategies to make SNAP benefits accessible to eligible immigrant populations. ${ }^{7}$

SNAP outreach workers tailored their strategies to create safe and convenient services for immigrants depending on the needs of their local population. Some of the strategies, such as conducting outreach at libraries or at food distribution sites, are not necessarily targeted at immigrants and could service many different populations at the same time. Although it is true that all populations may benefit from the provision of social services in a safe and convenient manner, the food bank outreach staff we interviewed made clear that they prioritized the needs of immigrant populations when designing their method of service delivery.

\section{Clarifying misinformation about SNAP participation}

Misinformation regarding both SNAP eligibility requirements and their potential effect on immigrant status was reported by staff from eight different sites as a widespread barrier to SNAP participation. Because immigrant eligibility for SNAP depends on immigration status, dual program knowledge is required to accurately advise and process applications. The SNAP outreach workers at seven sites reported informing their clients

\footnotetext{
${ }^{7}$ Note, however, that the 2014 Farm Bill impacted SNAP outreach by limiting marketing activities and outreach connected with foreign governments (i.e. at a foreign embassy or consulate; Agricultural Act of 2014).
} 
that SNAP use will not be reported to immigration and will not affect their path to citizenship. Additionally, immigrants often lacked basic knowledge about SNAP. For example, some immigrant food pantry clients erroneously believed that SNAP benefits would need to be repaid by the recipient.

SNAP outreach staff corrected the misinformation in a number of ways. In five locations, outreach staff offered confirmation that SNAP participation would not be reported to immigration services by showing potential applicants a letter from the Department of Homeland Security. Outreach workers told us that the immigrant clients they worked with were leery of government benefits and feared the consequences of becoming a public charge. Utilizing a letter from the government telling potential SNAP participants that SNAP use would not be considered a public charge and would not affect their immigration status in the future proved helpful to relieve some misperceptions. One outreach worker in Wisconsin told us:

I actually went to the immigration website and I carry around a sheet from the INS [Immigration and Naturalization Service] that shows that [SNAP] would not be ever counted as a public charge.

Another outreach worker from California told us something similar:

Regarding public's charge for our undocumented families and individuals, we have a great letter from Homeland Security, Department of Immigration Services where they are saying, the actual bureau is saying, that receiving and applying for SNAP is not gonna hurt their chances of becoming a legal permanent [resident] or citizens. So that letter is basically a tool that we use. 
The letter explains that SNAP participation does not impact immigration status, does not prohibit the recipient from applying for citizenship in the future, and that only those applying for SNAP assistance need to verify their immigration status (USDA 2011). Outreach workers from five sites viewed this formal letter as an important educational tool because it offers credibility: it is not just the SNAP outreach worker's word, but also the federal government's word. Clients had various reactions to the letter. Some kept a copy for their personal files, whereas others found it enough to have viewed the letter. An outreach coordinator in California told us that while she rarely went into the field, she had an experience where the immigration letter really made a difference for a potential SNAP participant:

We have seen that there is an applicant who she was scared because of her immigration status, she said, 'no, immigration is gonna come back... '. And I showed them this letter, and we explained to them that it's not a public charge. SNAP outreach workers also dispelled other myths about SNAP participation that are specific to immigrant populations. Outreach workers reported that mixed-status families were often reluctant to apply for SNAP benefits for their citizen children because the adults in the household did not want to be asked about their citizenship status. In at least one location, SNAP outreach workers worked with clients to prepare them for their eligibility interview, advising them not to answer questions that were not legally required. When [government employees] ask [potential SNAP clients] do you have a Social Security number or are you, what's your status here? We teach them how to answer those questions. We say you're only applying for your children, it's not 
for you. It's only for them....that's all you have to say because you have the right not to answer those questions because ...it's only for [the kids], and they feel safe. An additional barrier discussed was the difficulty documenting income. Many immigrants are employed as day laborers and seasonal workers, some with and some without a work visa. Regardless, documentation of income is required for SNAP eligibility determination. SNAP outreach workers reported providing a clear format and one-on-one education to help clients learn to document their income from day labor. One SNAP outreach worker in Arizona described her instructions:

We give them.... a self-employment sheet where they can write, 'Well, on this day, I worked so and so and I cleaned her yard. They paid me \$50.00' 'On this day, I fixed somebody's lamp and they gave me $\$ 10.00$, and here is her phone number.'

Thus, food bank employees used a variety of strategies to address misinformation in the immigrant community about potentially negative consequences of SNAP participation. SNAP outreach workers also provided clear instructions for immigrants on how to negotiate the application process, document income, and answer questions during the eligibility interview. This finding highlights that in order to be successful, SNAP outreach workers need a high level of knowledge about SNAP program rules, as well as an ability to communicate effectively with immigrant groups.

\section{Enhancing computer literacy and access}

Obtaining information regarding SNAP eligibility and applying for benefits directly with state or county agencies increasingly requires computer access and literacy. According to recent research on SNAP, program eligibility information is universally available online on state websites, and prescreening tools are available in 29 states to help 
individuals determine their household eligibility (Rowe et al. 2010). Additionally, at least 33 states have direct links to applications that can be submitted online (Rowe et al. 2010). Despite their usefulness for some applicants, online and computer-based information models may create barriers to participation for applicants who have difficulty navigating computers or accessing the internet. Heflin, London and Mueser (2013) found that nine out of ten Hispanic respondents in Florida had difficulty using a computer and accessing the online application system. This Florida study suggests that varying levels of computer literacy may create difficulties for some groups and can add an additional challenge when English language barriers are present.

In interviews, SNAP outreach workers acknowledged the advantages of a modernized system but also worried that the digital divide was acting as a barrier to SNAP. One food bank CEO acknowledged that outreach centers, such as those at food banks, could provide internet assistance as online applications become more and more the norm.

Doing kiosk and online apps [applications] is a way to avoid both office visit and call center waits, but there again you have all the digital divide issues...all those issues...for families that maybe struggle with English...to have comfort with the online stuff. So...we're hopeful that there's a way in which...they can get more kiosks and more...customer-friendly areas...like the food bank... and somehow kind of work through that process.

Our analysis of interview transcripts suggested that many SNAP outreach workers worked with clients by walking through the application question by question, then filling in the answers to the on-line application for them - a process that, for some, took many 
hours to complete. Providing these services to immigrant populations, at least according to one site, could be a niche for food bank SNAP workers:

A lot of the people that we serve are monolingual, like only speak Spanish or only speak Chinese. And that's where we come in, because they maybe are not familiar with the internet or don't feel comfortable going to the [county SNAP] office. The problem seems overwhelming for them, so that's the demographic I think that we most-I guess that's our niche.

Online application systems are becoming the norm for SNAP service delivery in the United States. Consequently, many of the food bank SNAP outreach sites within this study worked with online systems, although many reported having paper applications on hand if necessary. While reports of difficulty with online systems were not limited to immigrant populations (Heflin, London \& Mueser 2013; Mishra et al. 2014), access and computer literacy problems were frequently cited as especially problematic for immigrants. Reliance on online systems is likely to increase in coming years; it is therefore worthwhile to consider that online assistance could become an important niche for nonprofit organizations working with social service programs.

\section{Discussion}

In this study, we used data from 48 interviews with SNAP outreach workers from nine food banks in six states to document the range of strategies used to connect eligible immigrant populations to SNAP benefits. These strategies gave us insight into the specific barriers immigrant populations face in accessing social services and the potential for nonprofit organizations to help them overcome these barriers. In the case of SNAP, nonprofit outreach workers used innovative methods adapting to the perceived needs of 
their clientele. Food bank SNAP outreach workers utilized their neutral position to offer a non-governmental, safe space with more convenient hours and locations to apply for SNAP benefits compared to government offices. Lack of English language and computer literacy skills created access problems for eligible immigrants and have been exacerbated by modernized application processes. Food bank outreach workers utilized multifaceted approaches to overcome language barriers and the issues related to the modernized application procedure. They were also highly knowledgeable of SNAP eligibility and participation rules under varying situations and worked hard to rectify misinformation.

The geographic and demographic situation for each of the food banks deeply influenced their priorities for reaching immigrant populations. For example, Spanish language was an important trait for new hires in most of the sites we researched. However, in one site where Spanish was not prolific, other qualities were more important for new hires and sites in two states did not mention much regarding their interactions with immigrant populations. Food bank sites near areas with farm laborers or large refugee populations, on the other hand, discussed strategies to communicate with monolinguals, build trust, and reach these populations with unique needs. Strategies cited by interviewees were context specific and varied across food banks and counties.

Through our interviews, we found it apparent that the main goal of SNAP outreach was to build trust within immigrant communities and with clients in general. These nonprofit employees discussed how their work assists vulnerable populations who may otherwise fall through gaps of increasingly modernized government services. All four components discussed in this paper are deemed necessary to effectively work with immigrant populations, but among them, the ability to communicate in the language of 
the client was clearly most key. The barriers to public service access we find in this study echo previous literature regarding immigrant access to healthcare and human services (Derose, Escarce \& Luri 2007; Fortuny \& Chaudry 2011; Perreira et al. 2012); child welfare services (Earner 2007); and access to SNAP (FRAC 2008; Gorman et al. 2013; Skinner 2012). However, this study is unique because it documents the perceptions of outreach workers and other food bank employees and their actions based on their perceptions. Future, follow-up studies could build on this research by conducting client interviews, which would offer information on the effectiveness of food bank staff strategies.

Although this study and the strategies explained in this article stem from one type of nonprofit (food banks) working with immigrant populations to access one particular social service (SNAP), these strategies could be extended into other types of services and organizations. Utilizing nonprofit organizations and their employees to bridge vulnerable populations to government services by clarifying misinformation of eligibility rules, providing a safe space for clients to receive application assistance, using multiple approaches to overcome language barriers, and assisting clients with computer literacy problems are transferable strategies that could be used for other types of social services as well.

That said, this study does have some limitations that should be noted. Although 48 interviews over nine sites in six states is not a small sample, the results are specific to the context of the study sites. The value of our study lies in the qualitative richness and we offer our findings as suggestive of the range of barriers to SNAP participation experienced by immigrant groups and the strategies outreach workers use to connect 
immigrants to SNAP. Our study did not include client interviews, so we do not know if immigrants themselves would endorse our enumeration of barriers to participation or agree that the strategies we highlighted were effective. Additionally, the interviewees in this study were unable to follow their client applications through the governmental process. Because of this, we are unable to decipher if certain strategies had more impact on SNAP participation compared to others. As a qualitative study, our intent was not to evaluate or causally assess barriers and strategies to overcome them, but instead to generate a new understanding of them so that future studies can ask more refined causal and evaluative questions.

Limitations notwithstanding, there are several implications of this research that are worth noting. First, to the extent the 2014 Farm Bill has placed limits on allowable outreach activities, such as advertising or partnering with foreign consulates, this may limit access to information and limit participation for some groups eligible for benefits. Second, the American social welfare delivery system has typically adopted a one-size fits all approach for all population groups, even though states devise their own application and eligibility determination processes. Modernization (i.e., increased reliance on the internet and technology) appears to be the direction state and county governments are headed in order to accommodate current fiscal pressures and high local demand for services. We found that the increased dependence on online services and information sources may create additional barriers to entry for non-native English speaking immigrant populations. Finally, nonprofit organizations are a growing source of innovation in terms of bridging the needs of specialized populations and formal governmental services. Exploring ways that nonprofit organizations can complement and supplement 
government services may provide a way to increase access and participation for certain hard-to-reach populations

Although this study provides one look into the role of nonprofit organizations in connecting immigrants with services, important research questions remain unanswered. In what ways are other nonprofit organizations connecting under-serviced populations to formal governmental services such as SNAP? Is there evidence that the need for bridging services is growing with the increased diversity of the low-income population?

Additionally, a follow-up study that examines the perspectives of various roles within an organization, e.g., management, advocacy and frontline outreach professionals, could offer important organizational insight. Answers to these and other related questions will be critical to our understanding of growing barriers to participation in the social welfare system. 


\section{References}

Agricultural Act of 2014, H.R. 2642, $113^{\text {th }}$ Congress. (2014). Retrieved from https://www.congress.gov/bill/113th-congress/house-bill/2642.

Alford, S.; Heflin, C.; \& Waxman, E. 2014. SNAP Outreach Case Studies Coast to Coast: A summary analysis of policies, key findings, and outcomes. Chicago, Feeding America.

Allard, S. W. \& Roth, B. 2010. Strained Suburbs: The Social Service Challenges of Rising Suburban Poverty. Metropolitan Opportunity Series Report, Washington, DC, Brookings Institution.

Allard, S.W. \& Small. M.L. 2013. Reconsidering the Urban Disadvantaged: The Role of Systems, Institutions, and Organizations. The Annals of the American Academy, 647, 6-20.

Broder, T. 2007. State and Local Policies on Immigrant Access to Services Promoting Integration or Isolation? Los Angeles, National Immigration Law Center.

Castner, L. \& Rosso, R. 2000. Characteristics of Food Stamp Households Fiscal Year 1998. Washington, DC, Mathematica Policy Research.

Creswell, J. W. 2013. Qualitative inquiry \& research design: Choosing among five approaches ( $3^{\text {rd }}$ ed.). Los Angeles, Sage.

Daponte, B. O.; Sanders, S.; \& Taylor, L. 1999. Why Do Low-Income Households Not Use Food Stamps?. Evidence from an Experiment. Journal of Human Resources, 34, 612-628.

Derose, K. P.; Escarce, J. J.; \& Lurie, N. 2007. Immigrants and health care: sources of vulnerability. Health Affairs, 26, 1258-1268. 
Dion, M. R. \& Pavetti, L. 2000. Access to and Participation in MEDICAID and the Food Stamp Program: A review of the recent literature. MPR Reference No.: 8661-401, Washington, DC, Mathematica Policy Research.

Earner, I. 2007. Immigrant Families and Public Child Welfare: Barriers to Services and Approaches for Changes. Child Welfare, 86, 63-91.

Feeding America. 2014. SNAP Outreach Multi-State Case Study Evaluation Report: Feeding America National Office Evaluation Department. Chicago, Feeding America.

Fix, M.; Capps, R.; \& Kaushal, N. 2009. Immigrants and Welfare: Overview. In M. Fix (ed) Immigrants and Welfare, The Impact of Welfare Reform on America's Newcomers. New York, Russell Sage Foundation.

Fix, M. \& Passel, J. 2002. The Scope and Impact of Welfare Reform's Immigrant Provisions. Discussion Paper: Assessing the New Federalism, An Urban Institute Program to Assess Changing Social Policies, Washington, DC, The Urban Institute.

Fortuny, K. \& Chaudry, A. 2011. A Comprehensive Review of Immigrant Access to Health and Human Services. Washington, DC, The Urban Institute.

Food Research and Action Center (FRAC). 2008. Access and Access Barriers to Getting Food Stamps: A review of the literature. Retrieved from http://frac.org/wp-content/uploads/2009/09/fspaccess.pdf.

Food Research and Action Center (FRAC). 2011. SNAP Access in Urban America, A city-by city Snapshot. Retrieved from http://frac.org/wp-content/uploads/2011/01/ urbansnapreport_jan2011.pdf. 
Ganong, P. \& Liebman, J. B. 2013. The Decline, Rebound, and Further Rise in SNAP Enrollment: Disentangling Business Cycle Fluctuations and Policy Changes. NBER Working Paper No. 19363.

Gonzalez-Barrera, A. \& Lopez, M. H. 2013. Spanish is the most spoken non-English language in U.S. homes, even among non-Hispanics. Pew Research Center. Retrieved from http://www.pewresearch.org/fact-tank/2013/08/13/spanish-is-themost-spoken-non-english-language-in-u-s-homes-even-among-non-hispanics/.

Gorman, K. S.; Smith, A. M.; Cimini, M. E.; Halloran, K. M. \& Lubiner, A. G. 2013. Reaching the Hard to Reach: Lessons Learned from a Statewide Outreach Initiative. Journal of Community Practice, 21, 105-123.

Heflin, C. M.; London, A. S.; \& Mueser, P. R. 2013. Clients' Perspectives on a Technology-Based Food Assistance Application System. The American Review of Public Administration, 43, 656-673.

Leftin, J. 2010. Trends in Supplemental Nutrition Assistance Program Participation Rates: 2001 to 2008. Washington, DC, Mathematica Policy Research.

Magaña, L. \& Short, R. 2002. The Social Construction of Mexican and Cuban Immigrants by Politicians. The Review of Policy Research, 19, 78-94.

Mishra, A. N.; Ketsche, P.; Marton, J.; Snyder, A.; \& McLaren, S. 2014. Examining the potential of information technology to improve public insurance application processes: enrollee assessments from a concurrent mixed method analysis. Journal of the American Medical Informatics Association, 21, 1045-1052.

Moffitt, R. 1983. An Economic Model of Welfare Stigma. The American Economic Review, 73, 1023-1035. 
Parsons Dick, H. 2011. Making Immigrants Illegal in Small-Town USA. Journal of Linguistic Anthropology, 21, E35-E55.

Passel, J.S. \& Cohn, D. 2009. A Portrait of Unauthorized Immigrants in the United States. Washington DC, Pew Research Center.

Patton, M. Q. 2002. Qualitative Research and Evaluation Methods ( $3^{\text {rd }}$ ed.), Thousand Oaks, Sage.

Perreira, K. M.; Crosnoe, R.; Fortuny, K.; Pedroza, J.; Ulvestad, K.; Weiland, C.; Yoshikawa, H.; \& Chaudry, A. 2012. Barriers to Immigrants'Access to Health and Human Services Programs. ASPE Issue Brief, Washington DC, Office of the Assistant Secretary for Planning and Evaluation.

Rowe, G.; O’Brien, C.; Hall, S.; Pindus, N.; Eyster, L.; Koralek, R.; \& Stanczyk, A. 2010. Enhancing Supplemental Nutrition Assistance Program (SNAP) Certification: SNAP Modernization Efforts, Final Report, Volume 1. Alexandria, U.S. Department of Agriculture, Food and Nutrition Service.

Ryan, C. 2013. Language Use in the United States: 2011. American Community Survey Reports, U.S Census Bureau. Retrieved from https://www.census.gov/prod/2013pubs/acs-22.pdf.

Salamon, L. (1995). Partners in Public Service. Baltimore, Johns Hopkins Press.

Schneider, A. \& Ingram, H. 1993. Social Construction of Target Populations: Implications for Politics and Policy. American Political Science Review, 87, 334347.

Skinner, C. 2012. State Immigration Legislation and SNAP Take-Up among Immigrant Families with Children. Journal of Economic Issues, XLVI, 661-681. 
Tumlin, K.C. \& Zimmerman, W. 2003. Immigrants and TANF: A Look at Immigrant Welfare Recipients in Three Cities. Occasional Paper Number 69, Assessing the New Federalism, An Urban Institute Program to Assess Changing Social Policies, Washington, DC, The Urban Institute.

U. S. Department of Agriculture (USDA). 2007. 2002 Farm Bill. Retrieved from http://www.ers.usda.gov/publications/ap-administrative-publication/ap-022.aspx

U. S. Department of Agriculture (USDA). 2011. Supplemental Nutrition Assistance Program: Guidance on Non-Citizen Eligibility. Retrieved from http://www.fns.usda.gov/sites/default/files/Non-Citizen_Guidance_063011.pdf.

U. S. Department of Agriculture (USDA). 2012. SNAP Policy on Immigrant Access Issues. Retrieved from http://www.fns.usda.gov/sites/default/files/030912.pdf.

U. S. Department of Agriculture (USDA). 2014. Outreach: State Outreach Plan Guidance. Retrieved from http://www.fns.usda.gov/outreach/state-outreach-planguidance.

U. S. Department of Agriculture (USDA). 2016. Supplemental Nutrition Assistance Program. Retrieved from https://www.fns.usda.gov/snap/supplemental-nutritionassistance-program-snap.

Van Hook, J. \& Stamper Balistreri, K. 2006. Ineligible parents, eligible children: Food Stamps receipt, allotments, and food insecurity among children of immigrants. Social Science Research, 35, 228-251.

Young, D. 2000. Alternative Models of Government-Nonprofit Sector Relations: 
Theoretical and International Perspectives. Nonprofit and Voluntary Sector Quarterly, 29, 149-172.

Zimmerman, W. \& Tumlin, K. 1999. Patchwork Policies: State Assistance for Immigrants under Welfare Reform. Occasional Paper Number 24: Assessing the New Federalism, An Urban Institute Program to Assess Changing Social Policies, Washington, DC, The Urban Institute. 


\title{
CHAPTER 2:
}

\section{IMMIGRANT NONPROFIT ORGANIZATIONS IN NEW AND ESTABLISHED IMMIGRANT DESTINATION COUNTIES}

\author{
Kate C. Olson \\ Introduction
}

Governments increasingly rely on nonprofit organizations to serve immigrant and refugee groups (Joassart-Marcelli 2013; Tseng 2006). Nonprofits working predominately with or predominately run by immigrant populations are considered immigrant nonprofit organizations. Immigrant nonprofits are similar to general nonprofit organizations, offering human, social, and cultural service provision (Boris \& Steuerle 2006; Salamon 2012a); but they do so with cultural-specific perspectives, language capacity, and a focus on immigrant concerns (Gleeson \& Bloemraad 2013; Joassart-Marcelli 2013; Hung \& Ong 2012). In recent years, scholarly interest in immigrant nonprofit organizations has increased (i.e. Cordero-Guzmán 2005; de Graauw, Gleeson, \& Bloemraad 2013; Gleeson \& Bloemraad 2013; Hung 2007; Hung \& Ong 2012; Zhou \& Lee 2013). Much of the growing literature on immigrant nonprofits has focused on funding sources available (de Graauw, Gleeson \& Bloemraad 2013; Joassart-Marcelli 2013; Winders 2012) and how to identify immigrant nonprofits (Cordero-Guzmán 2005; de Graauw, Gleeson, \& Bloemraad 2013; de Leon et al. 2009; Gleeson \& Bloemraad 2013; Hung 2007; Hung \& Ong 2012). Additionally, a few studies have analyzed the presence of immigrant nonprofits in new immigrant destinations (de Graauw, Gleeson \& Bloemraad 2013; Gleeson \& Bloemraad 2013; Joassart-Marcelli 2013). 
New immigrant destinations tend to be located in suburban or rural areas and have experienced a rapid growth of their foreign-born population (Bada et al 2010; Singer 2013; Marrow 2009; de Graauw, Gleeson \& Bloemraad 2013). New destinations are generally unaccustomed to immigrant specific needs and potentially unprepared to provide services such as education, healthcare, language, or employment assistance to foreign-born residents (Crowley, Lichter, \& Qian 2006; de Graauw, Gleeson, \& Bloemraad 2013; Joassart-Marcelli 2013; Massey \& Capoferro 2008; Singer 2004, 2013; Stone et al. 2015). Especially in these settings, immigrant nonprofit organizations may be well suited to address the needs of the growing foreign-born population. ${ }^{8}$ Factors associated with the presence of an immigrant nonprofit, however, are not well known.

In this paper, I focus on three determinants used in the general nonprofit literature associated with nonprofit sector growth: community need (i.e. poverty), community resources (i.e. charitable giving), and the community structure (i.e. education, employment structure). Especially in new immigrant destinations, but also established destinations, understanding the characteristics associated with the presence of immigrant nonprofit organizations may assist strained local government officials in working with their constituent foreign-born populations. I examine community need, community resources, and community structure to understand the structural determinants of where immigrant nonprofit organizations are located across the United States. Specifically, I analyze county-level data from a national database of immigrant nonprofit organizations and the American Community Survey (ACS) focusing on three research questions:

\footnotetext{
${ }^{8}$ Throughout this text, foreign-born and immigrant are used interchangeably to refer to individuals born outside of the United States who were not a U.S. Citizen at birth. This can refer to naturalized U.S. citizens, legal permanent residents, refugees, asylum seekers and other non-citizens, including undocumented immigrants.
} 
1. Where are immigrant nonprofit organizations located? I use GIS mapping and immigrant nonprofit data from 2014 to answer this question.

2. How do community need, community resources and community structure differ in counties with and without an immigrant nonprofit and in new and established immigrant destination counties? To examine this question, I use descriptive statistics to document differences in county characteristics with and without an immigrant nonprofit organization and in new and established immigrant destination counties.

3. What county characteristics predict the likelihood of an immigrant nonprofit organization in a county? To answer the third research question, I analyze the probit regression model results related to the presence of an immigrant nonprofit.

This paper starts with a brief introduction explaining the definition of new and established immigrant destination counties. I then elaborate on the role of immigrant nonprofit organizations in the current literature and describe the ways in which previous researchers have defined immigrant nonprofit organizations. The third section focuses on the determinants of nonprofit sector growth from the general nonprofit literature, with a discussion of how these connect to the presence of immigrant organizations. Finally, I describe the data and methods for this study, including a description of the unique Immigrant Analysis Dataset (IAD) of immigrant nonprofit organizations used for this study. The three research questions guide the results section. Findings from the probit regression suggest that immigrant nonprofit organizations are located in counties with a large total population and the determinants of an immigrant nonprofit differ depending on destination type. 


\section{New and Established Immigrant Destinations}

Both new and established immigrant destinations are experiencing immigrant growth across the U.S. In this study, new immigrant destinations are counties experiencing new and rapid growth of foreign-born residents since the 1990s; established immigrant destinations are counties with a longer standing history of immigrant settlement (Fischer 2010; Singer 2004, 2013). Counties that do not fall into either of these categories are considered non-destination counties. According to research on the geography and history of immigrant settlement, the economic opportunities and lower costs of living in new immigrant destinations encouraged immigrants to seek opportunities in new destinations (Hall et al. 2011; Singer 2013). The economic opportunities, however, often appear to be in low-wage, low-skill, high risk jobs in the agricultural, meat processing and manufacturing sectors (Crowley, Lichter, \& Qian 2006; Hall 2013; Kandel \& Parrado 2005; Massey 2008; Singer 2004, 2013). The economic opportunities in new destinations also attract entrepreneurial immigrants, who are "more ambitious, healthier, and better able to work more hours or hold more jobs" compared to native born residents (Crowley, Lichter, \& Qian 2006, p. 356). While employment opportunities invite immigrants to settle and work in new destinations, their inclusion into the social, political, and economic life of the community is not always easy.

The government and organizational resources available to work with immigrant populations are different in new and established immigrant destinations. For example, residents and officials in established immigrant destinations are more likely to be familiar with the presence of foreign-born populations and to possess the structural resources and knowledge to address immigrant needs (Massey 2008). In new destinations, however, 
language services, schools, healthcare systems and other community level services often lack the infrastructure, cultural competence, and institutional support to meet the needs of the fast growing and increasingly diverse immigrant population (Anderson et al. 2003; Betancourt et al. 2005; Crowley, Lichter, \& Qian 2006; Hall 2013; Marrow 2009; Massey 2008; Singer 2004). Additionally, in new destinations, immigrant populations and immigrant nonprofit organizations are more likely to be invisible to government institutions, hindering recognition and allocation of resources to these groups (de Graauw, Gleeson, \& Bloemraad 2013; Winders 2012). At the same time, the demand for nonprofit organizations to provide acculturation and resettlement services to immigrant populations has increased in all areas (Joassart-Marcelli 2012; Salamon 2012b). Immigrant nonprofit organizations may be well suited to fill this role in both new and established destinations. New immigrant destinations, however, appear to have a greater need for these services.

\section{Immigrant Nonprofit Organizations}

Immigrant organizations assist immigrants throughout the immigration process and may include assistance integrating into the mainstream society, finding employment, navigating the healthcare system, religious guidance, and overcoming language and cultural barriers (Cordero-Guzmán 2005; de Leon, et al. 2009). Immigrant nonprofit organizations, in this study, include ethnic organizations serving clientele from one ethnic or national origin and larger service providers with a focus on multicultural programming for foreign-born residents (Joassart-Marcelli 2013). In the immigrant nonprofit literature, however, the definition of an immigrant nonprofit varies depending on the population served (i.e. a specific ethnic group or the foreign-born population in general) or the 
location of service (i.e. in the United States or internationally in the country of origin). The lack of a cohesive and widespread definition of an immigrant organization is, in part, due to the limited understanding of "who these groups are, what kinds of programs and services they provide, where they are located, who they serve, and what kinds of resources they have" (Cordero-Guzmán 2005, p. 891).

One common link in the varying definitions of an immigrant nonprofit organization is that an immigrant nonprofit provides services to or focuses on matters concerning specific immigrant or ethnic groups. One of the first studies focusing on immigrant (Latino) nonprofit organizations defined Latino nonprofits as "organizations whose missions focus on Latino community problems or aspirations and are controlled or led by Latino community members" (Cortes 1998, p. 439). In addition to the organizational focus, the organization needed a Latino director or a majority of Latino members. Hung (2007) focused on Latino and Asian American immigrant groups and similarly defined an immigrant nonprofit as "nonprofits that are run by Hispanic or Asian Americans, with a significant number of board members coming from these two immigrant groups" (Hung 2007, p. 711). Cordero-Guzmán’s (2005) definition from his study of New York social service immigrant nonprofits states that an immigrant organization is "formed by individuals who are members of a particular ethnic or national-origin group, for the purpose of providing social services primarily to immigrants from the same ethnic or national group" (p. 894). Gleeson and Bloemraad (2013) utilize a definition similar to Cordero-Guzmán: immigrant nonprofits "primarily serve, are run by, or focus on immigrant concerns" (p. 365). Also similar to CorderoGuzmán's (2005) definition, Joassart-Marcelli (2013) employed a broad definition in her 
study of Boston immigrant-serving nonprofits: immigrant nonprofits are "ethnic organizations that tend to serve a single group". Joassart-Marcelli (2013), however, also included "larger providers that deliver services to immigrants and refugees from diverse countries of origins" (p. 733). Still another definition including international organizations defines an immigrant nonprofit as a nonprofit with a mission "to serve or advocate on behalf of one or more immigrant communities, promote their cultural heritage, or engage in transnational relations with countries of origin" (de Graauw, Gleeson, \& Bloemraad 2013, p. 96). Depending on the definition used, one researcher may consider an organization focused on humanitarian work in the home country an immigrant organization, while another may only include organizations that work with people locally in the United States. These variations make it difficult to compare studies and to understand what an immigrant nonprofit does, whom immigrant nonprofits serve, and where they are located.

The growing literature on immigrant nonprofit organizations has primarily focused on the community level and used multiple sources to identify immigrant nonprofits. Previous studies have focused on different metropolitan areas largely due to the exploratory nature of these studies (i.e. Los Angeles, Chung 2005; New York City, Cordero-Guzmán 2005; San Francisco Bay area, de Graauw, Gleeson, \& Bloemraad 2013; Washington DC, de Leon et al. 2009; Silicon Valley, Gleeson \& Bloemraad 2013; major metropolitan areas, Hung 2007 and Hung \& Ong 2012; greater Boston area, Joassart-Marcelli 2013; Chicago, Martin 2012). Several of these studies utilized multiple sources to identify immigrant nonprofit organizations. Some examples of these data sources include: the National Center for Charitable Studies (NCCS) database; the 
Guidestar website (guidestar.org); local lists from government and ethnic media; and qualitative interviews of local government officials and leaders in the respective immigrant communities (Cordero-Guzmán 2005; de Graauw, Gleeson, \& Bloemraad 2013; de Leon et al. 2009; Gleeson \& Bloemraad 2013; Hung 2007; Hung \& Ong 2012). Previous research on immigrant nonprofits has generally centered around the organizational type (i.e. cultural; religious; political; service organizations; etc.; Hung 2007); specific immigrant groups and their organizations (i.e. Asian; Indian; Portuguese; Latino; etc.; Gleeson \& Bloemraad 2013; Hung 2007; Hung \& Ong 2012; JoassartMarcelli 2013; Zhou \& Lee 2013); the representation of immigrant nonprofits compared to the immigrant population (Gleeson \& Bloemraad 2013); and financial and policy resources available (Bloemraad 2005; de Graauw, Gleeson \& Bloemraad 2013; JoassartMarcelli 2013; Winders 2012). For example, Hung (2007) found that Asian organizations tend to be cultural organizations, whereas Latino nonprofits were primarily service organizations. Another study concluded that official data sources undercount immigrant nonprofit organizations and that Mexican-serving immigrant organizations are the most underrepresented compared to the number of Mexicans in the population (Gleeson \& Bloemraad 2013). Other studies found that immigrant nonprofits are at a disadvantage to receive local government grants because they are not fully visible to the officials making these decisions (de Graauw, Gleeson \& Bloemraad 2013; Winders 2012). The present study contributes to the existing immigrant nonprofit literature by examining factors associated with the presence of an immigrant nonprofit organization, located in the U.S. and serving immigrants in the U.S. 


\section{Determinants of Nonprofit Sector Growth}

The general nonprofit literature identifies three general factors associated with nonprofit sector growth: community need, community resources and community structure. In this section I discuss these three determinants of nonprofit growth and relate them to immigrant nonprofit organizations. Focusing on community need, community resources and community structure provides context for the settings that distinguish counties with immigrant nonprofits from those without.

\section{Community Need}

Community need is often considered when analyzing nonprofit density and generally focuses on the level of poverty in an area because nonprofit organizations are often thought to respond to the needs of the poor. Paarlberg and Gen (2009), for example, found that given sufficient human capital, formal organizations emerge when there are unmet needs. Other studies, however, have shown that nonprofits do not necessarily respond to need (Ben-Ner \& Van Hoomissen 1992; Grønbjerg \& Paarlberg 2001) but poverty is often associated with higher nonprofit density (Lecy \& Van Slyke 2013; Paarlberg \& Gen 2009). The concept of need is multifaceted and may be operationalized differently in immigrant communities.

For example, in addition to the level of poverty, immigrant need may be expressed by the size of the immigrant population and its linguistic isolation (Fortuny \& Chaudry 2011; Joassart-Marcelli 2013; Marrow 2009; Skinner 2012). In her study of the greater Boston area, Joassart-Marcelli (2013) found that immigrants with lower English proficiency, lower income, higher poverty, and who more recently migrated to the United States lived closer to an immigrant nonprofit organization. The number of immigrant 
nonprofits, however, was not related to the number of immigrants in a city or surrounding area, therefore also noting disparities to access. Disparities in accessing immigrant nonprofit organizations may be due to the partial invisibility of immigrant needs because immigrants may not be a "distinct part of the city's disadvantaged population" (de Graauw, Gleeson, \& Bloemraad 2013, p. 103). Additionally, two studies found fewer immigrant nonprofits in poor neighborhoods compared to areas with more resources (Gleeson \& Bloemraad 2013; Joassart-Marcelli 2013). Due to the resource dependence of nonprofit organizations in areas where they reside, I expect that the size of the foreignborn population will influence the presence of an immigrant nonprofit organization as opposed to poverty.

\section{Community Resources}

Human and financial resources are necessary for nonprofit creation; it is therefore easier for nonprofit organizations to locate in areas with more resources. Human resources are people with the capacity to create, work or volunteer for nonprofit agencies. These skills and capabilities, necessary for nonprofit organizers, come from educational achievement; work or volunteer experience; as well as the time for and value of voluntary engagement (Grønbjerg \& Paarlberg 2001; Paarlberg \& Gen 2009; Salamon 2012a, 2012b). Financial resources include nonprofit revenues from fees-for-services, membership dues, private donations, and government grants (Lecy \& Van Slyke 2013).

Human resources, such as an educated population, help nonprofit organizations thrive (Grønbjerg \& Paarlberg 2001; Joassart-Marcelli 2013; Paarlberg \& Gen 2009). Organizations also function as resources for other organizations. As such, the organizational density in an area can attract more nonprofits and therefore increase the 
number of organizations (Grønbjerg \& Paarlberg 2001). In addition, the presence of "cultural creatives" (Salamon 2012b, p. 41) may increase the likelihood of nonprofit organizations in a community due to their entrepreneurial drive. Cultural creatives are individuals with the capabilities, network, and creative passion to fulfill "their own sense of worth" working for or creating an organization to serve their community (Salamon 2012b, p. 41). Entrepreneurial individuals also need to be present for immigrant nonprofits to emerge. For example, immigrants with higher education, work experience, and knowledge of their community may start an organization serving their respective community (Cordero-Guzmán 2005, p. 895). Immigrant nonprofit organizers need skillssets and networks garnered from experience in the larger nonprofit sector to bring back the knowledge, capabilities, and funding sources, to their own organization (CorderoGuzmán 2005). These human resources are vital for nonprofit organizing, but nonprofit organizations are unable to exist without financial resources as well.

Financial support for non-profit organizations comes in the form of government grants, private donations or fees-for-service. While about 50 percent of public charity proceeds come from fees-for-services, about one-third comes from government contracts and grants (Blackwood, Roeger, \& Pettijohn 2012). Private donations account for 13 percent of public charity revenue and the remaining five percent come from other sources (Blackwood, Roeger, \& Pettijohn 2012). Studies have found that higher household incomes in an area are also a determinant of more nonprofit organizations; possibly a function of charitable giving within a community (Ben-Ner \& Van Hoomissen 1992; Corbin 1999; Grønbjerg \& Paarlberg 2001; Lecy \& Van Slyke 2013; Paarlberg \& Gen 
2009). I expect financial resources will be as important for immigrant nonprofits as they are for general nonprofit organizations.

Cordero-Guzmán (2005) stressed that networks are necessary for immigrant nonprofit organizers to secure funding for their organization. Securing funding is not always easy, especially in new immigrant destinations. In new destinations, resources for immigrant populations are limited and public servants responsible for awarding local grants may be unaware of immigrant nonprofit organizations and their services (de Graauw, Gleeson, \& Bloemraad 2013; Joassart-Marcelli 2013). This “invisibility" influences the amount of funding government entities allocate to these organizations, resulting in service disparities for immigrant populations (de Graauw, Gleeson, \& Bloemraad 2013; Winders 2012). Immigrant nonprofit organizations have more opportunity to receive government funding in established destinations, likely because the foreign-born population is acknowledged and an infrastructure is in place (de Graauw, Gleeson, \& Bloemraad 2013; Marrow 2009; Winders 2012).

\section{Community Structure}

In addition to the community resources discussed above, the community structure also affects nonprofit density, including such factors as population size, the diversity of the population, and employment opportunities (Boris 2006; Grønbjerg \& Paarlberg 2001; Twombly 2003). For example, historically small and stable communities with employment opportunities had greater nonprofit density (Gamm \& Putnam 1999; Grønbjerg \& Paarlberg 2001); and areas with rapid population growth see nonprofit growth (Boris 2006). The impact of community diversity on nonprofit density is mixed (Ben-Ner \& Van Hoomissen 1992; Corbin 1999; Matsunaga \& Yamauchi 2004; 
Paarlberg \& Gen 2001). Community diversity is often measured by religious or racial diversity and both are associated with more nonprofits in an area (Ben-Ner \& Van Hoomissen 1992; Corbin 1999; Matsunaga \& Yamauchi 2004). The type of nonprofit organization, however, varies depending on the level of religious or racial diversity (BenNer \& Van Hoomissen 1992; Grønbjerg \& Paarlberg 2001). I expect immigrant-serving nonprofit organizations are also sensitive to community characteristics.

The presence of a sizeable foreign-born population is also an essential community characteristic leading to the presence of an immigrant nonprofit (Cordero-Guzmán 2005; Gleeson \& Bloemraad 2013; Joassart-Marcelli 2013; Schrover \& Vermeulen 2005). Contrary to what one may expect, however, studies have shown that the size of the immigrant community does not necessarily relate to the number of immigrant nonprofits: there are fewer immigrant nonprofit organizations in proportion to the size of the immigrant community ${ }^{9}$ (Gleeson \& Bloemraad 2013; Joassart-Marcelli 2013). Populous urban areas with diverse immigrant groups had more immigrant nonprofits compared to non-urban areas (de Graauw, Gleeson, \& Bloemraad 2013; Joassart-Marcelli 2013). This follows government failure theory: in diverse communities with a wide range of demands (i.e. language and cultural specific needs), due to governmental limitations, government programs only respond to a portion of the need. More immigrant nonprofit organizations may be present as a result.

The employment structure in a community may also influence the number of immigrants who settle in that area. New immigrant destinations attract immigrant populations due to the stagnated economic situation in established destinations, but also

\footnotetext{
${ }^{9}$ See Appendix A, Figure A4. Out of the four geographic regions, the size of the foreign-born population in the South and West are larger than the percent of the immigrant nonprofits located in these regions.
} 
due to the relocation of certain industries outside of urban areas. New destinations generally have more economic opportunities available, albeit often in low-skill, lowwage, high-risk jobs (Crowley, Lichter, \& Qian 2006; Massey 2008). With more immigrants living in varied locations across the country, the demand for services generally provided by nonprofit organizations will likely also increase (Salamon 2012a, 2012b; Singer 2004).

Prior research on immigrant nonprofits has shown that characteristics such as the size and tenure of the immigrant community and availability of human resources are important in the formation of immigrant organizations (Cordero-Guzmán 2005; Moya 2005). Examining community need, community resources, and community structure in relation to the presence of an immigrant nonprofit organization will offer a sense of the environment necessary for immigrant nonprofit organizations to exist.

\section{Data, Measures, and Methods}

\section{Data}

This study provides a county-level analysis of the relationship between the presence of an immigrant nonprofit organization and community need, community resources and community characteristics including community size, composition of the foreign-born population, and employment opportunities. Data on these county level characteristics for the 3,143 U.S. counties and county equivalents come from the 20092013 American Community Survey. Information on immigrant nonprofit organizations comes from an unpublished Immigrant Analysis Database (IAD) managed by the National Center for Charitable Statistics (NCCS) at the Urban Institute. The immigrant 
nonprofit organizations in the IAD came from the 2014 Exempt Organizations Business Master Files (BMF) from the NCCS data web.

County-level data, such as community size, the composition of the foreign-born population, employment opportunities, and community need come from the American Community Survey (ACS), five-year sample from 2009-2013. The ACS is a nationally representative survey of households and collects information on demographic, social, and economic characteristics of household members. The advantage of using ACS 5-year estimates is that data is available for all counties with information averaged over the 5year time period (January 2009-December 2013). The 1-year and 3-year estimates suppress information in areas below 65,000 people for the 1-year estimates and below 20,000 people for the 3-year estimates; therefore, while the 5-year estimates are the least current, they are the most consistently reliable, offer the largest sample size, and include all counties (U.S. Census Bureau 2008, 2014). ${ }^{10}$

I conduct my analysis on four different groups of US counties. The first group includes all counties. The three remaining groups are separated into one of three immigrant destination types adapted from Fischer's (2010) destination categories (see Figure 1). Established immigrant destinations includes counties with a foreign-born population greater than two percent in 1990 and in 2013. New immigrant destinations includes counties with a small, less than two percent foreign-born population in 1990 and

\footnotetext{
${ }^{10}$ The ACS contains data on the total population in a county as well as the native and foreign-born populations. Data on the foreign born, however, is suppressed in counties with fewer than 7,000 foreignborn residents resulting in only 467 counties with data specific to the foreign-born population. Even though this study focuses on immigrant populations, this county analysis focuses on community characteristics in general and therefore uses the total county population.
} 
one that at least doubled from 1990 to 2013. In this study, non-destinations captures all other counties that were not a new or an established destination.

Figure 1: Immigrant Destination Types: New, Established, and Non-Destination Counties

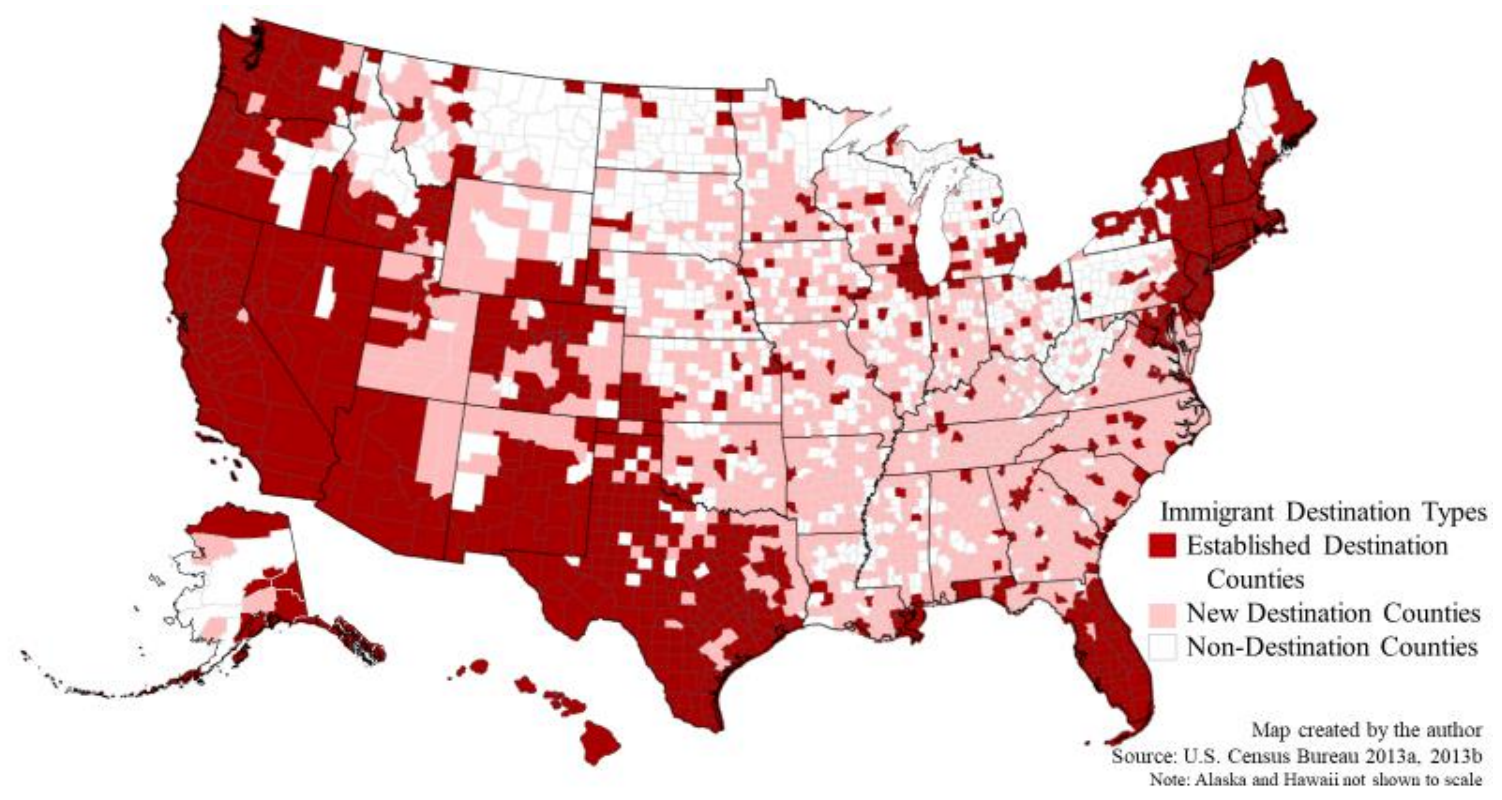

Immigrant Analysis Database. The Immigrant Analysis Database (IAD)

contains 5,826 immigrant nonprofit organizations across the country located in 665

different counties. The majority of counties with an immigrant nonprofit had only one organization (270 counties, 41 percent). The range, however, runs from one to more than 300 organizations in a single county. This database, however, does not capture small, informal immigrant nonprofit organizations not registered with the IRS. ${ }^{11}$ Larger organizations that do not focus on immigrants but have programs for immigrant or refugee populations were also not included in this database (i.e. Catholic Charities

\footnotetext{
${ }^{11}$ It would be beneficial to have data on small, informal immigrant nonprofit organizations because it would give a more complete picture of the immigrant nonprofit organization landscape. Information on small informal immigrant organizations may be especially important in new immigrant destination counties where immigrant nonprofit organizations may only be in the beginning stages. Unfortunately, this information is unavailable.
} 
Refugee and Immigration Services would not be included). Additionally, although religious organizations are not required to file with the IRS, this database contains a number of religious immigrant nonprofit organizations, including churches. The organizations in this database are not exhaustive of immigrant nonprofit organizations. However, the IAD is the most comprehensive, unique and reliable source of immigrant nonprofit organizations covering multiple nonprofit sectors available from a single source.

National Taxonomy of Exempt Entity (NTEE) codes categorize nonprofit organizations by their type and activities performed. Immigrant nonprofit organizations vary in scope and are present in all of the 26 main NTEE categories. ${ }^{12}$ Thirty-five percent of all immigrant nonprofits fall under the NTEE category "P: Human Services" (2,031 organizations), with just over 30 percent of all immigrant nonprofits in the sub-category "P84: Ethnic and Immigrant Centers" (1,841 organizations). Category "X: ReligionRelated" nonprofit organizations was the second largest group of immigrant nonprofits (23 percent of all immigrant nonprofits); Protestant, Christianity, and Hinduism were the largest subcategories. Twenty-one percent of immigrant nonprofits fall under the NTEE category "A: Arts, Culture, and Humanities" (1,231 organizations) and “A23: Cultural and Ethnic Awareness" was the largest subcategory (see Appendix A, Figure A1).

The majority of immigrant nonprofits in this database focus on Asian communities; there are 2,795 immigrant organizations (49 percent) focusing on countries and regions in Asia. The second largest region represented by immigrant nonprofit organizations was Latin America, including South America and the Caribbean; there

\footnotetext{
${ }^{12}$ For more information on NTEE codes and the coding system, please see http://nccs.urban.org.
} 
were 1,260 immigrant nonprofits focusing on this region (22 percent). European focused organizations were the third largest focus (12 percent) of immigrant nonprofits in this database (see Appendix A, Figure A2). ${ }^{13}$

\section{Measures}

The response variable used in this analysis is a dichotomous dependent variable indicating (1) if an immigrant nonprofit organization is present in a county and (0) if not. This variable was based on the immigrant nonprofit organizations in the IAD. I used a dichotomous variable because the majority of counties with an immigrant nonprofit organization had only one immigrant organization present (40 percent). Immigrant organizations in the IAD include organizations that predominantly serve immigrant populations and may include religious, arts, and cultural organizations also serving the general public. To examine how community need, community resources, and community structure relate to the presence of an immigrant nonprofit organization in a county, I used data from the American Community Survey and other data sources to collect relevant measures (see Appendix A, Table A1 for data sources).

Community need. Poverty is often used in the nonprofit literature to predict nonprofit density (Ben-Ner \& Van Hoomissen 1992; Grønbjerg \& Paarlberg 2001; Lecy \& Van Slyke 2013; Paarlberg \& Gen 2009). To determine how poverty may affect the presence of an immigrant nonprofit organization, the percentage of the population below the poverty level was included, as well as the percent of the population who are foreign born to indicate the need for an immigrant specific nonprofit organization in the county. ${ }^{14}$

\footnotetext{
${ }^{13}$ Please see Appendix B for more information on the data in the Immigrant Analysis Database.

${ }^{14}$ I considered using the percent of the population that speak English less than very well as an indicator of linguistic isolation. However, this variable was highly correlated with percent of the population who are
} 
Community resources. Community resource indicators included human and financial resources. Indicators of human resources include the percent of the population with a bachelor's degree or higher; organizational density (the number of nonprofits of all kinds per 10,000 residents); and the percent of residents who are self-employed. The percent of self-employed residents was included to measure entrepreneurial individuals. I used per capita charitable giving as a financial variable ${ }^{15}$ to indicate the per capita amount of itemized charitable donations in a county. ${ }^{16}$

Community structure. To measure community structure at the county level, I followed Grønbjerg and Paarlberg's (2001) use of indicators representing community size, employment structure, and also the diversity of the foreign-born population. Each is discussed below.

To make comparisons across counties, I controlled for population size using the log of the total county population and the log of population density using population size from the 2009-2013 ACS and the county's square miles from the 2010 U.S. Census. To reflect the county employment structure, I used the percent of the civilian labor force, 16 years and older, employed in specific industries. The categories include the percent of the labor force employed in: agriculture or construction; manufacturing; education, health,

foreign born (0.8972). As there was little difference to the analysis using either variable, I chose percent of the population who are foreign born to remain in the analysis.

${ }^{15}$ Originally, I included a per capita federal grants measure to capture federal money potentially available for nonprofit organizations. The federal grants measure was not ideal because it measured the total amount of federal grants the county received, not only for nonprofit organizations (Grønbjerg \& Paarlberg 2001). I did a sensitivity analysis with and without this measure. Per capita federal grants in a county were not statistically significant and did not alter my model when excluded. I therefore did not include this measure in my final analysis.

${ }^{16}$ Information for all counties was not available for the per capita charitable donations variable, bringing the total number of counties in the analysis from 3,143 to 3,11 . 
or public administration (public sector); information, finance, or management; retail or wholesale trade, or transportation; and arts and services.

Scholars have used religious denominations or racial diversity to measure the assortment of demands in an area (Ben-Ner \& Van Hoomissen 1992; Corbin 1999; Matsunaga \& Yamauchi 2004). The diversity of the foreign-born population indicates the variety of demands from a diverse immigrant population and was measured using three dummy variables. No regions included counties where the foreign-born population from one specific region of origin did not form one percent of the total county population. One to two regions of origin included counties with one or two regions of origin represented by the foreign-born population each forming more than one percent of the total county population. Finally, three plus regions of origin ${ }^{17}$ included counties with three or more regions of origin represented by the foreign-born population each forming more than one percent of the total county population. Additionally, I included a dummy variable for each of the four regions across the United States: Northeast, Midwest, South, and West (U.S. Census Bureau nd).

\section{Method}

This paper utilized descriptive statistics to examine the traits of counties with an immigrant nonprofit organization and probit regression to predict the likelihood of an immigrant nonprofit in a county. The probit model used is as follows:

$$
\text { ImmOrg }=\alpha+\text { need } \beta_{1}+\text { resources } \beta_{2}+\text { structure } \beta_{3}+e
$$

\footnotetext{
${ }^{17}$ There were eleven possible regions of origins for this measure including: Europe; Eastern Asia; South Central Asia; South Asia and Pacific Islands; Other Asia; Sub-Saharan Africa; Middle East and North Africa; Australia and New Zealand; Caribbean; Latin America; and North America.
} 
where ImmOrg is an indicator equal to one if an immigrant nonprofit organization is present in a county. Need is a vector representing community need in a county (poverty and percent foreign born); resources is a vector representing the human and financial resources present in a county; and structure is a vector representing the community structure of a county, including population size and density, the diversity of the foreignborn population, the employment structure in the community, and the geographic regions. Finally, $e$ is a random error term. I ran the probit model using robust standard errors to account for heteroscedasticity in the model. The results of the probit model are displayed using marginal effects and are interpreted as the change in probability when the explanatory variable increases by one unit. When interpreting results for this analysis, it is important to remember that the marginal effect shown is valid when all other variables are held at their means.

\section{Results}

There were several characteristics unique to counties with an immigrant nonprofit organization. To illustrate where immigrant nonprofits are located I used GIS mapping. Further, I used descriptive statistics to examine how community need, community resources and community structure differed in counties with and without an immigrant nonprofit and in new and established immigrant destination counties. Finally, I analyzed the results of the probit regression to understand the determinants of an immigrant nonprofit in a county.

\section{(1) Where are immigrant nonprofit organizations located?}

Using the 2014 IAD data on immigrant nonprofit organizations, I created a map of the United States showing the counties where immigrant nonprofit organizations are 
located. There were 5,826 immigrant nonprofit organizations located in 665 counties in 49 states across the country (see Figure 2). These immigrant nonprofit organizations were primarily located in established immigrant destinations where the majority of foreignborn residents live (92.9 percent, see Appendix A, Figure A3) and the foreign-born population was greater than two percent both in 1990 and in 2013 (See Figures 1 and 2). Only 29 percent of counties in the U.S. are established destination counties, yet 63 percent of established destination counties housed 91 percent of immigrant nonprofit organizations (5,329 organizations, see Appendix A, Figure A3 for the distribution of immigrant nonprofit organizations across destination types). ${ }^{18}$ Immigrant nonprofits in new destination counties were scarce—-just six percent of immigrant nonprofits (364 organizations) were located in new destinations, similar to the size of the foreign-born population in new destinations (6 percent, see Appendix A, Figure A3). The remaining immigrant nonprofits were located in non-destinations.

Immigrant nonprofit organizations were present in all regions of the U.S., but not entirely representative of the foreign-born population size. The majority of immigrant nonprofit organizations were located in the South (1,765 organizations, 30 percent), with a comparable foreign-born population size. The West had a lower percent of immigrant nonprofits compared to the size of the foreign-born population and the Northeast and Midwest had a larger share of immigrant nonprofits compared to the size of the foreignborn population (See Appendix A, Figure A4). To learn more about counties with an

\footnotetext{
${ }^{18}$ Some examples of established destination counties with an immigrant nonprofit include, among others, counties in the West such as Los Angeles County and the Seattle area. In the South, Miami-Dade and the large cities in Texas (Austin, Dallas, Houston and San Antonio) have immigrant nonprofit organizations. Established destination counties with an immigrant nonprofit in the Northeast include counties surrounding large cities such as Boston and New York City and in the Midwest include, for example, the Detroit area and Chicago.
} 
immigrant nonprofit, I examined the descriptive statistics capturing community need, community resources and the community structure.

Figure 2: Number of Immigrant Nonprofit Organizations by County

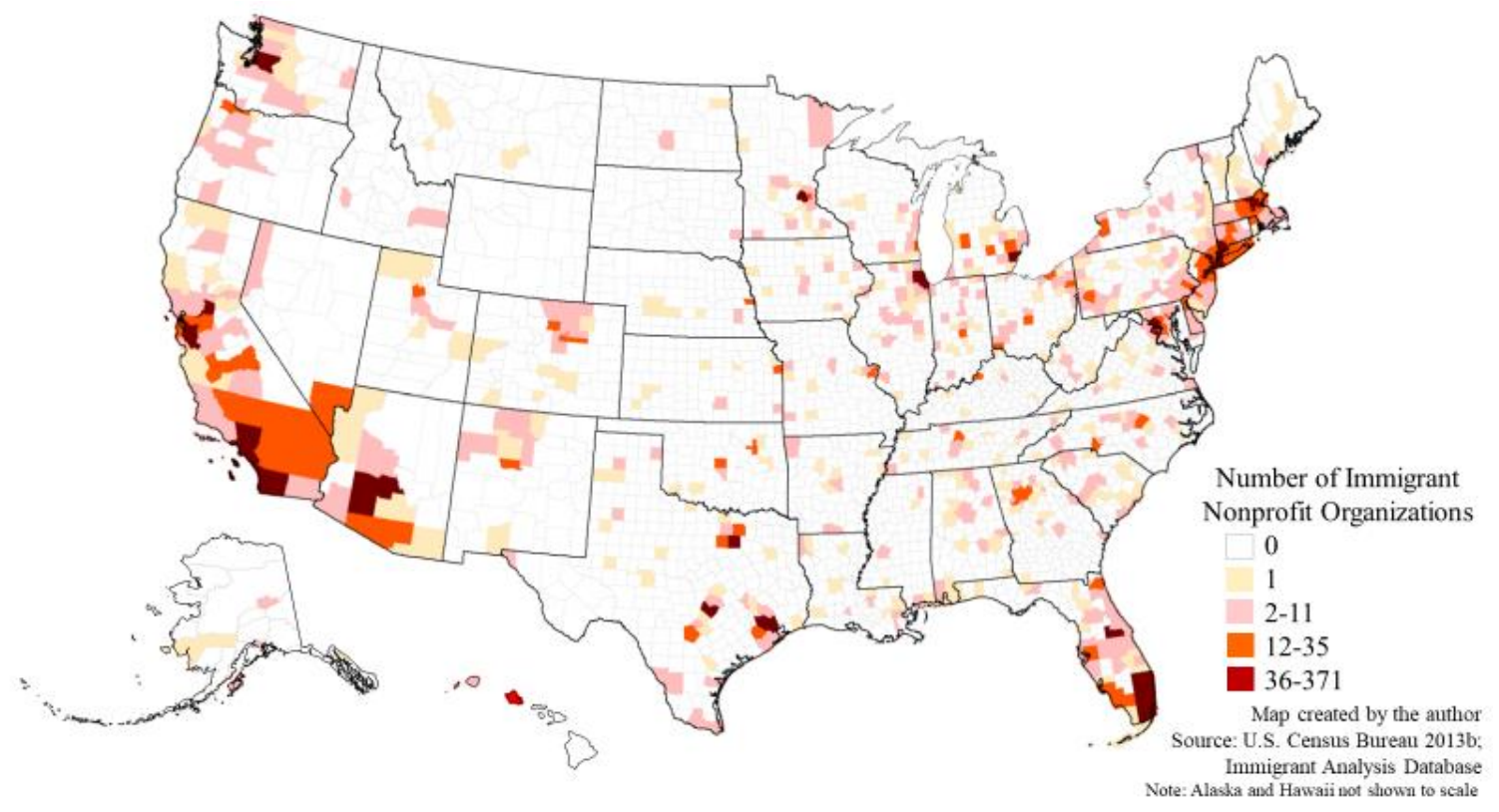

(2) How do community need, community resources, and community structure differ in counties with and without an immigrant nonprofit and in new and established immigrant destination counties?

Table 1 presents three panels of descriptive statistics; all differences between means discussed in this section are statistically significant with a p-value of less than five percent. The first panel includes all counties and shows that just 21 percent of counties in the U.S. had an immigrant nonprofit. The remaining descriptive statistics in Table 1, Panel 1 are for informational purposes. The focus in this analysis is on the descriptive statistics in Table 1, Panels 2 and 3. Panel 2 compares counties with an immigrant nonprofit (665 counties) to counties without an immigrant nonprofit (2,478 counties) and Panel 3 compares established and new destination counties with an immigrant nonprofit. 
The majority of counties with an immigrant nonprofit organization were in established destination counties (63 percent, 418 counties), while just 30 percent (186 counties) were in new destination counties. ${ }^{19}$

Community need. Compared to counties without an immigrant nonprofit, counties with an immigrant nonprofit had lower levels of poverty (15 percent compared to 17 percent) and, as expected, a larger foreign-born population in both 2013 and 1990 (see Table 1, Panel 2). Established destination counties ${ }^{20}$ also had, on average, fewer residents below the poverty line and a much larger foreign-born population compared to new destinations.

Community resources. Counties with an immigrant nonprofit had more residents with a bachelor's degree or higher (28 percent compared to 18 percent) and higher levels of charitable giving ( $\$ 530$ compared to $\$ 310$ ) compared to counties without an immigrant nonprofit. Contrary to expectations, however, counties with an immigrant nonprofit had lower rates of organizational density (10 fewer organizations per 10,000 residents) and self-employment (six percent compared to nine percent) compared to counties without an immigrant nonprofit. Table 1, Panel 3 also shows that established destination counties had more residents with a bachelor's degree and higher levels of charitable giving compared to new destination counties. Organizational density and the percent of the population that are self-employed did not significantly differ between destination types

\footnotetext{
${ }^{19}$ Very few counties with an immigrant nonprofit were located in non-destination counties (less than 10 percent, 61 counties), for this reason, I do not compare non-destination counties in the analysis.

${ }^{20}$ When referring to established and new destination counties in this section, I am referring to established and new destination counties with an immigrant nonprofit organization.
} 


$$
\begin{aligned}
& \text { ه }
\end{aligned}
$$

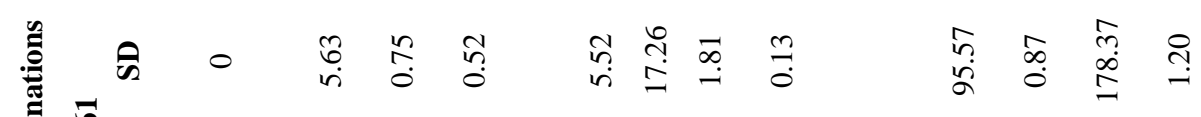

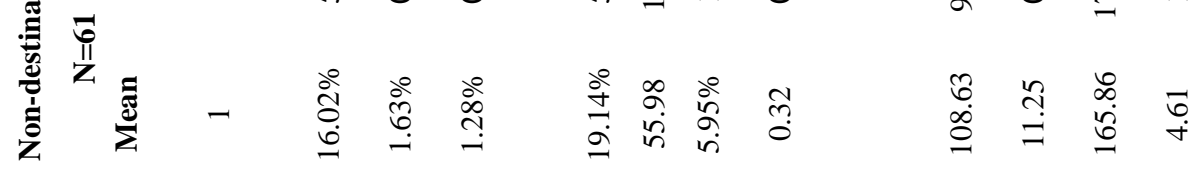

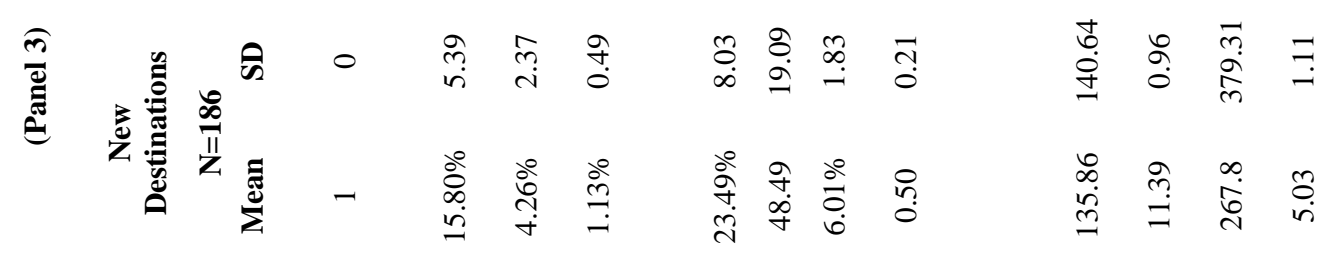

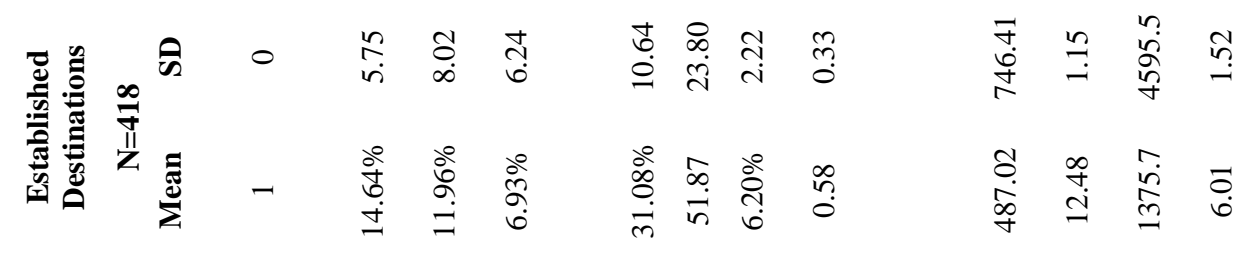

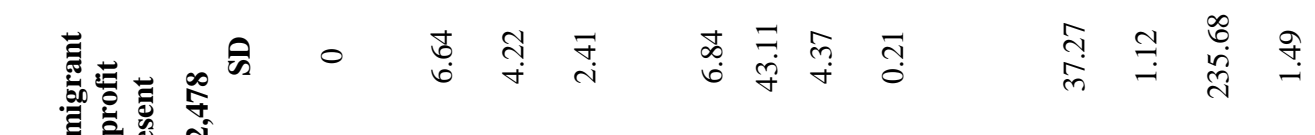

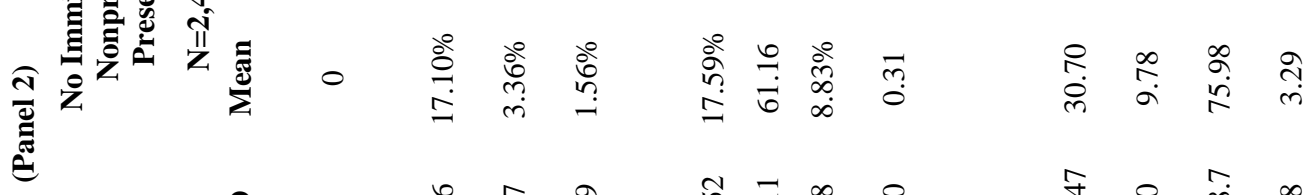

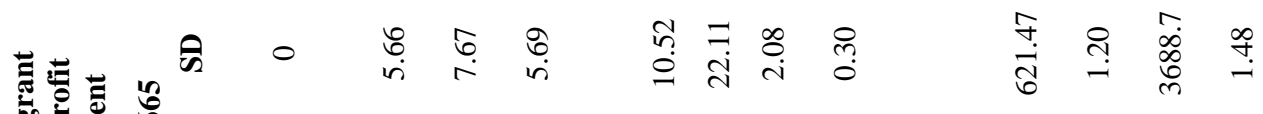

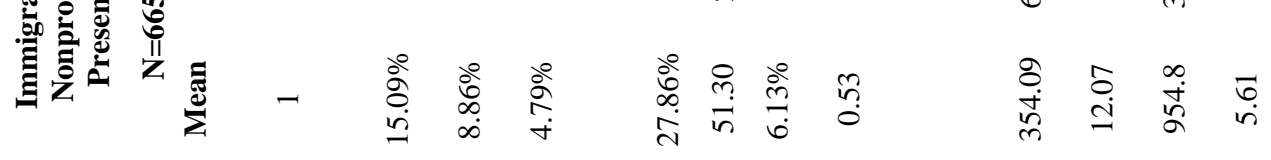

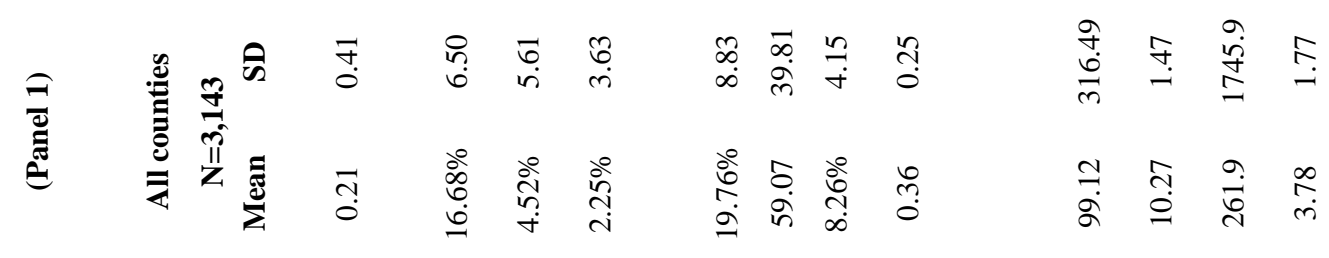

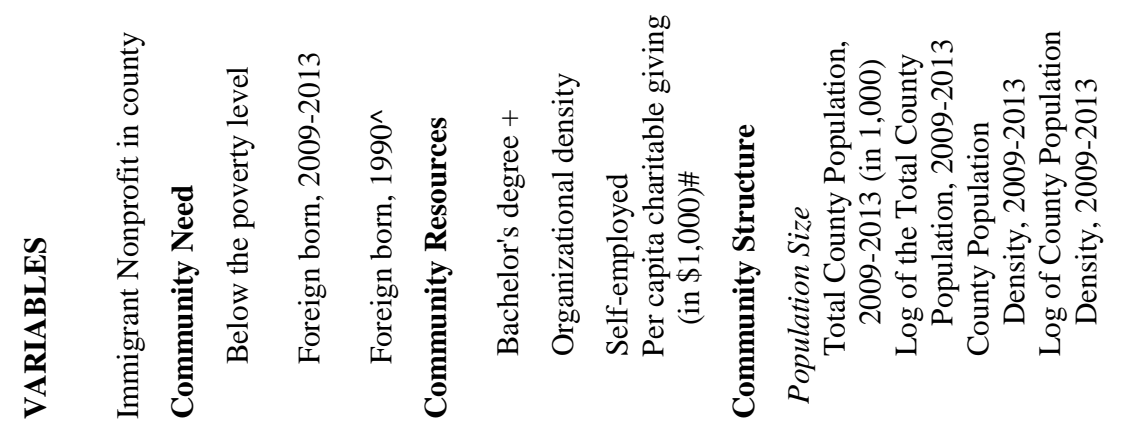

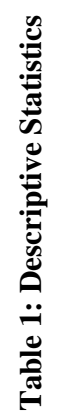




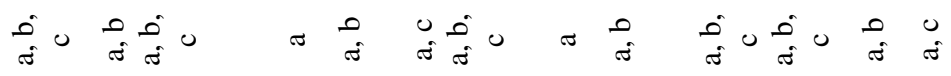

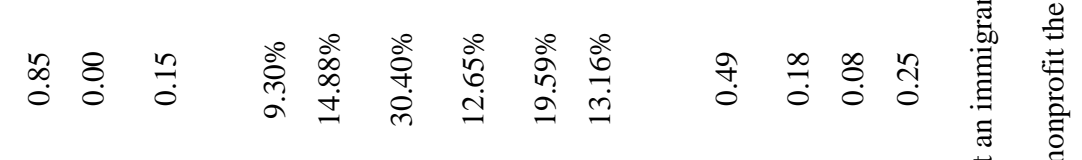

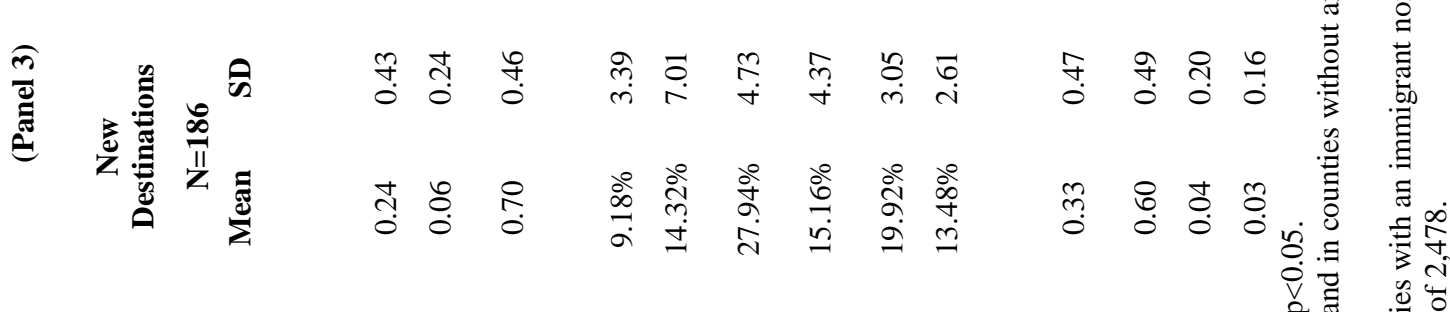

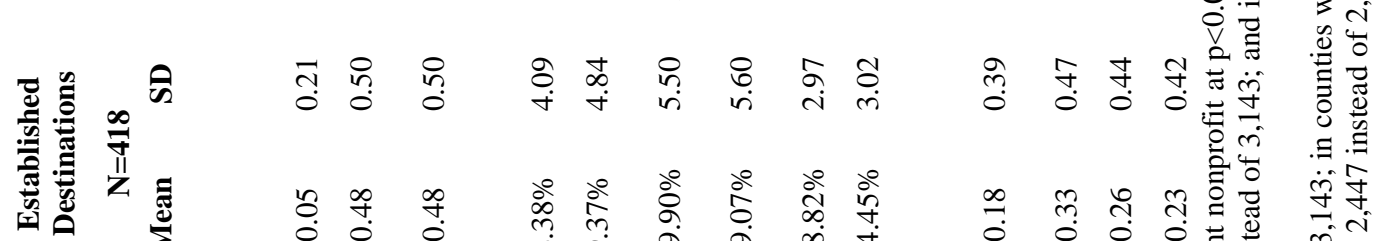

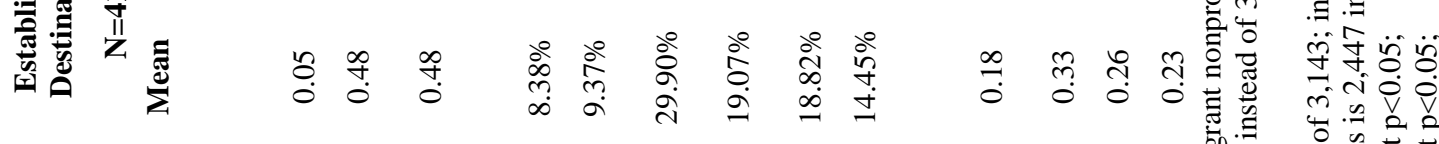

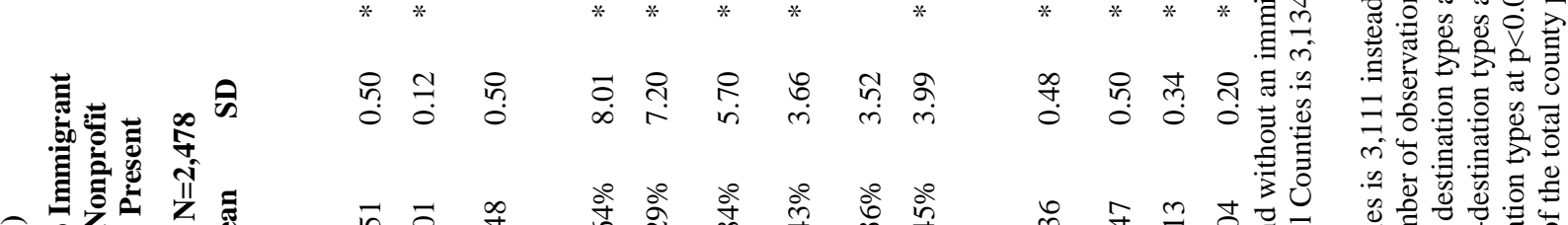

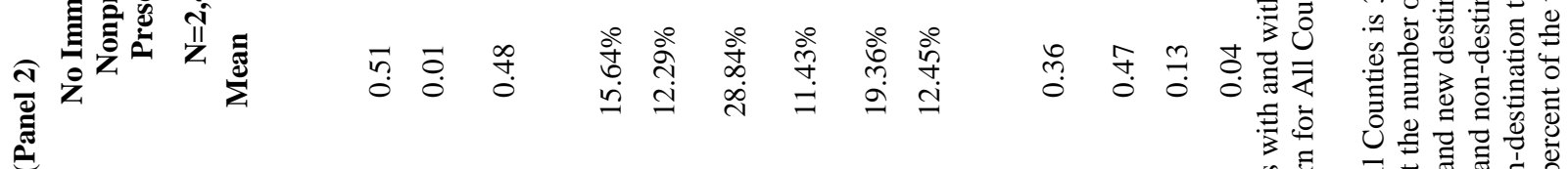

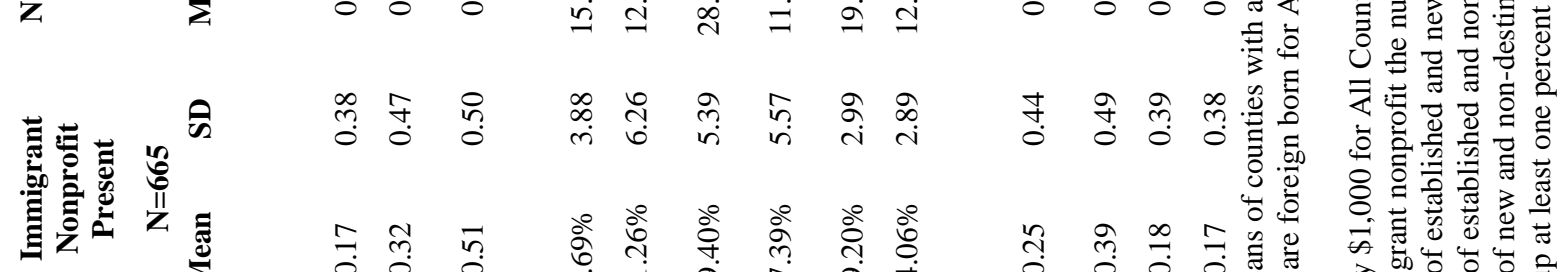

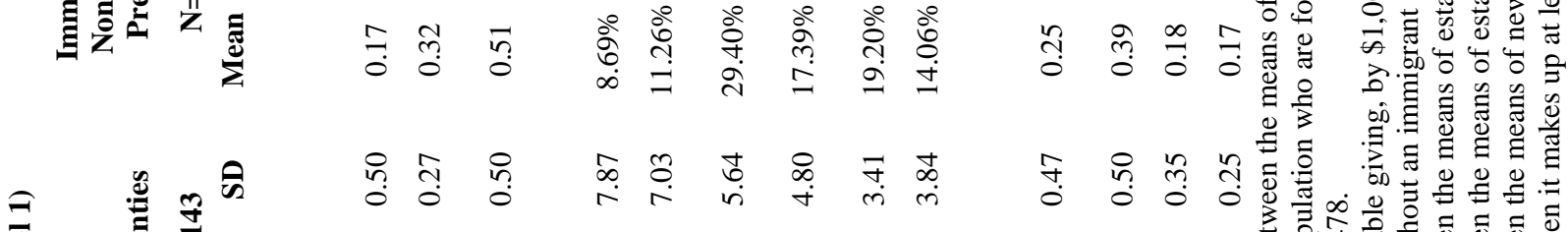

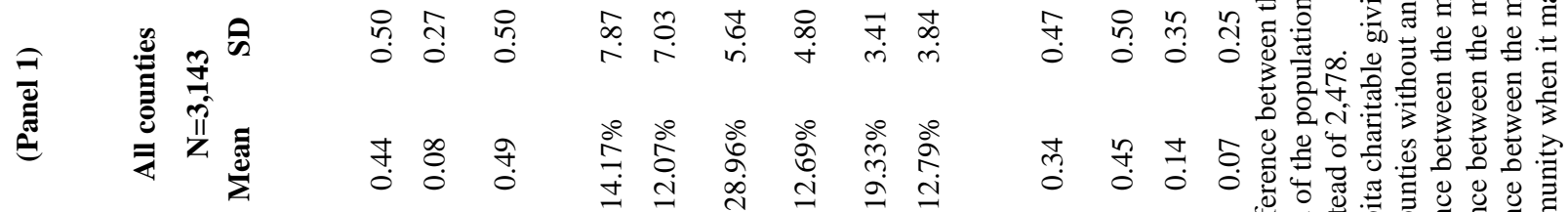

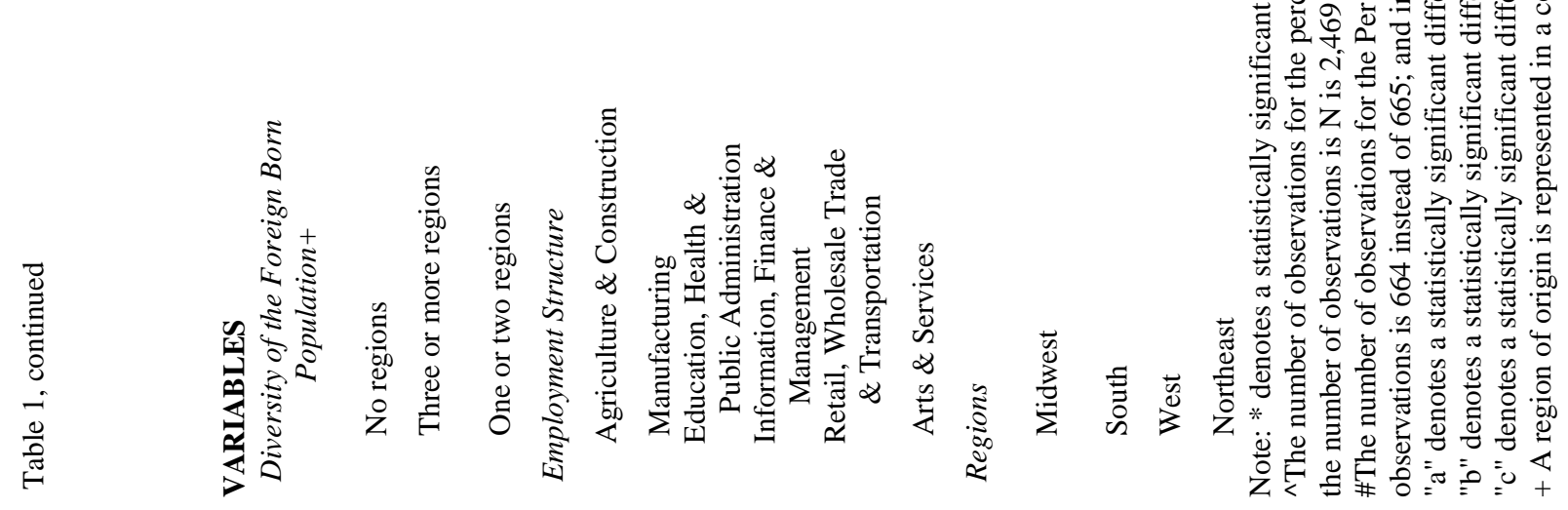


Community structure. Other factors within a community such as the population size, diversity of the foreign-born population, employment structure, and geographic location also differed between counties with an immigrant organization and those without. Table 1, Panel 2 shows that, compared to counties without an immigrant nonprofit, counties with an immigrant nonprofit had, on average, a much larger population size (more than 350,000 people compared to 31,000 ) and population density (954 compared to 76 people per square mile). On average, established, compared to new destination counties, were also much larger $(487,000$ people compared to 136,000$)$ with a higher population density (see Table 1, Panel 3). Counties with an immigrant nonprofit were also more diverse: 32 percent of counties with an immigrant nonprofit had three or more regions of origin present compared to just one percent of counties without an immigrant nonprofit. Established destination counties with an immigrant nonprofit, also had more regions of origin present compared to new destination counties.

The variation among the different employment types was small when comparing counties with and without an immigrant nonprofit organization. This was also true when comparing established and new destination counties. The largest differences between counties with and without an immigrant nonprofit were in agriculture and construction (9 percent compared to 16 percent) and information, finance and management (17 percent compared to 11 percent). Established compared to new destinations with an immigrant nonprofit had the lowest percentage of employees in agriculture and construction (8.4 percent compared to 9.2 percent) and manufacturing (9.4 percent compared to 14.3 percent). Established counties with an immigrant nonprofit had a larger percentage of the 
population working in information, finance and management compared to new destination counties.

Geographically, most counties with an immigrant nonprofit were located in the South (39 percent; see Table 1 Panel 2 ) and Midwest (25 percent). These two regions, however, also contain the majority of all U.S. counties (South: 1,423 counties, 45 percent; Midwest: 1,055 counties, 34 percent). Therefore, proportionally, counties with an immigrant nonprofit were largely located in the West and Northeast (18 percent and 17 percent, respectively). In established destinations, 18 percent of immigrant nonprofits were located in the Midwest, 33 percent in the South, 26 percent in the West, and 23 percent in the Northeast. The majority of new immigrant destination counties with an immigrant nonprofit were located in the Midwest and South (33 percent and 60 percent, respectively). Few new destination counties with an immigrant nonprofit were in the West or Northeast (4 percent and 3 percent, respectively).

This descriptive analysis examined the characteristics associated with the presence of an immigrant nonprofit. Compared to counties without an immigrant nonprofit, counties with an immigrant nonprofit had fewer residents in poverty, higher levels of charitable giving, higher educational attainment, a much larger and diverse foreign-born population, and a larger general population and population density. This was also true in established destination counties with an immigrant nonprofit.

(3) Using probit regression, what county characteristics predict the likelihood of an immigrant nonprofit organization in a county?

This section examines the probit regression results identifying characteristics predicting the presence of an immigrant nonprofit organization in a county. Aspects of 
community need, community resources and community structure were important in predicting the presence of an immigrant nonprofit organization. Some results, however, did not follow expectations. Table 2, Models 1 and 2 show that, while the results for established immigrant destinations closely follow the results for all counties, results differ by destination type.

Table 2: Probability of an Immigrant Nonprofit Organization in County

\begin{tabular}{|c|c|c|c|c|c|c|c|c|}
\hline \multirow{2}{*}{$\begin{array}{l}\text { VARIABLES } \\
\text { Community Need }\end{array}$} & \multicolumn{2}{|c|}{$\begin{array}{c}\text { (Model 1) } \\
\text { All Counties } \\
\text { Marginal } \\
\text { Effects } \\
\end{array}$} & \multicolumn{2}{|c|}{$\begin{array}{l}\text { Established } \\
\text { Destinations }\end{array}$} & \multicolumn{2}{|c|}{$\begin{array}{c}\text { (Model 2) } \\
\text { New } \\
\text { Destinations } \\
\text { Marginal Effects } \\
\end{array}$} & \multicolumn{2}{|c|}{$\begin{array}{c}\text { Non- } \\
\text { destinations }\end{array}$} \\
\hline & & & & & & & & \\
\hline Percent below the poverty level & $\begin{array}{l}0.0004 \\
(0.001)\end{array}$ & & $\begin{array}{l}-0.003 \\
(0.002)\end{array}$ & & $\begin{array}{r}0.003 \\
(0.002)\end{array}$ & $*$ & $\begin{array}{l}-0.001 \\
(0.003)\end{array}$ & \\
\hline Percent foreign born, 2009-2013 & $\begin{array}{r}0.005 \\
(0.002)\end{array}$ & $* *$ & $\begin{array}{r}0.010 \\
(0.003)\end{array}$ & $* * *$ & $\begin{array}{r}0.003 \\
(0.005)\end{array}$ & & $\begin{array}{l}-0.044 \\
(0.019)\end{array}$ & $* *$ \\
\hline Percent foreign born, 1990 & $\begin{array}{r}0.002 \\
(0.003)\end{array}$ & & $\begin{array}{l}-0.002 \\
(0.004)\end{array}$ & & $\begin{array}{r}0.036 \\
(0.022)\end{array}$ & & $\begin{array}{r}0.033 \\
(0.016)\end{array}$ & $* *$ \\
\hline $\begin{array}{l}\text { Community Resources } \\
\text { Percent with a bachelor's degree } \\
\text { or higher }\end{array}$ & $\begin{array}{r}0.002 \\
(0.001)\end{array}$ & & $\begin{array}{r}0.001 \\
(0.002)\end{array}$ & & $\begin{array}{r}0.004 \\
(0.002)\end{array}$ & $*$ & $\begin{array}{l}-0.001 \\
(0.003)\end{array}$ & \\
\hline Organizational density & $\begin{array}{r}0.000 \\
(0.000)\end{array}$ & & $\begin{array}{r}0.001 \\
(0.001)\end{array}$ & & $\begin{array}{r}0.000 \\
(0.000)\end{array}$ & & $\begin{array}{r}0.001 \\
(0.000)\end{array}$ & $* *$ \\
\hline Percent self-employed & $\begin{array}{r}0.002 \\
(0.003)\end{array}$ & & $\begin{array}{r}0.009 \\
(0.005)\end{array}$ & $*$ & $\begin{array}{l}-0.003 \\
(0.004)\end{array}$ & & $\begin{array}{l}-0.001 \\
(0.005)\end{array}$ & \\
\hline $\begin{array}{l}\text { Per capita charitable giving, } \\
\text { by } \$ 1,000\end{array}$ & $\begin{array}{r}0.097 \\
(0.037)\end{array}$ & $* * *$ & $\begin{array}{r}0.181 \\
(0.052)\end{array}$ & $* * *$ & $\begin{array}{r}0.051 \\
(0.042)\end{array}$ & & $\begin{array}{r}0.076 \\
(0.085)\end{array}$ & \\
\hline $\begin{array}{l}\text { Other Community Characteristics } \\
\text { Population Size }\end{array}$ & & & & & & & & \\
\hline County Population, 2013 (log) & $\begin{array}{r}0.121 \\
(0.008)\end{array}$ & $* * *$ & $\begin{array}{r}0.162 \\
(0.015)\end{array}$ & $* * *$ & $\begin{array}{r}0.102 \\
(0.014)\end{array}$ & $* * *$ & $\begin{array}{r}0.135 \\
(0.019)\end{array}$ & $* * *$ \\
\hline $\begin{array}{l}\text { County Population Density, } 2013 \\
\quad(\log )\end{array}$ & $\begin{array}{r}0.008 \\
(0.008)\end{array}$ & & $\begin{array}{r}0.024 \\
(0.014)\end{array}$ & * & $\begin{array}{r}-0.007 \\
(0.015)\end{array}$ & & $\begin{array}{l}-0.006 \\
(0.012)\end{array}$ & \\
\hline
\end{tabular}




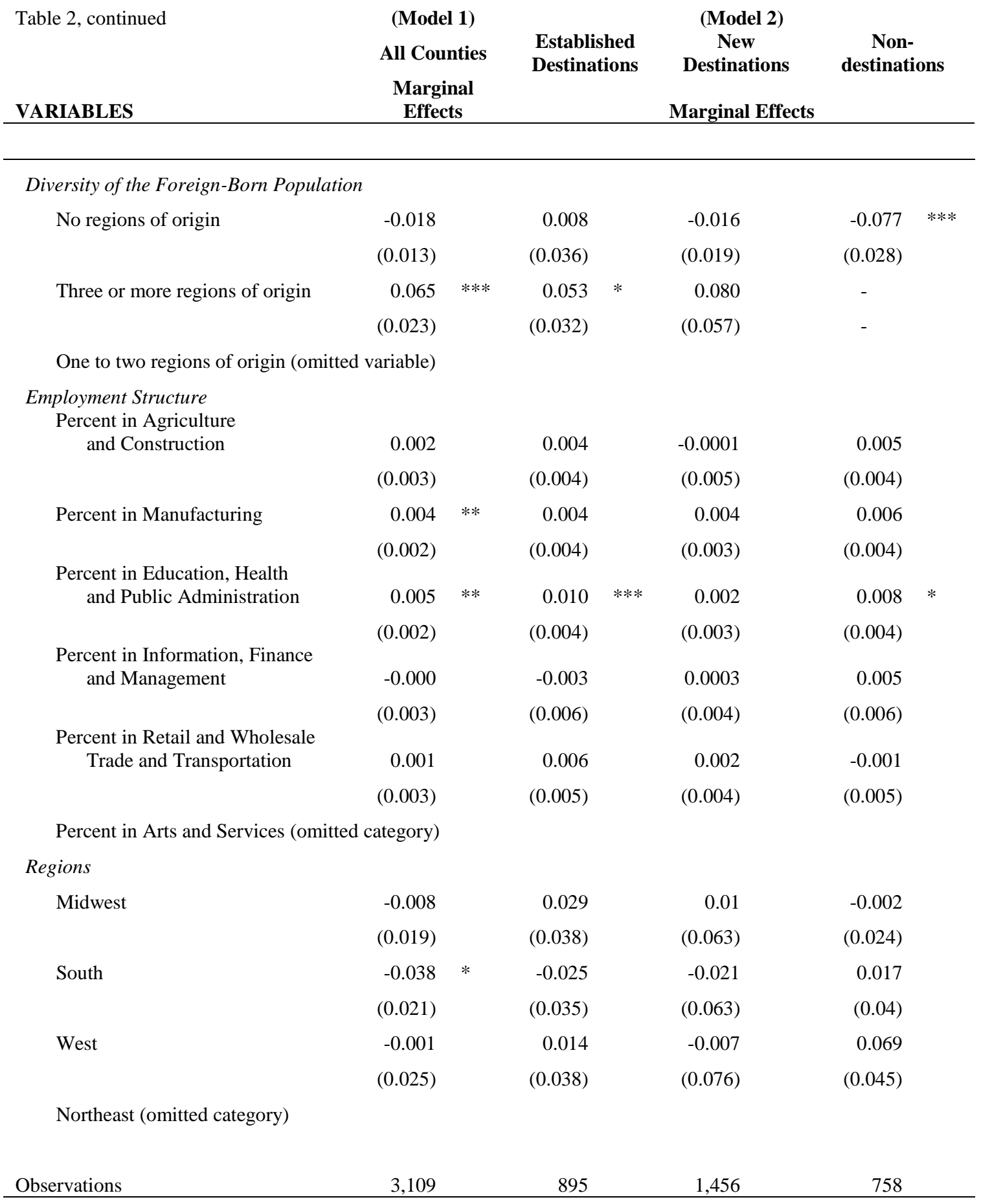

Standard errors in parentheses, $* * * \mathrm{p}<0.01, * * \mathrm{p}<0.05, * \mathrm{p}<0.1$

Community need. As seen in Table 2, the percent of the population below poverty was not a significant indicator for the presence of an immigrant nonprofit, with the exception in new destination counties. In new immigrant destinations, the percentage 
of the population below poverty was a statistically significant, but substantively small, correlate of the presence of an immigrant nonprofit $(0.003, \mathrm{p}<0.1$; Table 2, Model 2). Additionally, the size of the 2013 foreign-born population was an important factor in predicting the presence of an immigrant nonprofit in all counties as well as in established destinations. For example, if the 2013 foreign-born population were to increase by 10 percent, the probability of an immigrant nonprofit in the county increased by five percentage points (Table 2, Model 1). In established destination counties, the impact was double: a 10 percent increase of the 2013 foreign-born population increased the likelihood of an immigrant nonprofit in the county by 10 percentage points (Table 2 , Model 2). The size of the foreign-born population did not influence the presence of an immigrant nonprofit in new destination counties. In non-destination counties, an increase of the 2013 foreign-born population was associated with a decreased probability of an immigrant nonprofit in the county $(-0.044, \mathrm{p}<0.05$; Table 2 , Model 2$)$. However, only in non-destination counties the size of the 1990 foreign-born population increased the likelihood of an immigrant nonprofit $(0.033, \mathrm{p}<0.05)$.

Community resources. Community resources were only marginally successful in predicting the presence of an immigrant nonprofit organization. The size of the population with a bachelor's degree or higher was only statistically significant in new destination counties. With a 10 percent increase in the percent of the population with a bachelor's degree or higher, the likelihood of an immigrant nonprofit in the county increased by almost four percentage points in new destinations. Contrary to expectations, organizational density increased the likelihood of the presence of an immigrant nonprofit in non-destination counties: an increase of 100 organizations per 10,000 residents 
increased the likelihood of an immigrant nonprofit in that county by nine percentage points. Also contrary to expectations, self-employment only influenced the presence of an immigrant nonprofit organization in established destinations $(0.009, \mathrm{p}<0.1$; see Table 2 , Model 2). The per capita charitable donations were important in predicting the probability of an immigrant nonprofit in a county, primarily in established destinations, but also across all counties. In established destination counties, a $\$ 1,000$ increase in per capita charitable giving increased the probability of an immigrant nonprofit located in the county by 18 percentage points. This possibly signals that immigrant nonprofit organizations are present in counties with more financial resources. The per capita charitable giving variable, however, was not statistically significant in new destination counties, indicating that immigrant nonprofit organizations depend on different factors to determine their presence in different destination types.

Community structure. Some of the variables representing community structure were important in determining the presence of an immigrant nonprofit. The size of the county population was a statistically significant determinant predicting the presence of an immigrant nonprofit in both models and all destination types. If a county's population size increased by 10 percent, the likelihood of an immigrant nonprofit in the county increased by 12 percentage points (see Table 2, Model 1). The effect of population size was even larger in established destination counties $(0.162, \mathrm{p}<0.01$; Table 2 , Model 2). In new destination counties, a 10 percent increase in the population size increased the likelihood for an immigrant nonprofit in a county by 10 percentage points. Population density, on the other hand, was only statistically significant in established destination counties. 
In addition to the population size, the diversity of the foreign-born population was important in predicting the presence of an immigrant nonprofit. Counties with no regions of origin present ${ }^{21}$ did not affect the probability of an immigrant nonprofit in a county, except in non-destination counties. Non-destination counties with no regions of origin present were nearly eight percentage points less likely to have an immigrant nonprofit in the county compared to counties with one or two regions of origin present. Counties across the country with three or more regions of origin present had a 6.5 percentage point higher likelihood to have an immigrant nonprofit present compared to counties with one or two regions of origin present (see Table 2, Model 1). In established destination counties, the diversity of the foreign-born population was important $(0.053, \mathrm{p}<0.1$; see Table 2, Model 2), but in lower magnitude compared to counties across the U.S. ${ }^{22}$ The diversity of the foreign-born population was not statistically significant in predicting the probability of an immigrant nonprofit in new destination counties.

Few industries were important in predicting the probability of an immigrant nonprofit in a county. Counties across the country were more likely to have an immigrant nonprofit if they had a larger percent of their population working in manufacturing or the public sector (education, health and public administration) compared to the arts and service sector. Counties with 10 percent more of their population working in

\footnotetext{
${ }^{21}$ The number of regions of origin present in a county were included if the region of origin made up at least one percent of the total population.

${ }^{22}$ I ran a sensitivity analysis for the diversity of the foreign-born population comparing two or more regions of origin present compared to one region of origin (instead of three or more regions of origin compared to one or two regions of origin). The statistical significance remained in all counties, but with lower magnitude: counties with two or more regions of origin present each comprising at least one percent of the total population had a four-percentage point higher likelihood of having an immigrant nonprofit in the county. The diversity in established destination counties, however, was not statistically significant in this analysis. This shows the importance of more regions of origin present (a more diverse foreign-born population), but also represents that a larger foreign-born population is important for the presence of an immigrant nonprofit organization.
} 
manufacturing compared to arts and services had a four-percentage point higher likelihood to have an immigrant nonprofit. A 10 percent increase in public-sector employment, compared to arts and services, increased the likelihood of an immigrant nonprofit by nearly five percentage points across all counties (see Table 2, Model 1). In established destination counties, the only industry with statistical significance was employment in the public sector: a 10 percent increase in public-sector employment, compared to arts and services, increased the likelihood of an immigrant nonprofit by nearly 10 percentage points (see Table 2, Model 2). Employment in various industries did not influence the probability of an immigrant nonprofit in a new destination county. In non-destination counties, however, an increase of public-sector employment, compared to arts and services, increased the likelihood of an immigrant nonprofit $(0.008, \mathrm{p}<0.1$; see Table 2, Model 2). The geographic regions (Midwest, West compared to Northeast) were not significant predictors of an immigrant nonprofit. Only the South, compared to the Northeast, was statistically significant across all counties and immigrant nonprofits were slightly less likely to be located there $(-0.038, \mathrm{p}<0.1$; Table 2 , Model 1).

There is evidence that community need, community resources and other community factors are associated with the presence of an immigrant nonprofit organization. Findings varied, however, across destination types. The strongest predictor, and only variable statistically significant across all destination types, was the size of the county population: the larger the county population, the more likely an immigrant nonprofit was located there. Additionally, a larger foreign-born population in 2013 increased the likelihood of an immigrant nonprofit in a county across all counties and in established destinations. The per capita charitable contributions had the largest impact 
predicting an immigrant nonprofit in established destination counties. Counties with more public-sector employees, compared to the arts and services, had a higher likelihood of an immigrant nonprofit organization in counties across the U.S. and in established destinations. Public-sector employment, compared to arts and services, however, did not influence the likelihood of an immigrant nonprofit in new destination counties. In fact, no industry predicted the likelihood of an immigrant nonprofit in new destination counties.

\section{Discussion}

This paper examined the association between county level indicators and the presence of an immigrant nonprofit organization in counties across the United States and in established and new immigrant destination counties. Immigrant nonprofit organizations, in this paper, included ethnic organizations serving clientele from one ethnic or national origin and larger service providers with a focus on multicultural programming for foreign-born residents. These types of organizations are located in 665 counties, illustrated in Figure 2. Immigrant organizations were predominantly located in established immigrant destination counties and counties with a large total population (Figure 2 and Tables 1,2). Counties with an immigrant nonprofit organization generally have a large population, lower levels of poverty, higher levels of education, more charitable giving, and a larger and more diverse foreign-born population compared to counties without an immigrant nonprofit.

Characteristics predicting the presence of an immigrant nonprofit organization in a county varied across destination types. Community need, represented by the size of the foreign-born population, increased the probability of an immigrant nonprofit across all counties and in established destination counties. New destination counties, however, 
experienced community need differently - in new destinations, an increase in the percent of residents below poverty resulted in an, albeit slight, increase in the probability of an immigrant nonprofit. The financial aspect of community resources (per capita charitable giving) had the largest statistical and substantial impact across all counties and in established destination counties. Again, new destination counties differed and an increase in the percent of the population with a college education increased the probability of an immigrant nonprofit. Both human and financial resources are necessary for nonprofit organizations (Grønbjerg \& Paarlberg 2001; Paarlberg \& Gen 2009; Salamon 2012a, 2012b). The results from this study indicate that human and financial resources are also important for immigrant nonprofit organizations, but differ across destination types.

Some of the factors increasing the likelihood of an immigrant nonprofit in a county followed previous literature. For example, Joassart-Marcelli (2013) studied immigrant nonprofits in Boston, an established destination (Singer 2004; 2013). In her study, Joassart-Marcelli found a larger overall population size and increased diversity of the foreign-born population was related to more immigrant nonprofit organizations. In this study, population size and the diversity of the foreign-born population increased the probability of an immigrant nonprofit across all counties, in established destinations, and in non-destinations. However, only population size was statistically significant in new destination counties. This not only signifies that determinants of an immigrant nonprofit differ across destination type, but that it is still somewhat unclear what county characteristics are correlated with the presence of an immigrant nonprofit in new destination counties. 
New immigrant destination counties are emerging across the U.S. and comprise the vast majority of counties (47 percent, 1,462 counties). Few new destination counties, however, have an immigrant nonprofit (13 percent). ${ }^{23}$ The low number of immigrant nonprofit organizations in new destination counties may be a limiting factor of this study as the IAD only captures organizations formally registered with the IRS. This may mean that informal or newly formed immigrant nonprofits in new destinations are missing from this study. On the other hand, this may mean that immigrants in new destination counties are underserviced by immigrant nonprofit organizations or that immigrants are being served by other organizations, churches, or government programs. Another scenario could be that residents of a county without an immigrant nonprofit are "free riding" (de Graauw, Gleeson \& Bloemraad 2013) and using "urban immigrant service hubs" (Joassart-Marcelli 2013) in an adjacent county. I do not consider spatial relationships in this study and therefore cannot account for counties without an immigrant nonprofit bordering a county with an immigrant nonprofit organization.

The IAD is a unique and valuable database. However, the IAD likely contains a large undercount of immigrant nonprofit organizations. Gleeson and Bloemraad (2013) found that official NCCS data undercounted immigrant nonprofit organizations in Silicon Valley by more than 30 percent. In a study of nonprofit organizations in Indiana, Grønbjerg and Paarlberg (2002) also found a similarly large undercount of formally registered IRS nonprofit organizations compared to lists from the Secretary of State. McDougle (2015) also noted several "location-related limitations" from NCCS data in her study of nonprofit organizations in San Diego. Following the results from these

${ }^{23}$ Only 186 new destination counties had an immigrant nonprofit compared to 418 established destination counties. 
studies, the IAD likely also suffers an undercount of immigrant nonprofit organizations. During the data cleaning process, I was able to exclude false-positive immigrant nonprofit organizations in the database. However, false-negatives may have been missed during the initial data-mining process. Additionally, while the BMF should contain all organizations with tax-exempt status, not all immigrant nonprofit organizations are formally registered with the IRS, especially in new destinations were immigrant nonprofits may still be informal and young. These limitations make it difficult to study immigrant nonprofit organizations at a national level and to generalize about these types of organizations.

Another limitation of this study is that the charitable giving variable is far from a perfect measure. The charitable giving variable signifies, to a certain extent, the private resources available in a county. The variable does not indicate, however, where the charitable donations went or where the donations come from. From this variable, I am unable to determine how much, if any, of these financial resources went to immigrant organizations. I am also unable to determine if the donations primarily come from one source or are an indicator of total community giving.

\section{Conclusion}

In this paper, I focused on three main determinants of nonprofit sector growth to understand which factors may be unique to counties with an immigrant nonprofit and in new and established immigrant destination counties with an immigrant nonprofit. I identified several factors associated with an increased probability of having an immigrant nonprofit in a county and examined these traits by immigrant destination type. The findings suggest that immigrant nonprofits are located in counties with a large overall 
population and in counties with an established immigrant population. The determinants of an immigrant nonprofit also differed depending on destination type. For example, an increase in the size and diversity of the foreign-born population was associated with an increased probability of an immigrant nonprofit in established and non-destination counties. These factors, however, did not influence the presence of an immigrant nonprofit in new destination counties where, instead, increased poverty increased the probability of an immigrant nonprofit.

Immigrant nonprofit organizations are poised to assist newcomers in culturallyand language-appropriate ways and could ease the stress on local government. The foreign-born poverty rate surpasses that of the general population and the foreign-born population is increasing and diversifying. Government is depending more on nonprofit organizations to provide acculturation and resettlement services to immigrant and refugee groups (Joassart-Marcelli 2013; Salamon 2012b; Tseng 2006) and local governments in new destination counties may be most in need of assistance (Bada et al. 2010). With this increased reliance, social policies may be needed to encourage the creation of immigrant nonprofit organizations. Policies may also be useful to create incentives for these types of organizations to work with the low-income foreign-born population. Additionally, action is needed so local officials see their foreign-born constituents in areas where foreign-born residents may otherwise be invisible. Social policies aiming to reduce poverty in areas with a poor immigrant population may fail if there are no organizations or resources to assist with translation and other culturally sensitive practices.

Additional research is needed in the area of immigrant nonprofit organizations, especially in new destination counties. Caution, however, should be used when 
employing theoretical guidelines from the general nonprofit literature because immigrant nonprofit organizations do not always follow the same patterns as other nonprofit types (de Graauw, Gleeson \& Bloemraad 2013; Gleeson \& Bloemraad 2013; Joassart-Marcelli 2013). Moreover, for scholars working in this field, a consensual definition of an immigrant nonprofit may prove useful to allow for comparisons on research in this area. This study shows that predictors for immigrant nonprofits are different in new and established immigrant destinations. Using restricted data including information specifically on the foreign-born population could potentially clarify some of these differences in destination types and between the immigrant groups in those areas. Population size was a significant predictor for all destination types; therefore, future research on immigrant nonprofits should try to parse out the factors that drive the presence of immigrant nonprofit organizations in large areas and continue to expand on what is known about this specific type of nonprofit organization. 


\section{References}

Anderson, L. M.; Scrimshaw, S. C.; Fullilove, M. T.; Fielding, J. E.; \& Normand, J. 2003. Culturally competent healthcare systems. American Journal of Preventive Medicine, 24(3), 68-79.

Bada, X.; Fox, J.; Donnelly, R.; \& Selee, A. 2010. Context Matters: Latino Immigrant Civic Engagement in Nine U.S. Cities. Series on Latino Immigrant Civic Engagement. Washington, DC: Woodrow Wilson International Center for Scholars.

Ben-Ner, A. \& Van Hoomissen, T. 1992. An Empirical Investigation of the Joint Determination of the Size of the For-Profit, Nonprofit and Government Sectors. Annals of Public and Cooperative Economics, 3, 391-415.

Betancourt, J. R.; Green, A. R.; Carrillo, J. E.; \& Park, E. R. 2005. Cultural competence and health care disparities: Key perspectives and trends. Health Affairs, 24(2), 499-505. https://doi.org/10.1377/hlthaff.24.2.499

Blackwood, A.S.; Roeger, K.L.; \& Pettijohn, S.L. 2012. The Nonprofit Sector in Brief: Public Charities, Giving, and Volunteering, 2012. Washington DC: Urban Institute.

Bloemraad, I. 2005. The Limits of de Tocqueville: How Government Facilitates Organisational Capacity in Newcomer Communities. Journal of Ethnic and Migration Studies, 31(5), 865-887.

Boris, E. T. 2006. Introduction- Nonprofit Organizations in a Democracy: Varied Roles and Responsibilities. In Boris, E.T. \& Steuerle, C.E. (eds) Nonprofits and Government: Collaboration and Conflict. Washington DC: Urban Institute Press. 
Boris, E.T. \& Steuerle, C.E. (Eds.) 2006. Nonprofits and Government: Collaboration and Conflict. Washington DC: Urban Institute Press.

Chung, A. Y. 2005. 'Politics Without the Politics': The Evolving Political Cultures of Ethnic Non-Profits in Koreatown, Los Angeles. Journal of Ethnic and Migration Studies, 31(5), 911-929.

Corbin, J.J. 1999. A Study of Factors Influencing the Growth of Nonprofits in Social Services. Nonprofit and Voluntary Sector Quarterly, 28(3), 296-314.

Cordero-Guzmán, H. R. 2005. Community-based organisations and migration in New York City. Journal of Ethnic and Migration Studies, 31, 889-909.

Cortes, M. 1998. Counting Latino nonprofits: A new strategy for finding data. Nonprofit and Voluntary Sector Quarterly, 27, 437-458.

Crowley, M., Lichter, D. T., \& Qian, Z. 2006. Beyond gateway cities: Economic restructuring and poverty among Mexican immigrant families and children. Family Relations, 55(3), 345-360.

de Graauw, E.; Gleeson, S.; \& Bloemraad, I. 2013. Funding Immigrant Organizations: Suburban Free Riding and Local Civic Presence. American Journal of Sociology, 119(1), 75-130.

de Leon, E.; Maronick, M.; DeVita, C. J.; \& Boris, E. T. 2009. Community-Based Organizations and Immigrant Integration in the Washington, D.C., Metropolitan Area. Washington DC: Urban Institute.

Fischer, M. J. 2010. Immigrant educational outcomes in new destinations: An exploration of high school attrition. Social Science Research, 39(4), 627-641.

Fortuny, K. \& Chaudry, A. 2011. A Comprehensive Review of Immigrant Access to 
Health and Human Services. Washington DC: Urban Institute.

Gamm, G. \& Putnam, R.D. 1999. The Growth of Voluntary Associations in America, 1840-1940. The Journal of Interdisciplinary History, 29(4), 511-557.

Gleeson, S. \& Bloemraad, I. 2013. Assessing the Scope of Immigrant Organizations: Official undercounts and actual underrepresentation. Nonprofit and Voluntary Sector Quarterly, 42(2), 346-370.

Grønbjerg, K. A., \& Paarlberg, L. 2002. Extent and Nature of Overlap Between Listings of IRS Tax-Exempt Registration and Nonprofit Incorporation: The Case of Indiana. Nonprofit and Voluntary Sector Quarterly, 31(4), 565-594.

Grønbjerg, K. A., \& Paarlberg, L. 2001. Community Variations in the Size and Scope Of The Nonprofit Sector: Theory And Preliminary Findings. Nonprofit and Voluntary Sector Quarterly, 30(4), 684-706.

Hall, M. 2013. Residential Integration on the New Frontier: Immigrant Segregation in Established and New Destinations. Demography. 50: 1873-1896.

Hall, M.; Singer, A.; De Jong, G.F.; \& Roempke Graefe, D. 2011. The Geography of Immigrant Skills: Educational Profiles of Metropolitan Areas. Washington, DC: Brookings Institution.

Hung, C. R. 2007. Immigrant Nonprofit Organizations in U.S. Metropolitan Areas. Nonprofit \& Voluntary Sector Quarterly, 36(4), 707-729.

Hung, C.R. \& Ong, P. 2012. Sustainability of Asian-American Nonprofit Organizations in the U.S. Metropolitan Areas. Nonprofit and Voluntary Sector Quarterly, 41(6), $1136-1152$.

Joassart-Marcelli, P. 2012. For Whom and for What? Investigating the Role of 
Nonprofits as Providers to the Neediest. In Salamon, Lester M. (ed). The State of Nonprofit America. Washington DC: Brookings Institution.

Joassart-Marcelli, P. 2013. Ethnic Concentration and Nonprofit Organizations: The Political and Urban Geography of Immigrant Services in Boston, Massachusetts. International Migration Review, 47(3):730-772.

Kandel, W. \& Parrado, E. A. 2005. Restructuring of the US Meat Processing Industry and New Hispanic Migrant Destinations. Population and Development Review, $31(3), 447-471$.

Lecy, J., \& Van Slyke, D. 2013. Nonprofit Sector Growth and Density: Testing Theories of Government Support. Journal of Public Administration Research and Theory, 23(1), 189-214.

Marrow, H.B. 2009. Immigrant Bureaucratic Incorporation: The Dual Roles of Professional Missions and Government Policies. American Sociological Review. $74,756-776$.

Martin, N. 2012. "There is Abuse Everywhere": Migrant Nonprofit Organizations and the Problem of Precarious Work. Urban Affairs Review, 48,(3), 389-416.

Massey, D.S. \& Capoferro, C. 2008. The Geographic Diversification of American Immigration. In Massey, D.S. (ed). New Faces in New Places: The changing geography of American Immigration. New York: Russell Sage Foundation.

Massey, Douglas S. (Ed.). 2008. New Face in New Places: The Changing Geography of American Immigration. New York: Russell Sage Foundation.

Matsunaga, Y. \& Yamauchi, N. 2004. Is the Government Failure Theory Still Relevant? 
A panel analysis using US state level data. Annals of Public and Cooperative Economics, 75(2), 227-263.

McDougle, L.M. 2015. The Accuracy of the Core Files for Studying Nonprofit Location: How Many Nonprofits Are There? Nonprofit and Voluntary Sector Quarterly, 44(3), 609-624.

Moya, J.C. 2005. Immigrants and Associations: A Global and Historical Perspective. Journal of Ethnic and Migration Studies, 31(5), 833-864.

National Center for Charitable Statistics (NCCS). Nd. Overview of NCCS Data Files. Retrieved from: http://nccs.urban.org/database/overview.cfm.

National Center for Charitable Statistics (NCCS). 2013. NCCS Household Giving Table Wizard. Retrieved from: http://nccsdataweb.urban.org/tablewiz/cg.php.

Paarlberg, L.E. \& Gen, S. 2009. Exploring the Determinants of Nonprofit Coproduction of Public Service Delivery: The case of k-12 public education. The American Review of Public Administration, 39(4), 391-408.

Salamon, L. M. (ed). 2012a. The State of Nonprofit America. Washington DC: Brookings Institution.

Salamon, L.M. 2012b. The Resilient Sector: The Future of Nonprofit America. In Salamon, L. M. (ed). The State of Nonprofit America. Washington DC: Brookings Institution.

Schrover, M. \& Vermeulen, F. 2005. Immigrant Organizations. Journal of Ethnic and Migration Studies, 31(5), 825-832.

Singer, A. 2004. The Rise of New Immigrant Gateways. Washington, DC: Brookings Institution. 
Singer. 2013. Contemporary Immigrant Gateways in Historical Perspective. Dadalus, the Journal of the American Academy of Arts \& Sciences, 142(3).

Skinner, C. 2012. State Immigration Legislation and SNAP Take-Up Among Immigrant Families with Children. Journal of Economic Issues, 46(3), 661-681.

Stone, L. C.; Boursaw, B.; Bettez, S. P.; Larzelere Marley, T.; \& Waitzkin, H. 2015. Place as a predictor of health insurance coverage: A multivariate analysis of counties in the United States. Health \& Place, 34, 207-214.

Tseng, W. 2006. Government Dependence of Chinese and Vietnamese Community Organizations and Fiscal Politics of Immigrant Services. Journal of Health and Social Policy, 20(4), 51-74.

Twombly, E.C. 2003. What Factors Affect the Entry and Exit of Nonprofit Human Service Organizations in Metropolitan Areas? Nonprofit and Voluntary Sector Quarterly, 32(2), 211-235. DOI: 10.1177/0899764003251612.

U.S. Census Bureau. 2008. A Compass for Understanding and Using American Community Survey Data: What General Data Users Need to Know. Economics and Statistics Administration, U.S. Department of Commerce.

U.S. Census Bureau. 2013a. 2009-2013 American Community Survey 5- year Estimates. Retrieved from: https://www.census.gov/programs-surveys/acs/data/summaryfile.2013.html.

U.S. Census Bureau. 2013b. Cartographic Boundary Shapefiles - Counties. Retrieved from: https://www.census.gov/geo/maps-data/data/cbf/cbf_counties.html.

U. S. Census Bureau. 2014. 2013 ACS Summary File Technical Documentation. 
American Community Survey Office, Economics and Statistics Administration, U.S. Department of Commerce.

U.S. Census Bureau. Nd. Census Regions and Divisions of the United States. Economics and Statistics Administration, U.S. Department of Commerce. Retrieved from: http://www2.census.gov/geo/pdfs/maps-data/maps/reference/us_regdiv.pdf.

Winders, J. 2012. Seeing Immigrants: Institutional Visibility and Immigrant Incorporation in New Immigrant Destinations. The ANNALS of the American Academy of Political and Social Science, 641,(1), 58-78.

Zhou, M.; \& Lee, R. 2013. Transnationalism and Community Building: Chinese Immigrant Organizations in the United States. The ANNALS of the American Academy of Political and Social Science, 647,(1), 22-49. 


\section{Appendix A}

Figure A 1: National Taxonomy of Exempt Entities Codes for Immigrant Nonprofit Organizations in the immigrant Analysis Database $(\mathrm{N}=\mathbf{5 , 2 8 6})$

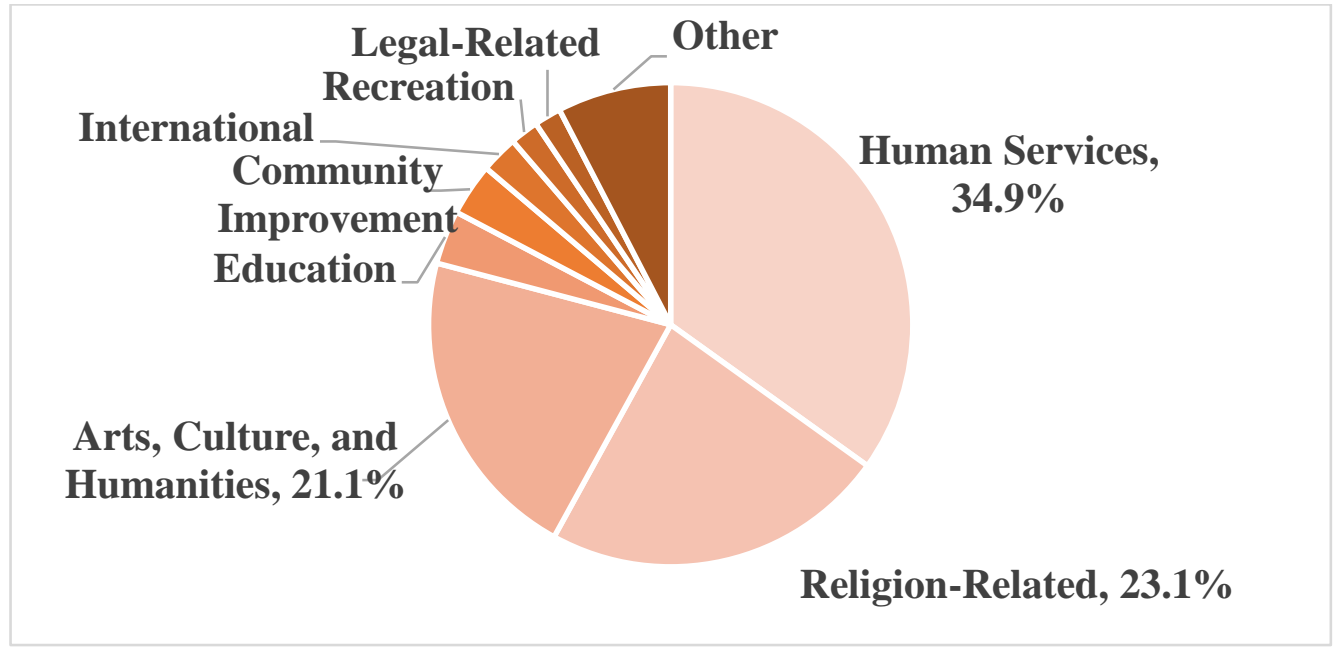

Note: Other contains NTEE Code categories that were less than $2 \%$ of all immigrant nonprofit organizations (less than 100 immigrant nonprofits in each of these categories).

Figure A 2: Regions of Origins Served by Immigrant Nonprofit Organizations in the Immigrant Analysis Database $(\mathrm{N}=\mathbf{5}, 286)$

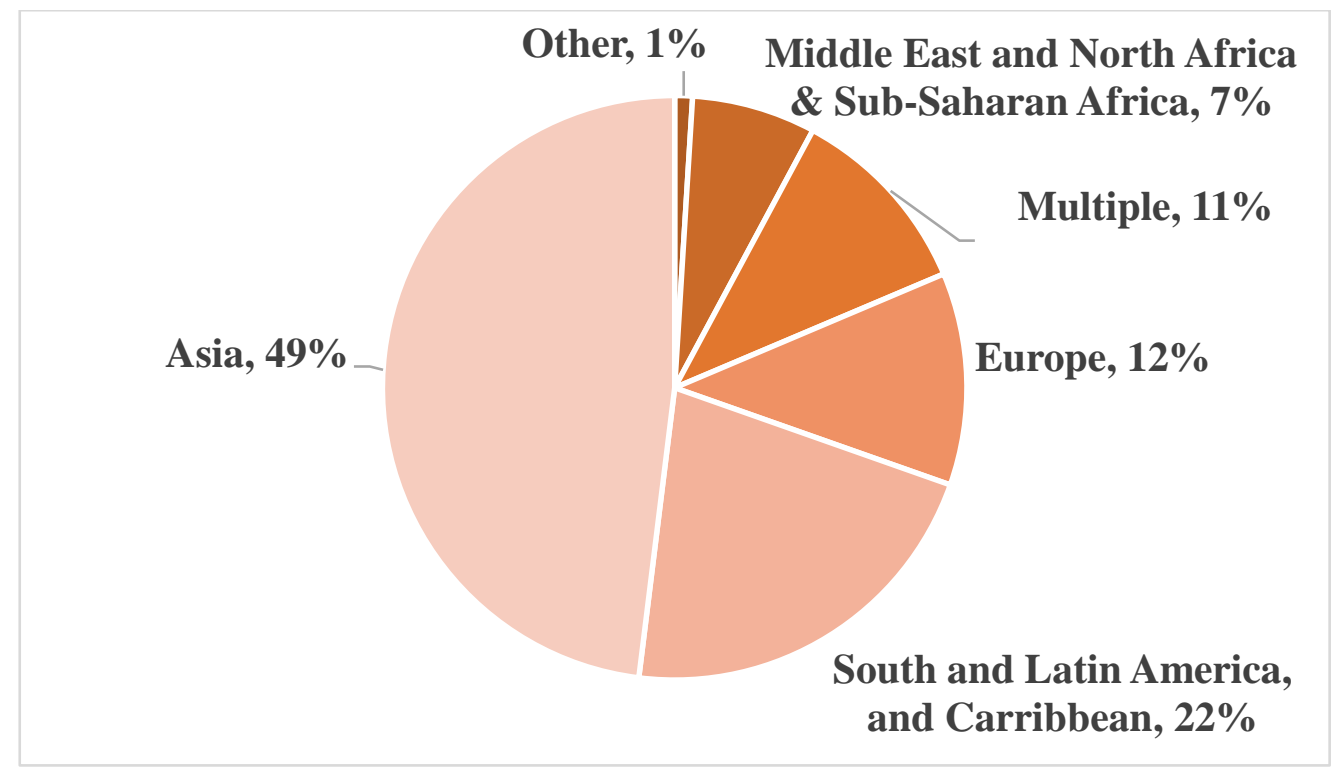



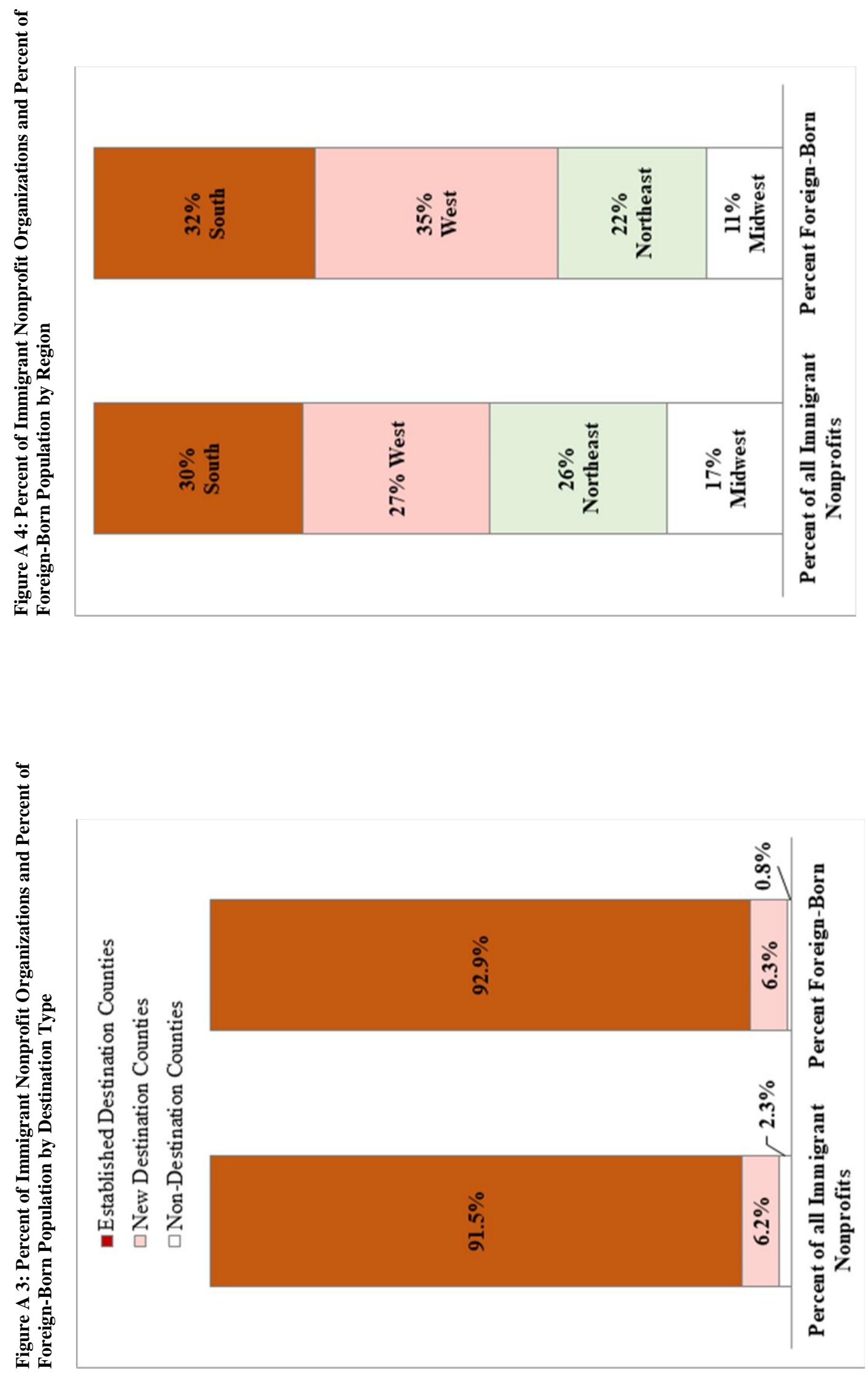


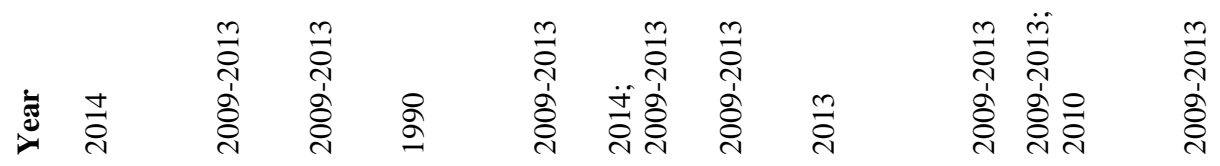
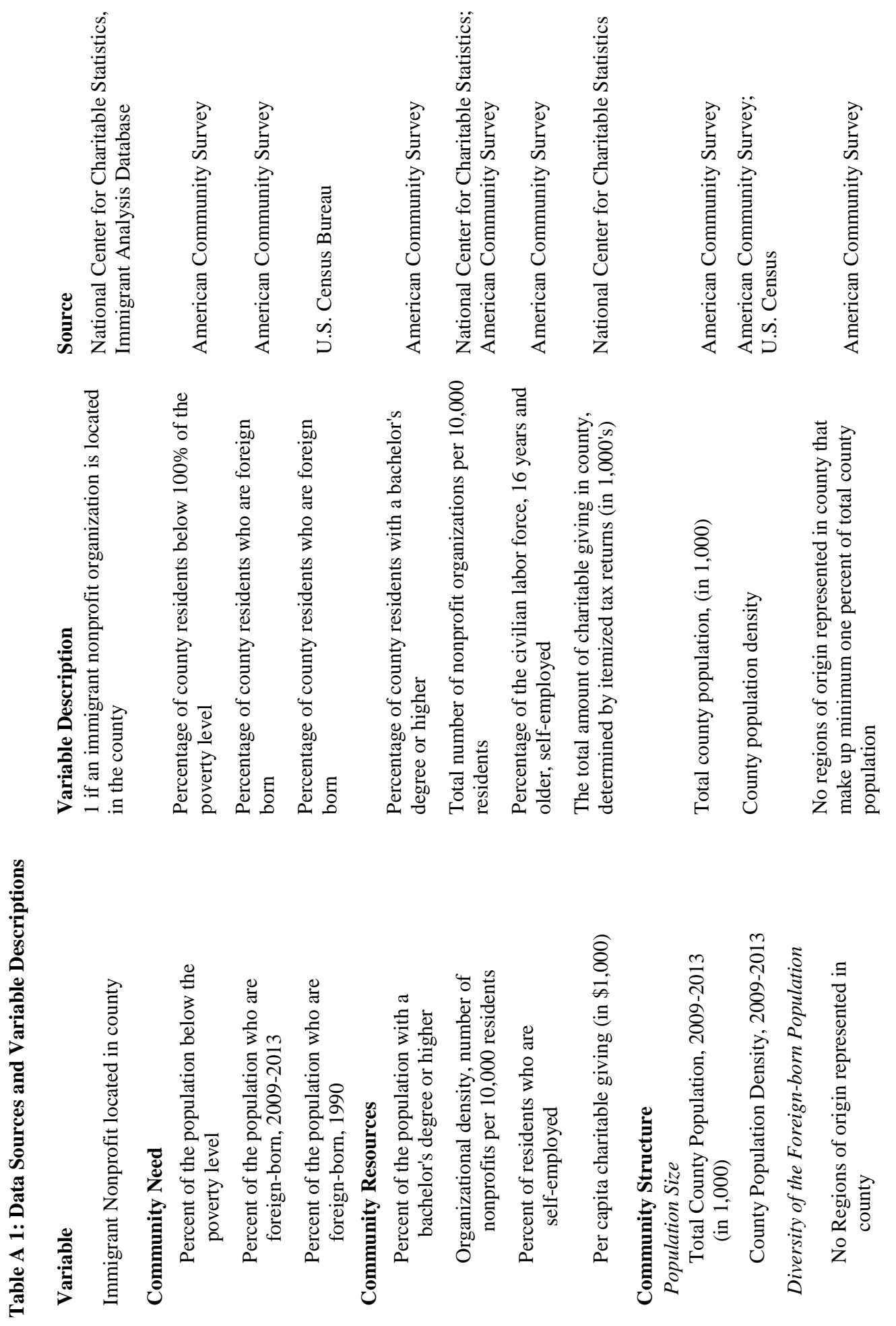


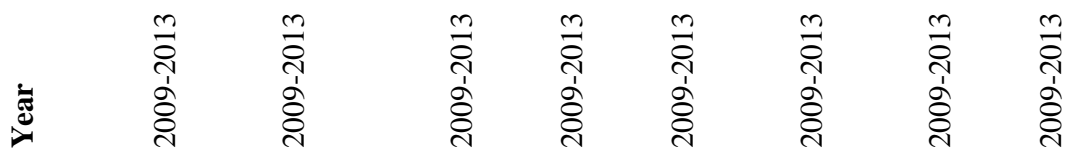
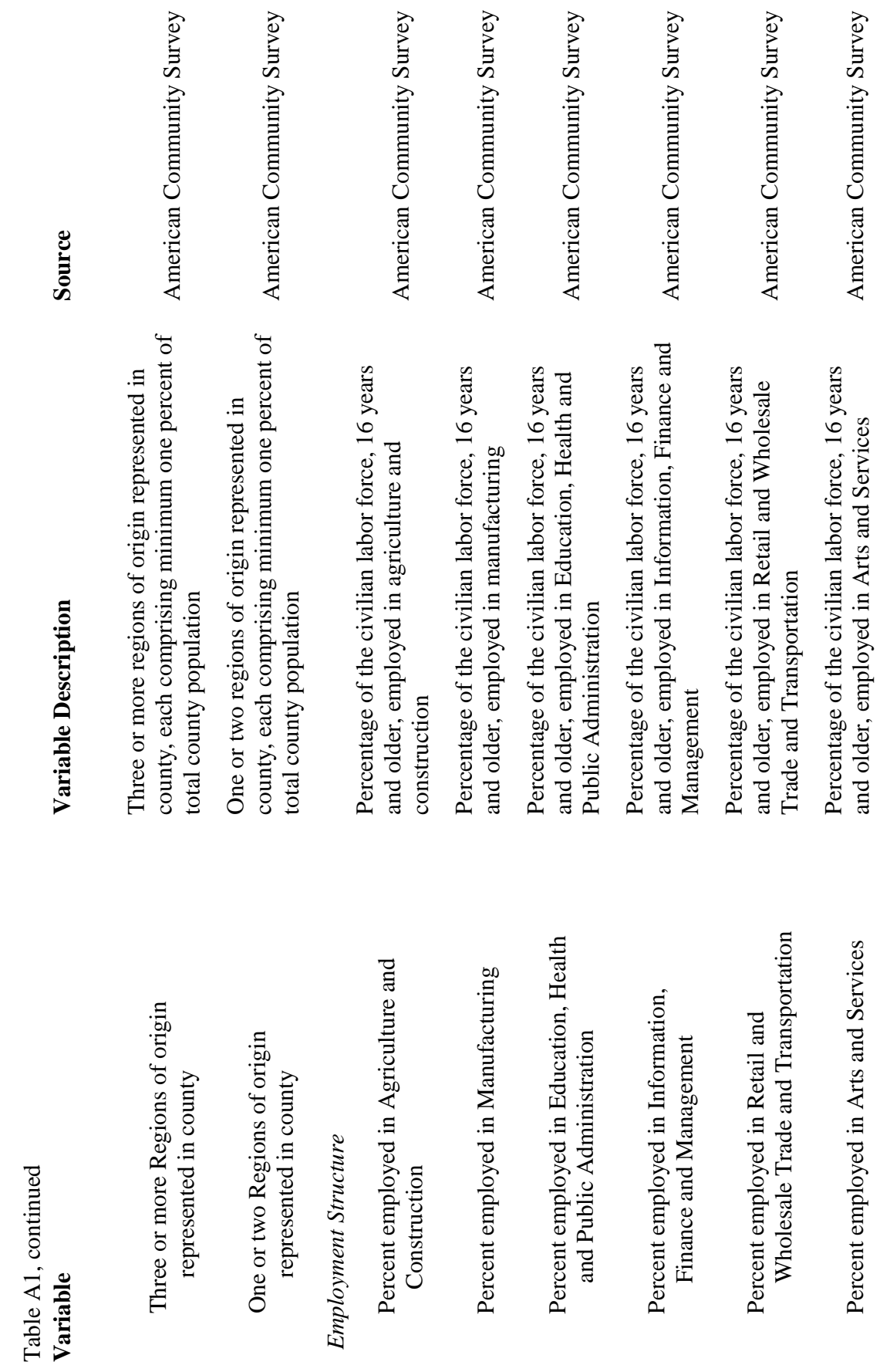


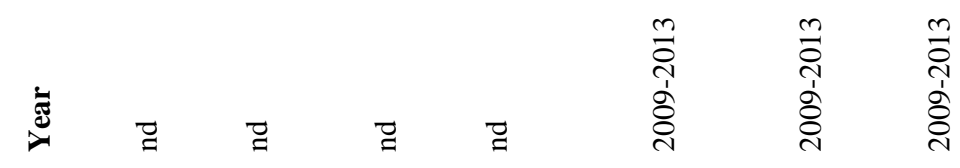
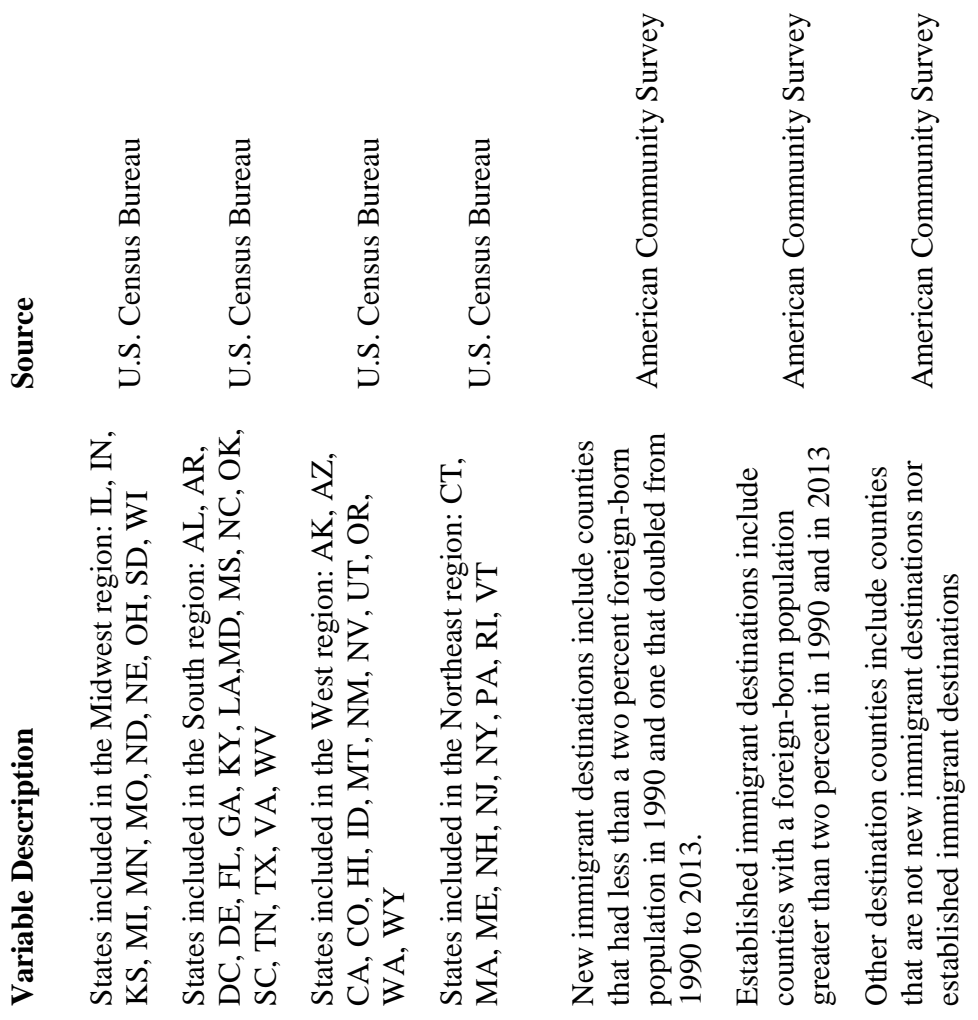

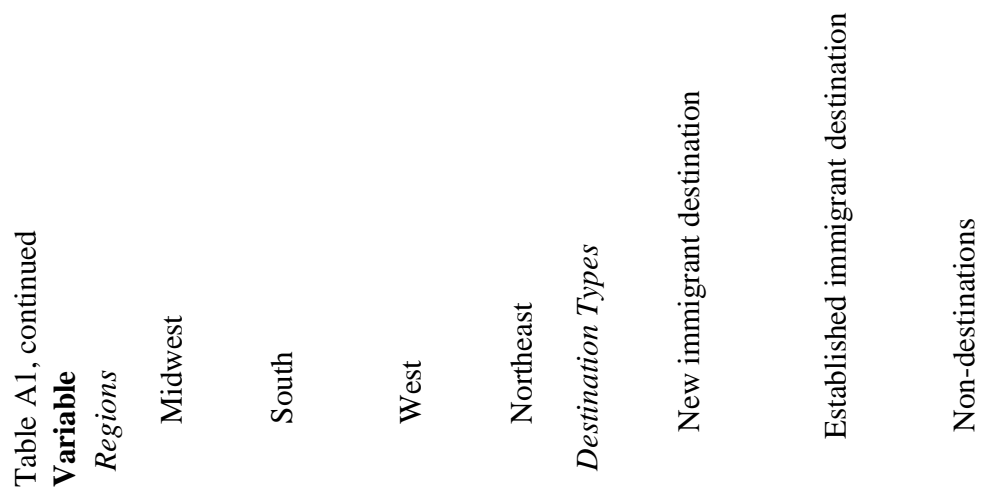


Appendix B

Immigrant Analysis Database

The Immigrant Analysis Database (IAD) is a unique unpublished database managed by the NCCS at the Urban Institute. The immigrant nonprofit organizations included in the IAD were selected from the 2014 Business Master File (BMF). The BMF includes information on active organizations registered for tax-exempt status with the Internal Revenue Service (NCCS nd). Organizations included in the IAD were selected from the BMF using automated content analysis with data-mining algorithms and key words including: country names (i.e. Mexico), adjective versions of country names (i.e. Mexican), and regional and ethnic keywords (i.e. Latino/a, Hispanic) for the top 10 sending countries to the United States (Mexico, China, India, Vietnam, El Salvador, Korea, Cuba, Dominican Republic, and the Philippines; personal correspondence de Leon, March 2015). All organizations coded with the National Taxonomy of Exempt Entities (NTEE) code P84 representing "Human Service Ethnic and Immigrant Centers" and Q71 "International Migration \& Refugee Issues" were included in this dataset. In the IAD, an organization was considered an immigrant organization if it appeared to currently serve immigrant populations in the United States.

To ensure organizations in the IAD were immigrant nonprofit organizations, I started the data cleaning process by reviewing the immigrant organizations one-by-one, as Cortes (1998) did after his automated search. I used a name-based approach to identify the region or immigrant group associated with or served by the organization; that the organization appeared to serve immigrant or refugee groups; and the organization was located in the United States. This approach is consistent with the approach used by Cortes 
(1998) and Gleeson and Bloemraad (2013). When I was unable to identify the geographic region or immigrant group associated with or served by the organization from the name of the nonprofit, I conducted an internet search.

After cleaning the IAD, out of the more than 7,000 immigrant nonprofit organizations originally present, 5,826 immigrant organizations remained. Examples of organizations omitted from the database include: organizations located internationally (i.e. humanitarian or international mission organizations); African American or Native American organizations (i.e. First African Educational Center; Indian Cultural Organization); religious organizations that did not or did not appear to serve immigrant or refugee populations (i.e. Collat Jewish Family Services; Public Employee Retirees, Inc.); organizations named after a town or geographical region (i.e. Arab Youth Athletics; Indian Hills Education Association).

The following are examples of my coding process: Religious organizations serving people from many different immigrant backgrounds, such as Islamic centers, were coded for serving multiple immigrant groups. Other, more specific religious organizations such as Hindu temples were coded for serving immigrants from India, Central, and Southern Asia, areas with large Hindu populations. If the name of an organization indicated a region or group of people, I conducted an internet search to confirm the countries affiliated with that region or group. An example of this would be the "Kirman Sikh Youth Association", coded for serving immigrants from India and Pakistan, yet may serve people from other regions as well. Another example is "The African Immigrants Social and Cultural Services" which I coded as serving immigrants from multiple countries of origin, but focused on immigrants from Sub-Saharan Africa. 
Similarly, if an organization name was in Spanish, such as "Centro de Servicios of Alameda County", it was coded for serving immigrants from multiple countries of origin, but focused on immigrants from Latin America. 


\title{
CHAPTER 3:
}

\section{A METROPOLITAN AREA'S RACIAL AND ETHNIC DISTRIBUTION AND IMMIGRANT NONPROFIT ORGANIZATIONS}

\author{
Kate C. Olson \\ Introduction
}

Racial or ethnic distribution patterns can take different forms within a community and may influence the presence of nonprofit organizations. Immigrant nonprofit organizations may be particularly sensitive to the distribution of racial and ethnic groups in a metropolitan area due to their immigrant specific focus. Immigrant nonprofit organizations provide many of the same services as general nonprofits, but generally serve foreign-born residents. In this study, I focus on the distribution of racial and ethnic populations in terms of diversity and segregation and their association with the presence of immigrant nonprofit organizations. In this paper, diversity in metropolitan areas refers to areas with several racial or ethnic groups of comparable size living relatively integrated. When examining diversity within a metropolitan area, the Entropy Index is generally used to measure the number and size of multiple racial and ethnic groups present within a census tract. On the other hand, segregation in metropolitan areas refers to areas where Black, Hispanic, or Asian residents live separate from White residents. ${ }^{24}$ The Dissimilarity Index is generally used to measure how evenly two groups are distributed (more or less segregated) within a census tract compared to the total population in the larger metropolitan area.

\footnotetext{
${ }^{24}$ When discussing Black, Asian, or White racial and ethnic groups throughout this text, I am referring to non-Hispanic Black, non-Hispanic Asian, and non-Hispanic White groups.
} 
Racial and ethnic distribution patterns may influence the presence of nonprofits in several ways. Putnam (2007) argues that high levels of diversity reduce trust and social capital in communities and may therefore reduce the number of nonprofit organizations. However, other studies find that high levels of diversity may also lead to diverse demands and therefore an increase in the number of nonprofit organizations (Corbin 1999; Paarlberg \& Gen 2009). Residents in segregated areas generally have lower access to resources, such as nonprofit organizations (Garrow 2015, 2012; Garrow \& Garrow 2014; Small \& McDermott 2006). On the other hand, living in extreme segregation, such as an immigrant enclave, can have positive effects on recent immigrant groups because of the community ties offering both economic and social support with language and other cultural provisions (Iceland 2009; Portes \& Manning 1986; Small \& McDermott 2006). In addition, Portes and Manning (1986) anticipated that immigrant nonprofit organizations experience high levels of participation in segregated immigrant enclaves. From these examples and other nonprofit research, it is apparent that a community's racial and ethnic composition matter for nonprofit development (Ben-Ner \& Van Hoomissen 1992; Corbin 1999; Matsunaga \& Yamauchi 2004; Paarlberg \& Gen 2009). The implications of immigrant segregation have been studied, however, how immigrant integration or segregation influences the presence of immigrant nonprofit organizations is not well known. Studies on immigrant settlement patterns and segregation have largely concentrated on the differences in new and established immigrant destinations ${ }^{25}$ and have not discussed a community's racial or ethnic

\footnotetext{
${ }^{25}$ New immigrant destinations are areas that have been experiencing new and rapid growth of foreign-born residents since the 1990s; whereas established immigrant destinations are areas with a longer standing history of immigrant settlement (Fischer 2010; Singer 2004, 2013; Massey 2008).
} 
distribution in relation to nonprofit organizations in general, or immigrant nonprofit organizations specifically (Hall \& Crowder 2014; Hall \& Stringfield 2014; Hall 2009; Park \& Iceland 2011). Researchers have found evidence that immigrants in both new and established immigrant destinations are subject to segregation from the mainstream White population (Hall 2013; Hall \& Stringfield 2014; Lichter et al. 2010; Park \& Iceland 2011). At the same time, Hispanic populations, both native and foreign born, have higher levels of segregation in new destinations (Hall \& Stringfield 2014; Lichter et al. 2010; Park \& Iceland 2011). In addition, among recent Hispanic and Asian immigrants, segregation is increasing and resulting in more isolated ethnic enclaves (Iceland 2004; Logan \& Stults 2011). The relationship between the racial or ethnic distribution of immigrant populations and immigrant nonprofit organizations, however, is unclear.

To examine the relationship between the distribution of racial and ethnic groups and immigrant nonprofit organizations, I employ multiple regression to answer the question: How does a metropolitan area's racial and ethnic distribution (i.e. diversity or segregation) influence the number of immigrant nonprofit organizations? I use the Entropy Index to measure the number and size of different racial and ethnic groups and I use the Dissimilarity Index to measure the distribution of racial or ethnic groups living in an area. These indices are not mutually exclusive and, for example, segregation may be present even when there is high diversity. In the next section, I discuss background information to understand diversity and segregation as two racial and ethnic distribution patterns. At the end of the literature section, I explain the hypotheses for this study. From there, I describe the data and regression method used for this analysis. Finally, I examine how the racial and ethnic distribution within a metropolitan area is associated with the 
number of immigrant nonprofit organizations. Findings suggest that highly diverse areas have fewer immigrant nonprofit organizations and areas with a high concentration of Hispanic residents (White-Hispanic segregated areas) have fewer immigrant nonprofit organizations per 1,000 foreign-born residents. To conclude, I discuss some implications related to these findings.

\section{Literature Review}

In this study, I examine how two different distribution possibilities of racial and ethnic groups in metropolitan areas are associated with the number of immigrant nonprofit organizations found there. Specifically, my focus is on metropolitan areas with many different racial and ethnic groups of similar sizes (diversity) and metropolitan areas where certain racial and ethnic groups live in separation from the majority White population (segregation). This section reviews the literature regarding these distribution possibilities.

\section{Diverse Metropolitan Areas}

Over the past 30 years, racial and ethnic diversity has increased in all areas of the United States, especially in metropolitan areas (Iceland 2009; Lee et al. 2012). High diversity metropolitan locations are characterized by a large total population and a substantial foreign-born population and many rental housing and employment options to accommodate individuals moving to these areas. Diverse metropolitan areas tend to be located on the coast or southern border (Lee et al. 2012). Diverse, global neighborhoods generally have a rather high level of residential integration and consist of different racial or ethnic groups of similar sizes (Lee et al. 2012; 2013). Examples of metropolitan areas 
with a high diversity score include the greater San Francisco Bay area, the greater Washington D.C. area, and the greater New York City area (see Appendix A, Table A1). There are varied implications related to increased diversity, both for residents and nonprofit organizations. For example, non-Hispanic Whites are less likely to live in completely homogenous communities, however, non-Hispanic Whites are also less likely to move into minority neighborhoods (Iceland 2009; Logan \& Zhang 2010; 2011). Logan and Zhang $(2010 ; 2011)$ also found that the existence of highly diverse areas is due to minority mobility. In addition, Putnam (2007) found that areas with high ethnic and racial diversity had lower social cohesion, social trust, and civic engagement. Findings from Putnam (2007), Logan and Zhang (2011), and Small and McDermott (2006), suggest that areas with high ethnic and racial diversity may lack the environment for any type of organization to thrive.

In contrast, other studies have found that diverse areas increase the number of programs or organizations (Polson 2015; Hung 2007; Joassart-Marcelli 2013). Polson (2015) found that diverse congregations in ethnically diverse counties had more community service programs compared to homogeneous congregations. As a result, Polson (2015) suggested that a congregation's physical location within an ethnically diverse neighborhood may have motivated the congregation to establish community service programs to serve the larger community. Hung (2007) also found that Hispanic or Asian religious organizations were more likely to be found in more diverse areas. Finally, Joassart-Marcelli (2013) found that "diverse immigrant populations are likely to be home to multiple organizations serving these groups' diverse needs" (p. 754). Diverse areas have varied needs and therefore organizations, especially religious organizations with 
more programs to accommodate the different demands (Hung 2007; Jossart-Marcelli 2013; Polson 2015). In the case of immigrant groups and immigrant nonprofits, it could be that certain immigrant nonprofits serve their own group and therefore, in diverse metropolitan areas with many different immigrant groups, multiple immigrant nonprofits may be present to meet the diverse demands.

Findings from Hung (2007), Joassart-Marcelli (2013), and Polson (2015) demonstrate that diverse communities are associated with more programs with potential outcomes following bridging social capital and contact theory. Bridging social capital connects people from different backgrounds working towards social inclusion. Contact theory posits that, under certain conditions, increased interaction between groups can improve their relationships. Increased bridging social capital and contact between groups may increase an area's social cohesion, social trust, and civic engagement. Immigrant nonprofit organizations may serve diverse communities and build connections between people from different backgrounds, building social capital among their clientele (Bagetta 2016; Polson 2015). Structured and facilitated contact between people in diverse neighborhoods, a service that immigrant nonprofit organizations could potentially provide, can reduce prejudice between groups, following contact theory (Allport 1954; Pettigrew \& Tropp 2006). In this way, immigrant nonprofit organizations could be a driving force in diverse communities to build stronger relationships and connect residents to mainstream resources.

\section{Segregated Metropolitan Areas}

Segregation refers to the separation and relative concentration of one racial or ethnic group in relation to another racial or ethnic group, generally in an urban 
environment (Massey \& Denton 1988, p. 282). Metropolitan areas with high levels of segregation are associated with poor health and educational outcomes; lower social mobility and trust; and increased social exclusion and discrimination among the segregated group, commonly African American and Hispanic residents (Iceland 2009; Lee et al. 2013; Madden 2001; Massey 2007; Wilkes \& Iceland 2004). In addition, residents of segregated communities are more likely to have limited access to resources that may potentially alleviate the negative effects of isolation (Lee \& Ousey 2005; Peterson et al. 2000; Yen \& Kaplan 1999). Examples of metropolitan areas with high levels of White-Hispanic segregation include Reading, Pennsylvania, Springfield, Massachusetts, and the Los Angeles metropolitan area (see Appendix A, Table A1). Previous research on nonprofit organizations has shown that areas with high levels of residential segregation have fewer nonprofit organizations due to white flight and limited resources (Garrow 2012, 2015; Garrow \& Garrow 2014; Logan 2011). Residents of residentially segregated areas may also experience gaps in service provision because "segregation effectively splinters social service efforts along racial and ethnic lines" (Gibbons 2014, p. 617). These results follow residential segregation theory, which predicts that more segregated communities have fewer resources, such as nonprofit organizations (Alba 2009; Massey \& Denton 1993; Small \& McDermott 2006).

Nonprofit organizations have a long history of service provision and advocating on behalf of vulnerable populations. Nonprofit organizations, and immigrant nonprofits in particular, provide various services to local populations including, for example, cultural and/or educational activities, employment or healthcare assistance, religious guidance, assistance with the immigration process, and language assistance (Cordero- 
Guzmán 2005; de Leon et al. 2009; Vu et al. 2017). In segregated communities where nonprofit organizations are present, nonprofits appear to mitigate some of the negative effects associated with living in residentially segregated areas, such as connecting residents to other organizations and resources; offering health or other types of information; and reducing levels of crime (Lee \& Ousey 2005; Peterson et al. 2000; Small 2006). Nonprofits may also serve as advocates increasing the political influence of those living in segregated areas (Massey \& Denton 1993).

Certain segregated groups, however, are less likely to use organizations to improve their visibility and political influence. Research has shown that due to their lack of political power, predominately African American and Hispanic populations living in segregated areas are less likely to use neighborhood organizations to advocate for their community's interests (Massey \& Denton 1993; Small \& Stark 2005). In these locations, however, it could be that nonprofit organizations are not available. A recent study on immigrant nonprofits noted that the number of Mexican-serving immigrant nonprofits were far fewer than expected given the large Mexican population (Gleeson \& Bloemraad 2013). In addition, research on immigrant segregation found that foreign-born Hispanics have higher levels of segregation compared to other foreign-born populations (Hall \& Stringfield 2014; Park \& Iceland 2011). Foreign-born Hispanics may be particularly vulnerable to the lack of immigrant nonprofit services due to their rapid growth, lower educational attainment, and increasing segregation and poverty (Massey 2007).

\section{Hypotheses}

In the literature section, I discussed different theoretical perspectives regarding diversity and segregation in metropolitan areas. Based on these perspectives, I discuss 
hypotheses to guide the research question: How does a metropolitan area's racial and ethnic distribution (i.e. diversity or segregation) influence the number of immigrant nonprofit organizations?

Following Putnam's (2007) rationale, areas with high ethnic diversity often have lower levels of social cohesion, social trust, and civic engagement, suggesting they would also have fewer nonprofit organizations. This leads to hypothesis 1: The number of immigrant nonprofit organizations per 1,000 foreign-born residents will decrease as the level of diversity (entropy score) increases, holding all else constant.

However, other scholars (i.e. Hung 2007; Joassart-Marcelli 2013; Polson 2015) found that areas with high ethnic diversity have many needs and not all of the population's demands can be met by major service-providers. In this instance, high diversity metropolitan areas would have more nonprofit organizations, especially religious organizations, with more programs to accommodate the diverse needs (Hung 2007; Joassart-Marcelli 2013; Polson 2015). This leads to hypothesis 2: The number of immigrant nonprofit organizations per 1,000 foreign-born residents will increase as the level of diversity (entropy score) increases, holding all else constant.

Although some scholars have found that extreme segregation in the form of an ethnic enclave may be positive for new immigrants (Portes \& Manning 1986), other scholars found that African American and Hispanic populations living in segregated areas were less likely to use neighborhood organizations and these resources may not be available (Massey \& Denton 1993; Small \& Stark 2005; Gleeson \& Bloemraad 2013). I expect that the negative effects of segregation and the lack of access to resources, such as nonprofit organizations, will also impact immigrant nonprofit organizations. This leads to 
hypothesis 3: The number of immigrant nonprofit organizations per 1,000 foreign-born residents will decrease as the level of residential segregation increases, holding all else constant.

\section{Data, Measures, and Methods}

\section{Data}

I test the hypotheses described above using data from several sources. This crosssectional analysis combines immigrant nonprofit data from a previously unpublished database of immigrant nonprofit organizations managed by the National Center for Charitable Statistics (NCCS), demographic data from_the American Community Survey, and residential segregation measures from the US2010, Diversity and Disparities Project (Brown University, nd).

The Immigrant Analysis Database (IAD) contains 5,826 immigrant nonprofit organizations from the 2014 Exempt Organizations Business Master Files from the National Center for Charitable Statistics data web (see also Olson 2017). The organizations in this database, however, are not exhaustive of immigrant nonprofit organizations. This database, for example, does not include small, informal organizations not registered with the Internal Revenue Service. Larger organizations with programs for immigrants or refugees, but without a primary focus on immigrants, were also not included (i.e. Catholic Charities Refugee and Immigration Services; see Olson 2017). Additionally, although religious organizations are not required to file with the IRS, this database contains many religious immigrant nonprofit organizations, including churches. These limitations notwithstanding, the IAD is the most comprehensive, unique and 
reliable source of immigrant nonprofit organizations across the U.S. covering multiple nonprofit sectors from a single source.

Consistent with other residential segregation research, I use the metropolitan-level of analysis (e.g. Friedman et al. 2013; Iceland et al. 2002). Metropolitan level demographic variables in this analysis, such as the size of the foreign-born population, educational attainment, poverty level and residential stability come from the American Community Survey (ACS) 2006-2010, 5-year sample. Using the 2006-2010 ACS data allows for a time lag between the demographic variables and racial or ethnic distribution patterns and the growing immigrant nonprofit response (Joassart-Marcelli 2013)._The ACS is a nationally representative survey of households and collects information on demographic, social, and economic characteristics of household members. Using the ACS 5-year estimates is advantageous because data are available for all of the metropolitan areas and variables included in this study with information averaged over the 5-year period (January 2006-December 2010). I restrict my sample to metropolitan areas with at least 1,000 members of each racial or ethnic group (non-Hispanic White, non-Hispanic Black, Hispanic, and non-Hispanic Asian) because segregation measures can be sensitive to small group populations (Friedman et al. 2013; Iceland et al. 2002). This reduces the sample from 358 to 333 metropolitan areas. ${ }^{26}$

The present study uses two dimensions of residential segregation-diversity and segregation (Massey \& Denton 1988) - to measure the association between residential segregation and the number of immigrant nonprofit organizations in a metropolitan area. The segregation measures come from the US2010, Diversity and Disparities Project

\footnotetext{
${ }^{26}$ The 25 excluded metropolitan areas had fewer than 1,000 Black or Asian residents. All 358 metropolitan areas had 1,000 or more Hispanic and White residents.
} 
(Brown University, nd). ${ }^{27}$ Researchers calculated the diversity and segregation measures from 2010 U.S. Census data.

\section{Measures}

The outcome variable in this study is the number of immigrant nonprofit organizations per 1,000 foreign-born residents in 333 metropolitan statistical areas across the U.S. The number of immigrant nonprofits per 1,000 foreign-born residents ranged from zero (56 metropolitan areas) to 1.5 in the Salisbury, MD metropolitan statistical area (MSA) ${ }^{28}$ More than 75 percent of metropolitan areas, however, had less than 0.3 immigrant nonprofit organizations per 1,000 foreign-born residents (about 1 immigrant nonprofit for every 3,333 foreign-born residents). In this analysis, there are 5,609 immigrant nonprofit organizations located in 277 metropolitan areas across the country. The number of immigrant nonprofit organizations ranged from zero to 835 immigrant nonprofits (New York City $\mathrm{MSA}^{29}$ ).

The variables of interest measure different aspects of the racial and ethnic distribution in metropolitan areas. To estimate how the distribution of different racial and ethnic groups are associated with the number of immigrant nonprofit organizations, I focus on two dimensions of segregation. I use the entropy index to measure the effect of diverse neighborhoods and the dissimilarity index to measure the effect of White-Black, White-Hispanic, and White-Asian segregation. Both the entropy index and the dissimilarity index measure racial and ethnic distribution at the census tract level and

\footnotetext{
27 The Diversity and Disparities Project at Brown University focuses on social and spatial inequalities and changes in the American society. The data are available as a public service (Brown University, nd; Lee et al. 2012; Logan \& Stults 2011; Logan 2011).

${ }^{28}$ The Salisbury MSA had 11 immigrant nonprofits and a foreign-born population comprising 5.8 percent of the residents.

${ }^{29}$ The New York City MSA had 0.16 immigrant nonprofits per 1,000 foreign-born residents.
} 
compare that to the larger metropolitan area. The entropy index measures multiple racial and ethnic groups in one formula whereas the dissimilarity index can only measure two different racial or ethnic groups in one formula. For that reason, the dissimilarity index is measured using White-Black, White-Hispanic, and White-Asian segregation. In addition, the entropy and dissimilarity index are not mutually exclusive categories.

In this study, diverse neighborhoods (census tracts) include areas with several racial and ethnic groups all of a comparable size and living relatively close together (Lee et al. 2012, 2013). To measure the level of diversity, researchers commonly use the entropy index (E). ${ }^{30}$ The entropy score ranges from 0-100; a score of zero indicates only one group present in the community (complete homogeneity) and a score of 100 indicates equal proportions of all groups present (Lee et al. 2012). The entropy index, however, does not take the racial and ethnic residential structure of a community or the spatial separation between groups into consideration.

To account for the racial and ethnic residential structure, I use a segregation measure. Segregation refers to the distribution and separation of different racial or ethnic groups (Massey \& Denton 1988, p. 282). The most common measure of residential segregation is the dissimilarity index (D). ${ }^{31}$ The dissimilarity score ranges from 0-100 and indicates how separately two groups live from each other. A low score (less than 30) indicates low levels of segregation and a high score (60 and above) indicates segregation

\footnotetext{
${ }^{30} E$ is defined as: $\sum_{r=1}^{n} p_{r} \ln \left(\frac{1}{p_{r}}\right)$ where $p_{r}$ is the proportion of racial-ethnic group $r$ 's population in a metropolitan area and $n$ is the number of groups. The natural $\log$ of $n$ is the maximum value of $E$ and can only be attained when all groups in the metropolitan area are of equal size (Lee et al. 2012, p. 21).

${ }^{31} D$ is defined as: $\sum_{i=1}^{n}\left[t_{i}\left|p_{i}-P\right|\right] /[2 T P(1-P)] * 100$ where $t_{i}$ is the total population in area $i$ and $p_{i}$ is the proportion of area $i$ 's population that is minority (Black, Hispanic, or Asian); and $P$ is the proportion of the total metropolitan population that is minority (Black, Hispanic, or Asian); $T$ is the sum of all $i$ 's, the total population (Iceland et al. 2002, p. 122).
} 
and that the two groups live largely in different census tracts (Logan \& Stults 2011). The dissimilarity score indicates the percent of one group that would have to move to a different census tract to achieve the same percentage in the tract as in the total metropolitan population. In this study, I consider the segregation between White-Black, White-Hispanic, and White-Asian. See Table 1 for the correlations between the variables of interest (entropy and dissimilarity index) and the number of immigrant nonprofit organizations per 1,000 foreign-born residents.

Table 1: Correlation between variables of interest

\begin{tabular}{|c|c|c|c|c|c|}
\hline VARIABLES & $\mathbf{A}$ & B & $\mathbf{C}$ & D & $\mathbf{E}$ \\
\hline \multicolumn{6}{|l|}{ Dependent Variable } \\
\hline $\begin{array}{l}\text { A. Number of Immigrant Nonprofits } \\
\text { per 1,000 foreign-born residents }\end{array}$ & 1 & & & & \\
\hline \multicolumn{6}{|l|}{ Residential Segregation Measures } \\
\hline B. Diversity (Entropy Index, E) & $-0.254 *$ & 1 & & & \\
\hline \multicolumn{6}{|l|}{ Segregation (Dissimilarity Index, D) } \\
\hline C. D-Score White-Black & $0.175^{*}$ & $0.210^{*}$ & 1 & & \\
\hline D. D-Score White-Hispanic & $-0.160 *$ & $0.416^{*}$ & $0.477 *$ & 1 & \\
\hline E. D-Score White-Asian & 0.082 & $0.178^{*}$ & $0.505^{*}$ & $0.288^{*}$ & 1 \\
\hline
\end{tabular}

Note: * indicates statistically significant at $\mathrm{p}<0.05$

The segregation indices comprise the variables of interest. The control variables used in this analysis follow previous literature predicting similar community level outcomes (e.g. Friedman et al. 2013; Polson 2015; Small \& McDermott 2006). Control variables include the percent of the population of different racial and ethnic groups (White, Black, Hispanic, Asian, and Other) and the percent of foreign-born residents in a metropolitan area; educational attainment; poverty; unemployment; residential stability; population size; and the region where the metropolitan area is located ${ }^{32}$. Educational

\footnotetext{
${ }^{32}$ With increasing scholarship on new and established immigrant destination areas, I ran a sensitivity analysis using new, established, and non-destination metropolitan areas instead of the region controls.
} 
attainment is the percent of the population with a bachelor's degree or higher and poverty is the percent of the population below the poverty level. Unemployment is the unemployment rate of the civilian population in the labor market who are 16 years and older. Residential stability refers to the percent of the population who live in the same house as the previous year and the metropolitan population is the log of the total population. Regions of the United States are also included to control for the metropolitan area's geography (West, South, Midwest; compared to the Northeast). See Table 2 for the descriptive statistics of the variables in this analysis.

\section{Method}

To study the influence of a community's racial and ethnic distribution patterns on the number of immigrant nonprofit organizations, I run ordinary least squares regression. The general model is as follows:

$$
\operatorname{ImmOrg}_{i}=\alpha_{i}+\text { Index }_{1 i}+\text { Control }_{2 i}+e
$$

Where:

$\operatorname{ImmOrg}_{i}$ is the number of immigrant nonprofit organizations per 1,000 foreignborn residents in metropolitan area $i$. Index $\beta_{1 i}$ represents the segregation measures used, the entropy and dissimilarity index, in metropolitan area $i$. I run three models and include all control variables in each model. Model 1 includes the diversity index; Model 2 includes the dissimilarity index; and in Model 3 I include both segregation measures. Model 3 is of interest because diversity and segregation within a metropolitan area is not mutually exclusive, and therefore controlling for both may uncover different results. Control $\beta_{2 i}$ is a vector of control variables including residential stability; poverty;

There were no changes in the variables of interest. Therefore, I continued using Northeast, West, South and Midwest as the control variables. 
unemployment; educational attainment; the percent foreign-born; the percent White,

Black, Hispanic, Asian, and Other; population size; and the region of metropolitan area $i$.

Finally, $e$ is a random error term and I use robust standard errors to account for heteroscedasticity.

\section{Findings}

This study examines the distribution of different racial and ethnic groups related to the number of immigrant nonprofit organizations per 1,000 foreign-born residents in a metropolitan area. Table 2 provides basic descriptive statistics for the variables in this analysis and Table 3 provides the regression analysis results. I also include a table with the names of the top 10 metropolitan areas with the highest levels of diversity and highest levels of White-Hispanic and White-Asian segregation to offer locational context, see Appendix A, Table A1. In this section, I first discuss the descriptive findings followed by the regression results.

\section{Descriptive Results}

There are a few interesting observations from the descriptive statistics in Table 2.

Table 2 shows that, in the average metropolitan area, there are approximately 17 immigrant nonprofit organizations, which is equal to about one immigrant nonprofit for every 5,000 foreign-born metropolitan residents. ${ }^{33}$ The diversity score $(E=49.7)$ for the average metropolitan area falls in the middle of the possible 0-100 range. The range of diversity among the 333 metropolitan areas in this study, however, is quite large $(E=13.7$ to $\mathrm{E}=89.3$ ). The average segregation scores were moderate for all three groups (White-

\footnotetext{
${ }^{33}$ When only including the 277 metropolitan areas with an immigrant nonprofit, there are approximately 20 immigrant nonprofits in the average metropolitan area and about one immigrant nonprofit for every 4,000 foreign-born metropolitan residents (results not shown).
} 
Black $\mathrm{D}=45.3$, White-Hispanic $\mathrm{D}=36.3$, White-Asian $\mathrm{D}=33.5$ ). A D-score of less than 30 indicates low segregation and above 60 indicates high segregation. The D-score ranges, however, were quite large. The range of dissimilarity scores for White-Black segregation ran from a low of $\mathrm{D}=16.2$ to a high of $\mathrm{D}=79.6$ and White-Hispanic segregation had a low of $\mathrm{D}=13.5$ and a high of $\mathrm{D}=68.7$. White-Asian segregation was the most moderate with a range of $\mathrm{D}=12.9$ to $\mathrm{D}=57$. Now I turn to the regression results.

Table 3: Descriptive Statistics, $\mathbf{N = 3 3 3}$ Metropolitan Areas

\begin{tabular}{|c|c|c|c|c|}
\hline VARIABLES & Mean & $\begin{array}{l}\text { Standard } \\
\text { Deviation }\end{array}$ & Min & Max \\
\hline \multicolumn{5}{|l|}{ Dependent Variable } \\
\hline Total Number of Immigrant Nonprofit Organizations & 16.84 & 61.02 & 0 & 835 \\
\hline Number of Immigrant Nonprofits per 1000 foreign-born residents & 0.207 & 0.222 & 0 & 1.504 \\
\hline \multicolumn{5}{|l|}{ Residential Segregation Measures } \\
\hline Diversity (Entropy Index, E) & 49.73 & 14.89 & 13.65 & 89.33 \\
\hline \multicolumn{5}{|l|}{ Segregation (Dissimilarity Index, $D$ ) } \\
\hline D-Score White with Black & 45.33 & 12.65 & 16.21 & 79.61 \\
\hline D-Score White with Hispanic & 36.3 & 10.82 & 13.46 & 68.72 \\
\hline D-Score White with Asian & 33.54 & 8.688 & 12.9 & 57.05 \\
\hline \multicolumn{5}{|l|}{ Control Variables } \\
\hline Percent Residential Stability & 82.43 & 3.955 & 69.51 & 91.34 \\
\hline Percent Below Poverty & 14.64 & 3.968 & 7.2 & 34.7 \\
\hline Percent Unemployed & 4.992 & 1.123 & 2.7 & 9.4 \\
\hline Percent Bachelor's Degree or higher & 25.87 & 7.787 & 11.8 & 57 \\
\hline Percent Foreign-Born & 8.01 & 6.58 & 0.839 & 37.27 \\
\hline Percent White & 70.59 & 17.06 & 7.816 & 96.01 \\
\hline Percent Black & 11.69 & 10.83 & 0.337 & 52.56 \\
\hline Percent Hispanic & 12.76 & 15.34 & 0.797 & 90.63 \\
\hline Percent Asian & 3.557 & 4.922 & 0.66 & 69.12 \\
\hline Percent Other (including multiple race) & 1.404 & 2.049 & 0.166 & 27.65 \\
\hline Total Population $(10,000)$ & 76.17 & 164.5 & 5.527 & 1,890 \\
\hline Log of Population & 12.77 & 1.061 & 10.92 & 16.75 \\
\hline Northeast & 0.12 & 0.326 & 0 & 1 \\
\hline Midwest & 0.258 & 0.438 & 0 & 1 \\
\hline South & 0.408 & 0.492 & 0 & 1 \\
\hline West & 0.213 & 0.41 & 0 & 1 \\
\hline
\end{tabular}




\section{Regression Results}

The remainder of this section focuses on the regression results examining how the distribution of racial and ethnic groups is associated with the number of immigrant nonprofit organizations. Table 3 provides the regression analysis results testing

hypotheses 1,2 , and 3. Box 1 offers an overview of the hypotheses and whether the regression results supported the hypothesis. The outcome variable is the number of immigrant nonprofit organizations per 1,000 foreign-born residents. I ran the regression using three models, each model includes all control variables but the independent variable of interest changes. Model 1 shows the regression results including the Entropy Index; Model 2 shows the regression results including the Dissimilarity Index; and Model 3 shows the regression results including both the entropy and dissimilarity index.

\section{Box 1: Overview of Hypotheses Support}

Hypothesis:

1: The number of immigrant nonprofit organizations per 1,000 foreign-born residents will decrease as the level of diversity (entropy score) increases, holding all else constant.

2: The number of immigrant nonprofit organizations per 1,000 foreign-born residents will increase as the level of diversity (entropy score) increases, holding all else constant.

3: The number of immigrant nonprofit organizations per 1,000 foreign-born residents will decrease as the level of residential segregation increases, holding all else constant.

\section{Supported?}

Supported

Not supported

Mixed support: Supported in areas with White-Hispanic segregation;

Not supported in areas with WhiteBlack segregation.

The results in Model 1 show the association between diversity, measured using the entropy index, and the number of immigrant nonprofit organizations per 1,000 foreign-born residents. Model 1 tests hypotheses 1 and 2. The regression results in Model 1 indicate that as the level of diversity increases, the number of immigrant nonprofit 
organizations per 1,000 foreign-born residents decreases $(-0.003, \mathrm{p}<0.1)$, providing support for Hypothesis 1: The number of immigrant nonprofit organizations per 1,000 foreign-born residents will decrease as the level of diversity (entropy score) increases, holding all else constant. With this result, it could be that areas with high diversity have lower levels of social cohesion, social trust, and civic engagement and therefore fewer immigrant nonprofits, as posited by Putnam (2007) and other scholars (i.e. Small \& McDermott 2006).

There were also statistically significant control variables in Model 1. Residential stability had a small positive influence on the number of immigrant nonprofit organizations per 1,000 foreign-born residents $(0.009, \mathrm{p}<0.05)$, as does the size of the population with a bachelor's degree or higher $(0.003, \mathrm{p}<0.1)$. In this model, as in Model 2 and 3 , an increase in the foreign-born population is associated with a decrease in the number of immigrant nonprofits per 1,000 foreign-born residents $(-0.005, \mathrm{p}<0.05)$. Only in this model, population size was positively correlated with the number of immigrant nonprofit organizations per 1,000 foreign-born residents $(0.022, \mathrm{P}<0.1)$.

Model 2 displays the association between segregation, measured using the dissimilarity index, and the number of immigrant nonprofit organizations per 1,000 foreign-born residents. Model 2 tests Hypothesis 3 with the expectation that the negative effects of residential segregation would result in fewer immigrant nonprofit organizations. The results in Model 2 offer mixed support for Hypothesis 2. Contrary to suggestions from previous research (Garrow 2015), higher levels of White-Black segregation resulted in more immigrant nonprofit organizations per 1,000 foreign-born 
residents $(0.003, \mathrm{p}<0.05)$. This may be a unique finding specific to immigrant nonprofit organizations that does not generalize to other nonprofit organizations and could be

Table 4: Number of immigrant nonprofit organizations per 1,000 foreign-born residents

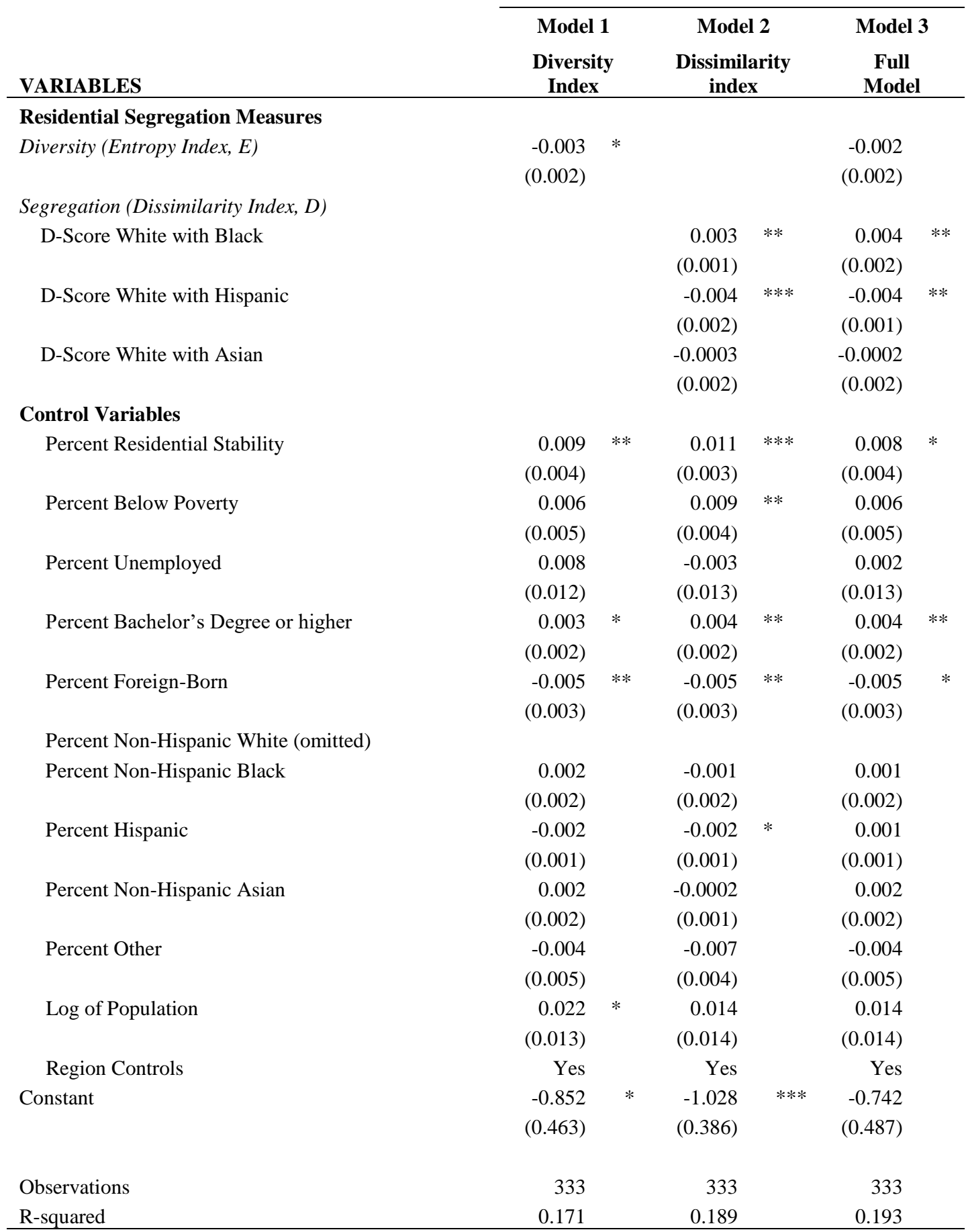

Robust standard errors in parentheses, $* * * \mathrm{p}<0.01$, ** $\mathrm{p}<0.05, * \mathrm{p}<0.1$ 
identifying the more diverse, "global" neighborhoods that Black residents tend to live in compared to White residents (Logan \& Zhang 2010; 2011). Increasing White-Hispanic segregation, however, was associated with fewer immigrant nonprofit organizations per 1,000 foreign-born residents $(-0.004, \mathrm{p}<0.001)$. This finding is consistent with other research and supports Hypothesis 2. Gleeson and Bloemraad (2013) noted far fewer Hispanic focused nonprofit organizations compared to what may be expected given the size of the Hispanic population: only two percent of officially registered immigrant nonprofits were Mexican-focused while in Gleeson and Bloemraad's study area, 21 percent of the population had Mexican-origins. This population may be underserved, but it could be that one large nonprofit or church are serving this population. It is also possible that other, perhaps informal, networks are fulfilling needs that immigrant nonprofits would otherwise perform. I am also unable to control for these possibilities within my data.

The statistically significant control variables in Model 2 were similar to those in Model 1. In addition to the statistically significant controls in Model 1, the size of the population below poverty in Model 2 was associated with a slight increase in the number of immigrant nonprofits per 1,000 foreign-born residents $(0.009, \mathrm{p}<0.05)$. Increases in the size of the Hispanic population was associated with a small decrease in the number of immigrant nonprofit organizations per 1,000 foreign-born residents, further supporting the disparate access to immigrant nonprofits in areas with high Hispanic populations.

The results from Model 2 suggest that for the Hispanic population in general, living segregated from the mainstream population is associated with less access to immigrant nonprofit organizations. From these results, I cannot determine if other formal 
organizations, government programs, or churches are working with these populations; or if Hispanic populations depend on other, more informal, networks, support systems, or organizations. Gleeson and Bloemraad (2013) found that some immigrant groups maintain informal organizations because they do not garner benefits from formally registering their organization. Gleeson and Bloemraad (2013) also found that some groups lack the human and economic capital to formalize their organization.

Model 3 includes variables for both segregation indices in one regression to control for these different racial and ethnic distribution patterns and the influence they may have on each other. Both the entropy index measuring diversity and the dissimilarity index measuring White-Black, White-Hispanic, and White-Asian segregation were included. This model indicates support for Hypothesis 3: The number of immigrant nonprofit organizations per 1,000 foreign-born residents will decrease as the level of residential segregation increases, holding all else constant, but again only for the Hispanic population (-0.004, $\mathrm{p}<0.05)$. As in Model 2, increases in White-Black segregation were associated with increases in the number of immigrant nonprofit organizations per 1,000 foreign born residents $(0.004, \mathrm{p}<0.05)$. Due to the correlations between the variables of interest, the standard errors in Model 3 are larger than in Model 1 or 2 . In Model 3, the entropy index was not statistically significant, but the coefficient results follow Model 1. Due to the larger standard errors in Model 3, I conclude that the results from Models 1 and 2 hold in Model 3. Therefore, not only Hypothesis 3, but also Hypothesis 1: The number of immigrant nonprofit organizations per 1,000 foreign-born residents will decrease as the level of diversity (entropy score) increases, holding all else constant, is also supported in Model 3. White-Asian segregation was not a statistically 
significant factor associated with the number of immigrant nonprofits per 1,000 foreignborn residents in this model. In Model 3, there were three statistically significant control variables: residential stability, population with a bachelor's degree or higher, and the size of the foreign-born population. An increase in residential stability and the percent of the population with a higher degree were associated with an increase in the number of immigrant nonprofit organizations per 1,000 foreign-born residents. The size of the foreign-born population, similar to Models 1 and 2, was associated with a decrease in the number of immigrant nonprofit organizations per 1,000 foreign-born residents.

Sensitivity analysis. Here I present four additional sensitivity analyses to reduce concerns that these findings may represent the nonprofit sector in general instead of immigrant nonprofits specifically and to address concerns about omitted variable bias based on previous literature and different measures of segregation. In addition, I include a sensitivity analysis controlling for immigrant destination type. The first analysis used all nonprofits per 10,000 residents as the outcome variable and the second analysis included a control variable for the size of the nonprofit sector. The third analysis included a control variable for the foreign-born population's length of tenure in the metropolitan area (entering the U.S. prior to or after 2000). Related to length of tenure, the fourth sensitivity analysis included new and established destination areas compared to nondestination areas. The sensitivity analysis results presented here are not shown, but are available from the author upon request.

In the first sensitivity test, I used the number of nonprofit organizations per 10,000 residents as the outcome variable. Results for the variables of interest (diversity or segregation scores) in this sensitivity test were not statistically significant in any of the 
models. There were, however, some differences in the control variables. ${ }^{34}$ This sensitivity test strengthens the argument that using general nonprofit theories for immigrant nonprofit organizations leads to different conclusions regarding how context may be associated with nonprofit density and therefore may not be appropriate for immigrant nonprofit organizations (de Graauw, Gleeson \& Bloemraad 2013; Gleeson \& Bloemraad 2013; Joassart-Marcelli 2013). This sensitivity analysis also further strengthens the argument in this paper that immigrant nonprofit organizations are more sensitive to the distribution patterns of racial and ethnic groups in a metropolitan area, more than nonprofit organizations in general.

In the second sensitivity analysis, using the number of immigrant nonprofits per 1,000 foreign-born residents as the outcome variable, I controlled for the size of the general nonprofit sector. The size of the nonprofit sector is often used in the nonprofit literature measured as the number of nonprofit organizations per 10,000 residents (Corbin 1999; Matsunaga \& Yamauchi 2004). When I included the number of general nonprofit organizations per 10,000 residents, no significant changes occurred in the three models. In all models, the size of the general nonprofit sector was a statistically significant variable, was associated with a small (0.004) increase in the number of immigrant nonprofits per 1,000 foreign-born residents, and changed the statistical significance of

\footnotetext{
${ }^{34}$ Similar to my analysis using the number of immigrant nonprofits per 1,000 foreign-born residents, residential stability and the percent of residents with a bachelor's degree or higher were statistically significant and associated with an increase in the number of nonprofits per 10,000 people. The size of the population in poverty, the percent of the population who are unemployed, as well as the metropolitan population size were statistically significant and associated with fewer general nonprofit organizations per 10,000 residents. In addition, more general nonprofits per 10,000 residents were located in the Midwest compared to the Northeast.
} 
some control variables. ${ }^{35}$ In the end, I chose not to include a control for the size of the general nonprofit sector because there were no substantial changes in my model.

In the third sensitivity analysis, I controlled for the foreign-born length of tenure in the United States. Previous research on immigrant integration includes this measure generally examining differences between immigrants who arrived prior to 2000 and those who arrived after 2000 (Iceland \& Scopilliti 2008). However, after controlling for the foreign-born length of tenure using the percent of metropolitan area residents who entered after 2000 compared to those who entered prior to 2000 , there were no changes in the variables of interest and the variable was not statistically significant. This potentially means that foreign-born length of tenure in an area does not influence the presence of immigrant nonprofit organizations. More research investigating length of tenure and immigrant nonprofit organizations may be able to uncover more specific details.

Finally, in the fourth sensitivity analysis, I controlled for immigrant destination types instead of regions. I included variables to control for new, established, and nondestination metropolitan areas, following the typology used by Hall and Crowder (2014). Hall and Crowder utilized four destination types to account for the demographic changes in an area over time, Developing, New, Established, and Non-destinations. In my study, I utilized Hall and Crowder's typology from 2008, the most recent year categorized in their

\footnotetext{
${ }^{35}$ Including a control for the number of general nonprofits per 10,000 residents changed the statistical significance for some of the control variables. In my original regressions, housing stability was statistically significant in all models. Once the size of the nonprofit sector was considered, residential stability was not statistically significant in Model 1. In my original model, the size of the population below poverty was only statistically significant in Model 2. In the regression controlling for the size of the nonprofit sector, increases in the size of the population in poverty was associated with an increase in the number of immigrant nonprofit organizations per 1,000 foreign-born residents (a coefficient of approximately 0.01 in all models and a minimum significance of $\mathrm{p}<0.1$ ). The population size also became statistically significant in all regression models, but the size of the population with a bachelor's degree or higher was no longer statistically significant after including the size of the general nonprofit sector.
} 
study. I collapsed Hall and Crowder's developing and new destination areas into "new destinations" in this study. Established destination metropolitan areas, in this typology, had a large foreign-born population (minimum 200,000) and the proportion of immigrants in the metropolitan area was larger than the national average (Hall \& Crowder 2014, p. 2186). ${ }^{36}$ New destination metropolitan areas had a relatively large foreign-born population and experienced faster immigrant growth compared to the national average (Hall \& Crowder 2014, p. 2186). Non-destinations include the metropolitan areas that do not qualify as an established or new immigrant destination. Following these guidelines, the majority of metropolitan areas in this study were nondestinations (61 percent). New destinations made up about a quarter of the metropolitan areas in this analysis (26 percent), and established destinations were about 14 percent of metropolitan areas. When I ran the analysis including destination type instead of region controls, there were no significant differences in the analysis results. New destination metropolitan areas, compared to non-destinations, had fewer immigrant nonprofit organizations per 1,000 foreign-born residents in Models 1 and $2(-0.056, p<0.01 ;-0.037$, $\mathrm{p}<0.1$, respectively), with similar results in Model 3, but not statistically significant. The number of immigrant nonprofit organizations per 1,000 foreign-born residents were not statistically significant in established destinations compared to non-destinations. This was an important sensitivity analysis to ensure that areas with a rapid influx of immigrants (new destinations) or a large foreign-born population (established destinations) were not influencing the variables of interest. As the variables of interest were not impacted by the change of region controls, I did not alter my original analysis.

\footnotetext{
${ }^{36}$ For the exact criteria used for the destination categories, please refer to Hall and Crowder (2014), p. 2185-2186.
} 


\section{Discussion}

This study examined how two different racial and ethnic distribution possibilities (diversity and segregation) were associated with one specific type of nonprofit organization, immigrant nonprofits. Specifically, I examined the influence of diversity and segregation on the number of immigrant nonprofit organizations per 1,000 foreignborn residents. Based on the prior literature, I constructed hypotheses to test two dimensions of segregation using the entropy and dissimilarity index (Massey \& Denton 1988). Hypothesis 1 and 2 offered possibilities for the relationship between areas with high levels of diversity and the number of immigrant nonprofits per 1,000 foreign-born residents. Hypothesis 3 postulated that areas with high levels of residential segregation have fewer immigrant nonprofits per 1,000 foreign-born residents.

The regression results offered mixed support for the hypotheses. Support for Hypothesis 1 demonstrated that increases in the level of diversity (entropy score) in metropolitan areas are associated with fewer immigrant nonprofit organizations per 1,000 foreign-born residents. Hypothesis 3 had mixed support: an increase in White-Hispanic segregation was associated with fewer immigrant nonprofit organizations per 1,000 foreign-born residents while an increase in White-Black segregation was associated with more immigrant nonprofit organizations per 1,000 foreign-born residents. These results have varied implications for immigrant integration, access to immigrant nonprofit organizations, and policy.

Asians and Latinos are the largest foreign-born groups in the United States and face disparities in nonprofit involvement and access. For example, across California, Asians and Latinos are missing from nonprofit leadership (Gleeson \& Bloemraad 2013, 
p. 347). Across the country, however, there are more Asian immigrant nonprofits compared to Hispanic immigrant nonprofits, even though the Hispanic population is larger and growing (Hung 2007, Olson 2017). In addition, research has shown that segregated and isolated Hispanic populations live in areas with fewer resources (Gleeson \& Bloemraad 2013; Hall \& Stringfield 2014; Logan 2011; Park \& Iceland 2011). Results from this study support these findings.

Increased White-Hispanic segregation was associated with declines in the number of immigrant nonprofit organizations per 1,000 foreign-born residents. What this may mean in practice, however, is unclear: It could be that inhabitants in these segregated areas are lacking services or that they are receiving services from sources other than immigrant nonprofits. It is also plausible that informal support networks or informal organizations exist and these would not be captured within the formalized structure of nonprofit organizations and this data.

In metropolitan settings with high levels of White-Hispanic segregation, inclusive policy with culturally sensitive measures and appropriate language access may be important to access this population. This may be especially important for foreign-born Hispanics who may be particularly vulnerable to a lack of any services due to their rapid growth, lower educational attainment, and increasing segregation and poverty (Massey 2007). Public partnerships with immigrant nonprofit organizations may increase the wellbeing of those living in segregated areas by, among other things, connecting residents to other resources and social networks, and help alleviate some of segregation's negative consequences (Garrow 2015; Lee \& Ousey 2005; Massey \& Denton 1993; Peterson et al. 2000; Yen \& Kaplan 1999). In addition, immigrant nonprofit organizations may assist 
with building bridging social capital connecting clientele with other resources. Immigrant nonprofits may also help reduce prejudice between groups by offering structured and facilitated contact between people from different backgrounds. Public partnerships with immigrant nonprofits may also relieve some of the stress on local governments in areas unaccustomed to large-scale immigration without infrastructure to provide the necessary services to these new populations (Gleeson \& Bloemraad 2013). Immigrant nonprofits, not only assist people from their target group in culturally and language specific ways, but tend to work with immigrants through common procedures for societal integration into the mainstream society (i.e. finding employment, navigating the healthcare system, religious guidance, and overcoming language and cultural barriers; Cordero-Guzmán 2005; de Leon et al. 2009; Vu et al. 2017). In addition, immigrant nonprofit organizations may also provide services to the general public.

In this study, I discussed how diversity and segregation may influence the number of immigrant nonprofits per 1,000 foreign-born residents in a metropolitan area. These findings, however, are not without limitations. The sample size of 333 metropolitan areas misses portions of the country, yet covers about 82 percent of the total U.S. population. Due to data constraints for both the segregation indices and the Immigrant Analysis Database (IAD), data for this period (2010 for the segregation indices and 2014 for the immigrant nonprofits) and these metropolitan areas were the only data available. Constructing county level segregation indices may lead to different outcomes and may be worthwhile to investigate in future research. Additionally, while the IAD has a broad number of immigrant nonprofit organizations from across the U.S. at one moment in time, it does not capture all immigrant nonprofit organizations, nor does it change over 
time. The undercount of immigrant nonprofits may bias the results, especially if the database has systematically fewer immigrant organizations from a particular group than may actually be present. It is hard to estimate the direction of this bias, however, because it is very difficult to estimate the actual number of immigrant nonprofit organizations. The IAD has fewer Hispanic-focused organizations and more Asian-focused organizations, but following the discrepancy in the number of Hispanic immigrant organizations compared to Asian immigrant organizations in the literature (Hung 2007; Gleeson \& Bloemraad 2013), the organizations in the IAD may be representative.

In conclusion, there is much more to be learned about the dispersion of different racial and ethnic groups and immigrant nonprofit organizations in metropolitan areas. The results from this study indicate that increases in diversity and White-Hispanic segregation are associated with fewer immigrant nonprofit organizations per 1,000 foreign-born residents. Also, unexpectedly, the results show that increases in WhiteBlack segregation are associated with increases in the number of immigrant nonprofit organizations per 1,000 foreign-born residents. There is a limited amount of scholarship on this subject and therefore many questions remain unanswered. Future research to understand the conditions necessary for immigrant nonprofit formation in diverse or segregated areas may be helpful to improve access to resources in such metropolitan settings. Understanding the conditions ripe for immigrant nonprofit formation may also assist local governments working in areas with high levels of segregation or other areas with new or large immigrant populations. It may also be pertinent to continue learning about the informal networks, support systems, churches, or other organizations working in these areas with foreign-born populations. Finally, future research to understand the 
association between White-Black segregation and immigrant nonprofits as well as examining immigrant nonprofits and immigrant entrepreneurship would prove interesting. 


\section{References}

Alba, R. 2009. Blurring the Color Line: The new Chance for a More Integrated America. Cambridge, MA: Harvard University Press.

Allport, G. 1954. The Nature of Prejudice. Cambridge, MA: Addison-Wesley.

Bagetta, M. 2016. Representative Bridging: Voluntary Associations’ Potential for Creating Bridging Ties in Demographically Diverse Urban Areas. Nonprofit and Voluntary Sector Quarterly, 45(15), 725-945.

Ben-Ner, A. \& Van Hoomissen, T. 1992. An Empirical Investigation of the Joint Determination of the Size of the For-Profit, Nonprofit and Government Sectors. Annals of Public and Cooperative Economics, 3, 391-415.

Brown University. nd. Spatial Structures in the Social Sciences: American Communities Project, Diversity and Disparities. Retrieved from: https://s4.ad.brown.edu/Projects/Diversity/

Corbin, J.J. 1999. A Study of Factors Influencing the Growth of Nonprofits in Social Services. Nonprofit and Voluntary Sector Quarterly, 28, 296-314.

Cordero-Guzmán, H. R. 2005. Community-based organisations and migration in New York City. Journal of Ethnic and Migration Studies, 31, 889-909.

de Leon, E.; Maronick, M.; DeVita, C. J.; \& Boris, E. T. 2009. Community-Based Organizations and Immigrant Integration in the Washington, D.C., Metropolitan Area. Washington DC: Urban Institute.

Fischer, M. J. 2010. Immigrant educational outcomes in new destinations: An exploration of high school attrition. Social Science Research, 39(4), 627-641.

Friedman, S.; Tsao, H.; \& Chen, C. 2013. Housing Tenure and Residential Segregation in 
Metropolitan America. Demography, 50, 1477-1498.

Garrow, E. E. 2015. Racial and Ethnic Composition of the Neighborhood and the Disbanding of Nonprofit Human Service Organizations. Du Bois Review, 12(1), 161-185.

Garrow, E. E. 2012. Does Race Matter in Government Funding of Nonprofit Human Service Organizations? The Interaction of Neighborhood Poverty and Race. Journal of Public Administration Research and Theory, 24, 381-405.

Garrow, E.E. \& Garrow, S.H. 2014. White Flight and the Presence of Neighborhood Nonprofit Organizations: Ethno-racial Transition, Poverty, and Organizational Resources. Race and Social Problems, 6, 328-341.

Gibbons, J. 2014. Does racial segregation make community-based organizations more territorial? Evidence from Newark, NJ, and Jersey City, NJ. Journal of Urban Affairs, 37(5), 600-619.

Gleeson, S. \& Bloemraad, I. 2013. Assessing the Scope of Immigrant Organizations: Official undercounts and actual underrepresentation. Nonprofit and Voluntary Sector Quarterly, 42(2), 346-370.

Hall, M. 2009. Interstate Migration, Spatial Assimilation, and the Incorporation of US Immigrants. Population, Space and Place, 15, 57-77.

Hall, M. \& Crowder, K. 2014. Native Out-Migration and Neighborhood Immigration in New Destinations. Demography, 51, 2179-2202.

Hall, M. \& Stringfield, J. 2014. Undocumented migration and the residential segregation of Mexicans in new destinations. Social Science Research, 47, 61-78.

Hung, C. R. 2007. Immigrant Nonprofit Organizations in U.S. Metropolitan 
Areas. Nonprofit \& Voluntary Sector Quarterly, 36(4), 707-729.

Iceland, J. 2009. Where We Live Now: Immigration and Race in the United States. Berkeley: University of California Press.

Iceland, J. 2004. Beyond Black and White Metropolitan residential segregation in multiethnic America. Social Science Research, 33, 248-271.

Iceland, J. \& Scopilliti, M. 2008. Immigrant Residential Segregation in U.S. Metropolitan Areas, 1990-2000. Demography, 45(1), 79-94.

Iceland, J., Weinberg, D. H., \& Steinmetz, E. 2002. Racial and ethnic residential segregation in the United States: 1980-2000 (U.S. Census Bureau, Series CENSR-3). Washington, DC: U.S. Government Printing Office.

Joassart-Marcelli, P. 2013. Ethnic Concentration and Nonprofit Organizations: The Political and Urban Geography of Immigrant Services in Boston, Massachusetts. International Migration Review, 47(3):730-772 DOI: 10.1111/imre.12041.

Lee, B.A.; Iceland, J. \& Farrell, C.R. 2013. Is Ethnoracial Residential Integration on the Rise? Evidence from Metropolitan and Micropolitan America Since 1980. US2010 Project, Research Brief. New York: Russell Sage Foundation.

Lee, B.A.; Iceland, J. \& Sharp, G. 2012. Racial and Ethnic Diversity Goes Local: Charting Change in American Communities Over Three Decades. US2010 Project, Research Brief. New York: Russell Sage Foundation.

Lee, M.R. \& Ousey, G.C. 2005. Institutional Access, Residential Segregation, and Urban Black Homicide. Sociological Inquiry, 75(1), 31-54.

Lichter, D. T.; Parisi, D.; Taquino, M. C.; \& Grice, S. M. 2010. Residential segregation 
in new Hispanic destination: Cities, suburbs, and rural communities compared. Social Science Research, 39, 215-230.

Logan, J. R. 2011. Separate and Unequal: The Neighborhood Gap for Blacks, Hispanics and Asians in Metropolitan America. US2010 Project, Research Brief. New York: Russell Sage Foundation.

Logan, J.R. \& Stults, B.J. 2011. The Persistence of Segregation in the Metropolis: New Findings from the 2010 Census. US2010 Project, Research Brief. New York: Russell Sage Foundation.

Logan, J.R. \& Zhang, C. 2011. Global Neighborhoods: New Evidence from Census 2010. US2010 Project, Research Brief. New York: Russell Sage Foundation.

Logan, J.R. \& Zhang, C. 2010. Global Neighborhoods: New Pathways to Diversity and Separation. American Journal of Sociology, 115(4), 1069-1109.

Madden, J. F. 2001. Do Racial Composition and Segregation Affect Economic Outcomes in Metropolitan Areas? In Anderson, E. \& Massey, D.S. (Eds). Problem of the Century: Racial Stratification in the United States. New York: Russell Sage Foundation.

Massey, D. S. 2007. Categorically Unequal, The American Stratification System. New York: Russel Sage Foundation.

Massey, D. S. (Ed.), 2008. New Face in New Places: The Changing Geography of American Immigration. New York: Russell Sage Foundation.

Massey, D. \& Denton, N. 1993. American Apartheid. Cambridge, MA: Harvard University Press.

Massey, D. S. \& Denton, N.A. 1988. The Dimensions of Residential Segregation. Social 
Forces, 67(2), 281-315.

Matsunaga, Y. \& Yamauchi, N. 2004. Is the Government Failure Theory Still Relevant? A panel analysis using US state level data. Annals of Public and Cooperative Economics, 75(2), 227-263.

Olson, K.C. 2017. Immigrant nonprofit organizations in new and established immigrant destinations. Unpublished doctoral dissertation.

Park, J., \& Iceland, J. (2011). Residential segregation in metropolitan established immigrant gateways and new destinations, 1990-2000. Social Science Research, $3(40), 811-821$.

Paarlberg, L.E. \& Gen, S. 2009. Exploring the Determinants of Nonprofit Coproduction of Public Service Delivery: The case of k-12 public education. The American Review of Public Administration, 39(4), 391-408.

Peterson, R.D.; Krivo, L.J.; \& Harris, M.A. 2000. Disadvantage and Neighborhood Violent Crime: Do local institutions matter? Journal of Research in Crime and Delinquency, 37(1), 31-63.

Pettigrew, R.F. \& Tropp, L.R. 2006. A meta-analytic test of intergroup contact theory. Journal of Personality and Social Psychology, 90(5), 751-783.

Polson, E.C. 2015. Social Diversity and Civic Engagement: The Effects of Ethnic and Social Heterogeneity on the Community Involvement of American Congregations. Nonprofit and Voluntary Sector Quarterly, 44(5), 968-987.

Portes, A. \& Manning, R.D. 1986. The Immigrant Enclave: Theory and Empirical Examples. In Olsak, S. and Nagel, J. (eds) Competitive Ethnic Relations. Orlando, FL: Academic Press 
Putnam, R. D. 2007. E Pluribus Unum: Diversity and Community in the Twenty-First Century. Scandinavian Political Studies 30:137-74.

Singer, A. 2013. Contemporary Immigrant Gateways in Historical Perspective. Dadalus, the Journal of the American Academy of Arts \& Sciences, 142(3).

Singer, A. 2004. The Rise of New Immigrant Gateways. Washington, DC: Brookings Institution.

Small, M.L. 2006. Neighborhood Institutions as Resource Brokers: Childcare Centers, Interorganizational Ties, and Resource Access among the Poor. Social Problems, 53(2), 274-292.

Small, M.L. \& McDermott, M. 2006. The Presence of Organizational Resources in Poor Urban Neighborhoods: An Analysis of Average and Contextual Effects. Social Forces, 84(3), 1697-1724.

Small, M.L. \& Stark, L. 2005. Are Poor Neighborhoods Resource Deprived? A Case Study of Childcare Centers in New York. Social Science Quarterly, 86s, 10131036.

Vu, C.M.; Nguyen, D.; Tanh, D.B.; \& Chun, J. 2017. Case Study of an Ethnic Community-Based Organization in the United States. Nonprofit and Voluntary Sector Quarterly, 46(1), 199-217.

Wilkes, R. \& Iceland, J. 2004. Hypersegregation in the Twenty-First Century. Demography, 41(1), 23-36.

Yen, I.H. \& Kaplan, G.A. 1999. Neighborhood Social Environment and Risk of Death: Multilevel Evidence from the Alameda County Study. American Journal of Epidemiology, 149(10), 898-907. 


\section{Appendix A}

Table A 2: Top 10 metropolitan areas with highest Diversity or Segregation scores ${ }^{37}$

\begin{tabular}{|c|c|c|c|c|c|}
\hline Metropolitan Area Name & $\begin{array}{l}\text { Number } \\
\text { Immigrant } \\
\text { Nonprofits }\end{array}$ & $\begin{array}{c}\text { Immigrant } \\
\text { Nonprofits } \\
/ 1,000 \\
\text { Immigrants }\end{array}$ & $\begin{array}{l}\text { Diversity } \\
\quad(E)\end{array}$ & $\begin{array}{c}\text { White- } \\
\text { Hispanic } \\
\text { Segregation } \\
(D)\end{array}$ & $\begin{array}{c}\text { White- } \\
\text { Asian } \\
\text { Segregation } \\
(D)\end{array}$ \\
\hline \multicolumn{6}{|l|}{ Diversity (Entropy Index, E) } \\
\hline Honolulu, HI & 23 & 0.13 & 77.61 & 31.94 & 40.07 \\
\hline Los Angeles-Long Beach-Santa Ana, CA & 433 & 0.10 & 79.55 & 62.15 & 45.73 \\
\hline Houston-Sugar Land-Baytown, TX & 149 & 0.12 & 79.59 & 52.51 & 48.72 \\
\hline Las Vegas-Paradise, NV & 23 & 0.05 & 79.80 & 42.02 & 26.84 \\
\hline $\begin{array}{l}\text { San Jose-Sunnyvale-Santa Clara, CA } \\
\text { New York-Northern New Jersey-Long }\end{array}$ & 92 & 0.14 & 80.12 & 47.62 & 43.03 \\
\hline Island, NY-NJ-PA & 835 & 0.16 & 80.51 & 62.00 & 50.41 \\
\hline $\begin{array}{l}\text { Washington-Arlington-Alexandria, DC-VA- } \\
\text { MD-WV }\end{array}$ & 283 & 0.25 & 80.77 & 48.30 & 36.86 \\
\hline Stockton, CA & 19 & 0.12 & 82.45 & 34.06 & 45.89 \\
\hline San Francisco-Oakland-Fremont, CA & 248 & 0.20 & 85.26 & 49.59 & 44.28 \\
\hline Vallejo-Fairfield, CA & 2 & 0.02 & 89.33 & 29.15 & 38.42 \\
\hline Average Top 10 Highest E-score & 210.7 & 0.13 & 81.50 & 45.93 & 42.03 \\
\hline \multicolumn{6}{|l|}{ Segregation (Dissimilarity Index, D) } \\
\hline Miami-Fort Lauderdale-Pompano Beach, FL & 228 & 0.11 & 74.91 & 57.36 & 32.71 \\
\hline Hartford-West Hartford-East Hartford, CT & 23 & 0.15 & 58.03 & 58.36 & 34.95 \\
\hline Bridgeport-Stamford-Norwalk, CT & 40 & 0.22 & 64.08 & 59.15 & 28.98 \\
\hline Boston-Cambridge-Quincy, MA-NH & 156 & 0.21 & 55.69 & 59.58 & 43.38 \\
\hline Providence-New Bedford-Fall River, RI-MA & 28 & 0.14 & 47.19 & 60.11 & 36.49 \\
\hline $\begin{array}{l}\text { Salinas, CA } \\
\text { New York-Northern New Jersey-Long }\end{array}$ & 1 & 0.01 & 66.07 & 60.91 & 37.16 \\
\hline Island, NY-NJ-PA & 835 & 0.16 & 80.51 & 62.00 & 50.41 \\
\hline Los Angeles-Long Beach-Santa Ana, CA & 433 & 0.10 & 79.55 & 62.15 & 45.73 \\
\hline Springfield, MA & 9 & 0.16 & 52.14 & 63.40 & 37.49 \\
\hline Reading, PA & 4 & 0.15 & 46.22 & 68.72 & 30.35 \\
\hline $\begin{array}{l}\text { Average Top } 10 \text { Highest White-Hispanic D-score } \\
\text { D-Score White with Asian }\end{array}$ & 175.7 & 0.14 & 62.44 & 61.17 & 37.77 \\
\hline $\begin{array}{l}\text { Ithaca, NY } \\
\text { New York-Northern New Jersey-Long }\end{array}$ & 2 & 0.16 & 46.89 & 26.45 & 49.61 \\
\hline Island, NY-NJ-PA & 835 & 0.16 & 80.51 & 62.00 & 50.41 \\
\hline Atlantic City-Hammonton, NJ & 7 & 0.17 & 72.99 & 46.93 & 50.59 \\
\hline Buffalo-Niagara Falls, NY & 24 & 0.37 & 45.82 & 50.74 & 51.00 \\
\hline Beaumont-Port Arthur, TX & 1 & 0.04 & 66.85 & 50.81 & 51.17 \\
\hline Amarillo, TX & 4 & 0.19 & 60.14 & 45.50 & 53.80 \\
\hline Blacksburg-Christiansburg-Radford, VA & 3 & 0.34 & 32.36 & 23.14 & 55.81 \\
\hline Utica-Rome, NY & 2 & 0.11 & 34.31 & 52.54 & 55.89 \\
\hline Lafayette, IN & 2 & 0.11 & 42.90 & 31.33 & 56.23 \\
\hline Napa, CA & 2 & 0.07 & 64.75 & 30.13 & 57.05 \\
\hline Average Top 10 highest White-Asian D-score & 88.2 & 0.17 & 54.75 & 41.96 & 53.16 \\
\hline
\end{tabular}

${ }^{37}$ Due to the low presence of foreign-born residents in areas with high White-Black segregation, I did not include these top 10 metropolitan areas. The average foreign-born population size in the top 10 metropolitan areas with high White-Black segregation was 8.7 percent. 


\section{CONCLUSION}

Each of the essays in this dissertation examined nonprofit organizations working with immigrant populations. Chapter 1 described different strategies food bank SNAP outreach workers used to engage immigrant groups in nine counties across six states. In Chapter 2, I analyzed how certain community characteristics in new and established immigrant destinations may be associated with the presence of immigrant nonprofit organizations in counties across the U.S. Chapter 3 analyzed how different racial and ethnic distribution patterns influenced the number of immigrant nonprofit organizations per 1,000 foreign-born residents in 333 metropolitan areas. All three chapters indicated that local context is important when considering new immigrant populations, policy solutions, and the role of nonprofit organizations as well as immigrant nonprofit organizations.

The strategies highlighted by SNAP outreach workers in Chapter 1 offered insight into the specific barriers immigrant populations face in accessing social services. Food bank employees could reach out to immigrant populations differently than a SNAP agency due to their non-governmental position. Food banks offered clients a nongovernmental safe space with more convenient hours and locations to apply for SNAP benefits compared to government offices. Among others, outreach workers noted that the lack of English language and computer literacy skills were barriers immigrants faced to accessing services. In the case of SNAP, food bank nonprofit outreach workers used innovative methods adapting to the perceived language and cultural needs of their clientele. 
In Chapters 2 and 3, I discussed immigrant nonprofit organizations. I defined immigrant nonprofits as ethnic organizations serving clientele from one ethnic or national origin and includes larger service providers with a focus on multicultural programming for foreign-born residents. In Chapter 2, I found that counties with an immigrant nonprofit organization generally have a large population, lower levels of poverty, higher levels of education, more charitable giving, and a larger and more diverse foreign-born population compared to counties without an immigrant nonprofit. In Chapter 3, I found that more diverse metropolitan areas and metropolitan areas with White-Hispanic segregation were associated with fewer immigrant nonprofit organizations per 1,000 foreign-born residents. Contrary to previous literature on nonprofit organizations and segregation, White-Black segregation was associated with a small, but statistically significant, increase in the number of immigrant nonprofits per 1,000 foreign-born residents.

Examining immigrant nonprofit organizations nationally with the Immigrant Analysis Database is the main contribution of this research. At the same time, I learned that even when using a national database, the local context is important. For example, county level attributes predicting the likelihood of an immigrant nonprofit are different depending on whether the county has had a rapid influx of immigrants (new destination) or if the county has a long history with immigrants (established destination).

Results from these dissertation chapters offer multiple venues for future research. I would be interested to further examine the relationship between White-Black segregation and immigrant nonprofits as well as the association between White-Black segregation and nonprofit organizations in general. This type of research likely needs 
qualitative fieldwork to gather information about specific nonprofits in White-Black segregated areas. It may, however, be possible to use mapping technology and multiple sources to identify immigrant nonprofit organizations and census data to locate WhiteBlack segregated areas to analyze these relationships. Continued local level research on immigrant nonprofit organizations will add to the existing knowledge about this specific type of nonprofit organization. Local level studies offer specific information and context about the everyday operations of immigrant nonprofits, funding sources, and the best sources to use to identify immigrant nonprofits. Maintaining a database of immigrant nonprofit organizations could be a resource for local governments, researchers, and immigrant populations. Currently, the Immigrant Analysis Database is just a one-time snapshot of immigrant nonprofits from 2014. A dynamic database maintaining data over time would be beneficial to understand the life-cycle of immigrant nonprofits. While maintaining such a database would be a large project, it could potentially be done by collaborating with researchers and practitioners across the country. Continued research on immigrant nonprofits would benefit by using a common definition of an immigrant organization. Finally, future research will continue answering some of the initial questions about immigrant nonprofits such as "who these groups are, what kinds of programs and services they provide, where they are located, who they serve, and what kinds of resources they have" (Cordero-Guzmán 2005, p. 891).

In addition to research, the results from these three dissertation chapters have varied implications for immigrant integration, access to services and immigrant nonprofit organizations, and policy. On average, foreign-born populations have higher levels of poverty and eligible immigrants use public benefits at lower rates compared to native- 
born populations (Fix, Capps, \& Kaushal 2009; Fortuny \& Chaudry 2011; Leftin 2010; Raphael \& Smolensky 2009; Skinner 2012). In addition, the foreign-born population is increasing and diversifying and the government is increasingly depending on nonprofit organizations to provide acculturation and resettlement services to immigrant and refugee groups (Joassart-Marcelli 2013; Salamon 2012; Tseng 2006). Inclusive policies with culturally sensitive measures and appropriate language services are necessary to improve access to resources, especially in segregated White-Hispanic areas. Social policies aiming to reduce poverty in areas with a poor immigrant population may fail if there are no organizations or resources to assist with translation and other culturally sensitive practices. In new immigrant destination counties, the local government often lacks the infrastructure to work with the large influx of foreign-born populations and segregated Hispanic populations have less access to immigrant nonprofit organizations and other resources. To avoid creating an "underclass" (Massey 2007) of foreign-born individuals, specifically from Latin American countries, continued research on immigrant integration, immigrant use of social services, and the potential of immigrant nonprofits as intermediaries between immigrant groups and others, including local government officials, is essential.

Immigrant nonprofit organizations are poised to assist newcomers in culturallyand language-appropriate ways. Research has shown that nonprofit organizations help alleviate some of segregation's negative consequences (Garrow 2015; Lee \& Ousey 2005; Massey \& Denton 1993; Peterson et al. 2000; Yen \& Kaplan 1999). Public partnerships with immigrant nonprofit organizations may increase the wellbeing of those living in segregated areas by, among other things, connecting residents to other resources 
and social networks. Because few new destination counties have an immigrant nonprofit, understanding the conditions suitable for immigrant nonprofit formation, and creating policies to encourage these conditions, may also assist local governments working in areas with new or large immigrant populations. Encouraging funding opportunities for immigrant nonprofits working with low-income immigrant populations may also be useful to assist with integration into mainstream societal norms as well as assist with training and employment options. While the American population is diversifying, the demographic changes are not associated with an increase in the number of immigrant nonprofit organizations. To understand how and where immigrant nonprofits may benefit a community, it is important to understand the personal networks and support systems immigrant populations use and to understand what preexisting community organizations, such as churches, are working with immigrant communities. 


\section{References}

Cordero-Guzmán, H. R. 2005. Community-based organisations and migration in New York City. Journal of Ethnic and Migration Studies, 31, 889-909.

Fix, M.; Capps, R.; \& Kaushal, N. 2009. Immigrants and Welfare: Overview. In M. Fix (ed) Immigrants and Welfare, The Impact of Welfare Reform on America's Newcomers, New York, Russell Sage Foundation.

Fortuny, K. \& Chaudry, A. 2011. A Comprehensive Review of Immigrant Access to Health and Human Services, Washington, DC, The Urban Institute.

Garrow, E. E. 2015. Racial and Ethnic Composition of the Neighborhood and the Disbanding of Nonprofit Human Service Organizations. Du Bois Review, 12(1), $161-185$.

Joassart-Marcelli, P. 2013. Ethnic Concentration and Nonprofit Organizations: The Political and Urban Geography of Immigrant Services in Boston, Massachusetts. International Migration Review, 47(3):730-772 DOI: 10.1111/imre.12041.

Lee, M.R. \& Ousey, G.C. 2005. Institutional Access, Residential Segregation, and Urban Black Homicide. Sociological Inquiry, 75(1), 31-54.

Leftin, J. 2010. Trends in Supplemental Nutrition Assistance Program Participation Rates: 2001 to 2008. Washington, DC, Mathematica Policy Research.

Massey, D. S. 2007. Categorically Unequal, The American Stratification System. New York: Russel Sage Foundation.

Massey, D. \& Denton, N. 1993. American Apartheid. Cambridge, MA: Harvard University Press.

Peterson, R.D.; Krivo, L.J.; \& Harris, M.A. 2000. Disadvantage and Neighborhood 
Violent Crime: Do local institutions matter? Journal of Research in Crime and Delinquency, 37(1), 31-63.

Raphael, S. \& Smolensky, E. 2009. Immigration and Poverty in the United States. In Cancian, M. \& Danziger, S. (Eds.) Changing Poverty, Changing Policies. New York: Russell Sage Foundation.

Salamon, L.M. 2012. The Resilient Sector: The Future of Nonprofit America. In Salamon, L. M. (ed). The State of Nonprofit America. Washington DC: Brookings Institution.

Skinner, C. 2012. State Immigration Legislation and SNAP Take-Up Among Immigrant Families with Children. Journal of Economic Issues, 46(3), 661-681.

Tseng, W. 2006. Government Dependence of Chinese and Vietnamese Community Organizations and Fiscal Politics of Immigrant Services. Journal of Health and Social Policy, 20(4), 51-74.

Yen, I.H. \& Kaplan, G.A. 1999. Neighborhood Social Environment and Risk of Death: Multilevel Evidence from the Alameda County Study. American Journal of Epidemiology, 149(10), 898-907. 


\section{VITA}

Kate Olson, Ph.D., entered the Truman School of Public Affairs doctoral program in 2012 with the G. Ellsworth Huggins Fellowship. Her research interests include social demography, social policy, and program evaluation. She is also interested in immigrant use of social services, immigrant integration, and immigrant nonprofit organizations. Kate has a bachelor of arts in Cultural Studies from the University of Minnesota and a master's degree in Cultures and Development Studies from the Catholic University of Leuven, Belgium. Prior to her doctoral work, Kate received a Masters of Public Administration from Minnesota State University, Mankato where she also taught a diversity course to law enforcement students. 